\title{
Fuel Thermo-physical Characterization Project: Fiscal Year 2014 Final Report
}

\section{Office of Material Management and Minimization}

March 2015

DE Burkes

AM Casella

EC Buck

AJ Casella

MK Edwards

\author{
PJ MacFarlan \\ KN Pool \\ BD Slonecker \\ FN Smith \\ FH Steen
}




\title{
DISCLAIMER
}

This report was prepared as an account of work sponsored by an agency of the United States Government. Neither the United States Government nor any agency thereof, nor Battelle Memorial Institute, nor any of their employees, makes any warranty, express or implied, or assumes any legal liability or responsibility for the accuracy, completeness, or usefulness of any information, apparatus, product, or process disclosed, or represents that its use would not infringe privately owned rights. Reference herein to any specific commercial product, process, or service by trade name, trademark, manufacturer, or otherwise does not necessarily constitute or imply its endorsement, recommendation, or favoring by the United States Government or any agency thereof, or Battelle Memorial Institute. The views and opinions of authors expressed herein do not necessarily state or reflect those of the United States Government or any agency thereof.

\author{
PACIFIC NORTHWEST NATIONAL LABORATORY \\ operated by \\ BATTELLE \\ for the \\ UNITED STATES DEPARTMENT OF ENERGY \\ under Contract DE-AC05-76RL01830
}

Printed in the United States of America
Available to DOE and DOE contractors from the Office of Scientific and Technical Information,
P.O. Box 62, Oak Ridge, TN 37831-0062;
ph: (865) 576-8401
fax: $(865) 576-5728$
email: reports@adonis.osti.gov
Available to the public from the National Technical Information Service
5301 Shawnee Rd., Alexandria, VA 22312 ph: (800) 553-NTIS (6847)
email: orders@ntis.gov $<$ http://www.ntis.gov/about/form.aspx $>$
Online ordering: http://www.ntis.gov

This document was printed on recycled paper. 


\title{
Fuel Thermo-physical Characterization Project: Fiscal Year 2014 Final Report
}

\section{Office of Material Management and Minimization}

\author{
DE Burkes $\quad$ PJ MacFarlan \\ AM Casella KN Pool \\ EC Buck BD Slonecker \\ AJ Casella FN Smith \\ MK Edwards FH Steen
}

March 2015

Prepared for

the U.S. Department of Energy

under Contract DE-AC05-76RL01830

Pacific Northwest National Laboratory

Richland, Washington 99352 



\section{Summary}

The Office of Material Management and Minimization (M3) Reactor Conversion Fuel ThermoPhysical Characterization Project at Pacific Northwest National Laboratory (PNNL) was tasked with using PNNL facilities and processes to receive irradiated low enriched uranium-molybdenum (LEU-Mo) fuel plate samples and perform analysis in support of the M3 Reactor Conversion Program. This work is in support of the M3 Reactor Conversion Fuel Development Pillar that is managed by Idaho National Laboratory. The primary research scope was to determine the thermo-physical properties as a function of temperature and burnup. Work conducted in Fiscal Year (FY) 2014 complemented measurements performed in FY 2013 on four additional irradiated LEU-Mo fuel plate samples. Specifically, the work in FY 2014 investigated the influence of different processing methods on thermal property behavior, the absence of aluminum alloy cladding on thermal property behavior for additional model validation, and the influence of higher operating surface heat flux / more aggressive irradiation conditions on thermal property behavior. The model developed in FY 2013 and refined in FY 2014 to extract thermal properties of the U-Mo alloy from the measurements conducted on an integral fuel plate sample (i.e., U-Mo alloy with a thin Zr coating and clad in AA6061) continues to perform very well. Measurements conducted in FY 2014 on samples irradiated under similar conditions compare well to measurements performed in FY 2013. In general, there is no gross influence of fabrication method on thermal property behavior, although the difference in LEU-Mo foil microstructure does have a noticeable influence on recrystallization of grains during irradiation. Samples irradiated under more aggressive irradiation conditions, e.g., higher surface heat flux, revealed lower thermal conductivity when compared to samples irradiated at moderate surface heat fluxes, with the exception of one sample. This report documents thermal property measurements conducted in FY 2014 and compares results to values obtained from literature and measurements performed in FY 2013, where applicable, along with appropriate discussion. 



\section{Acknowledgments}

The authors wish to acknowledge Mr. Jason Schulthess, Mr. Adam Robinson, Dr. Barry Rabin, and Mrs. Susan Case from Idaho National Laboratory for the delivery of the fuel segments. Installation of equipment into hot cells and the operations conducted in hot cells is a large undertaking. The authors wish to acknowledge those at Pacific Northwest National Laboratory who were involved in the preparation of samples and performance of measurements, specifically Ms. Nicole Green, Mr. Jake Bohlke, Mr. Jamin Trevino, Mr. Dustin Blundon, Mr. Jason Cartwright, Mr. Jeffrey Chenault, Mr. Steve Halstead, Mr. Eric Hanson, Mr. Kevin Heaton, Mr. Robert Orton, Mr. Stan Owsley, Mr. Ben Palma, Mr. Mario Pereira, Mr. Timothy Smith, Mr. Randy Thornhill, and Mr. Patrick Valdez. The authors wish to acknowledge Sharon Eaton for her assistance with formatting and copyediting and Dr. David Senor for his technical peer review of this report. Finally, the authors wish to acknowledge the sponsor, the Office of Material Management and Minimization (NA-23), for the opportunity to conduct this work under contract DE-AC05-76RL01830. 



\section{Acronyms and Abbreviations}

AA

AFIP

ATR

$C_{P}$

DIW

DSC

DU

EDF

FB

$f_{D}$

FY

GEA

GTRI

HIP

ICP-OES

INL

LEU

LEU-Mo

LFA

$\mathrm{M}^{3}$

MCNP

NIST

NRC

OM

PNNL

SEM

$t_{\text {clad }}$

$t_{\text {fuel }}$

TIMS

$t_{\mathrm{Zr}}$

U-Mo

$\rho$

$\alpha$

$\lambda$

aluminum alloy

Advanced Test Reactor Full-size Plate In Center Flux Trap Position

Advanced Test Reactor

specific heat capacity

de-ionized water

differential scanning calorimeter

depleted uranium

extended depth of focus

friction bonding

fission density

fiscal year

gamma energy analysis

Global Threat Reduction Initiative

hot isostatic pressing

inductively coupled plasma-optical emission spectroscopy

Idaho National Laboratory

low enriched uranium

low enriched uranium-molybdenum

laser flash apparatus

Office of Material Management and Minimization

Monte Carlo N-Particle

National Institute of Standards and Technology

U.S. Nuclear Regulatory Commission

optical microscopy

Pacific Northwest National Laboratory

scanning electron microscopy

cladding thickness

U-Mo fuel thickness

thermal ionization mass spectroscopy

zirconium thickness

uranium-molybdenum alloy

density

thermal diffusivity

thermal conductivity 



\section{Contents}

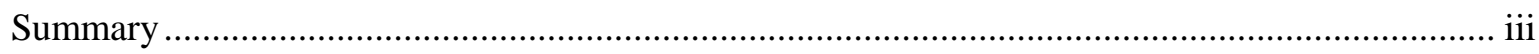

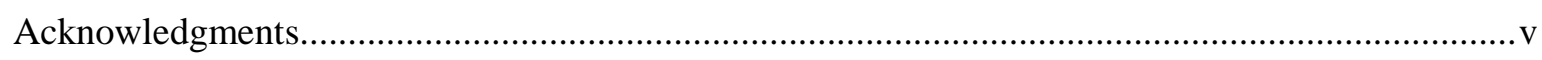

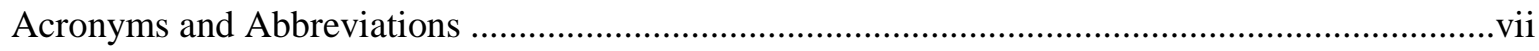

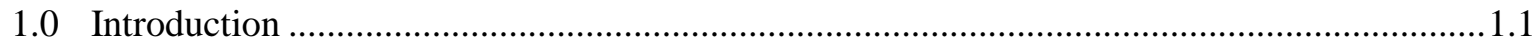

2.0 Experimental Processes, Methods, and Materials .............................................................2. 2.1

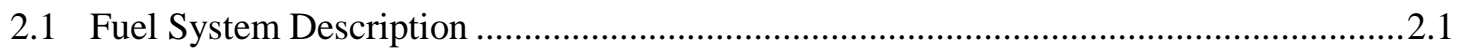

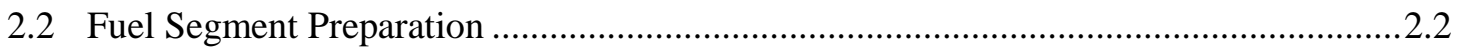

2.3 As-received Fuel Segment Conditions .....................................................................2.2

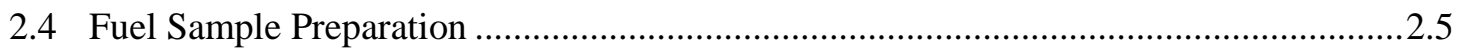

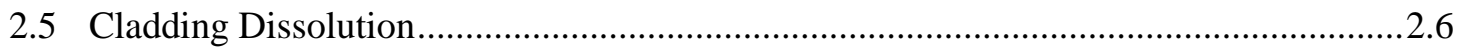

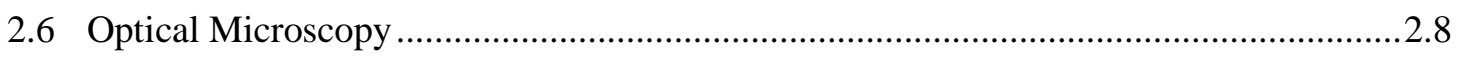

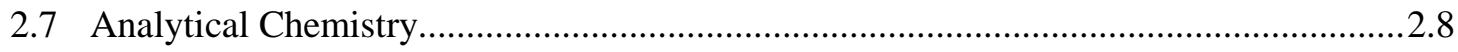

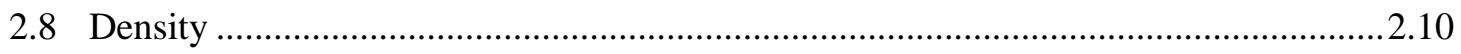

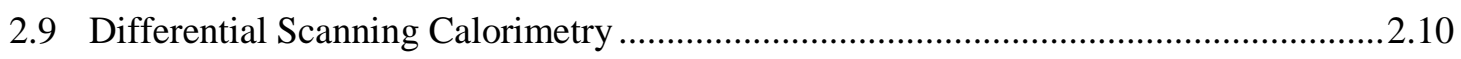

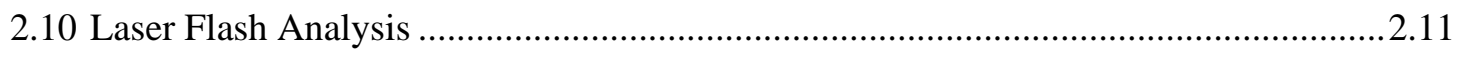

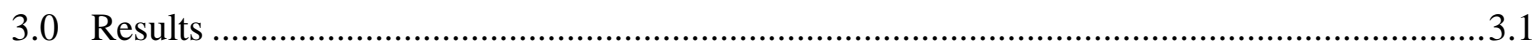

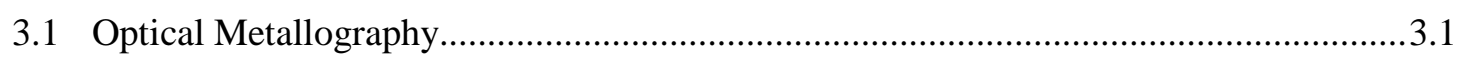

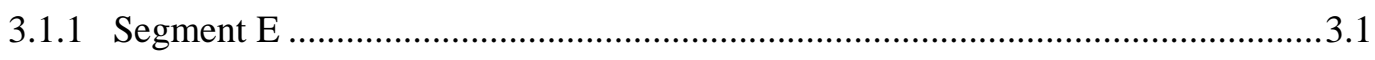

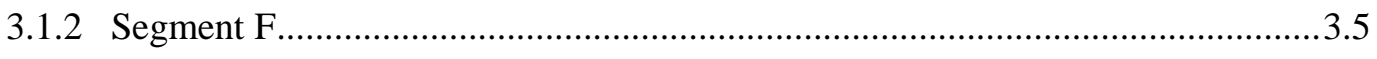

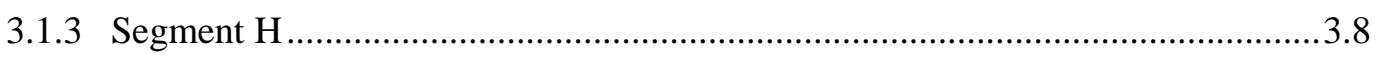

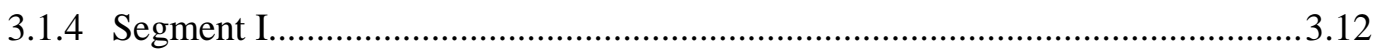

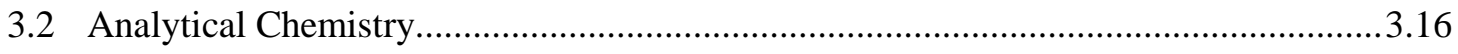

3.2.1 Inductively Coupled Plasma—Optical Emission Spectroscopy..........................3.16

3.2.2 Gamma Energy Analysis.................................................................................. 3.18

3.2.3 Thermal Ionization Mass Spectroscopy .............................................................19

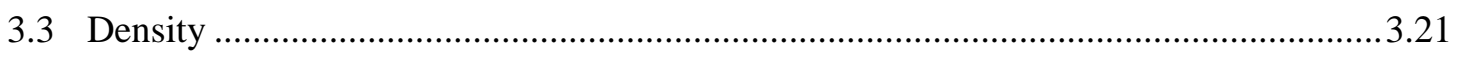

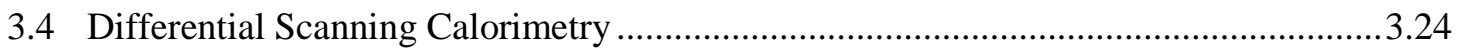

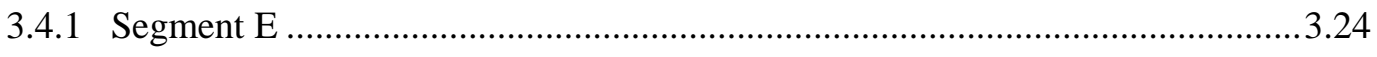

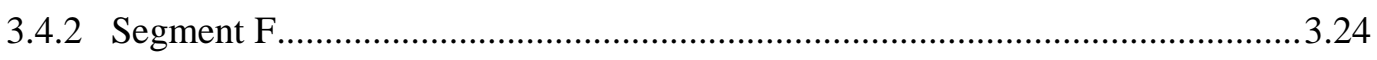

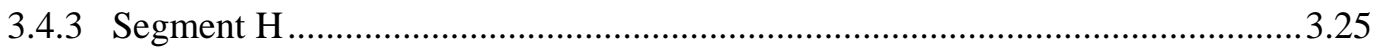

3.4.4 Segment I......................................................................................................2.

3.4.5 Calculated Specific Heat Capacity of U-Mo ....................................................2.

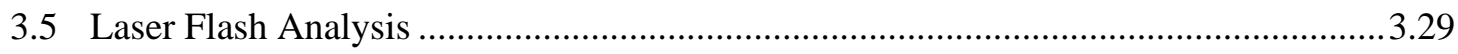

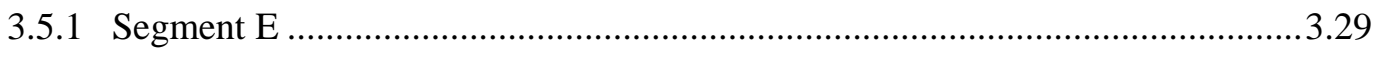

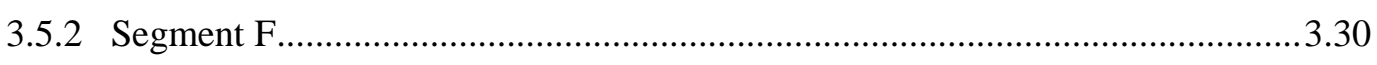

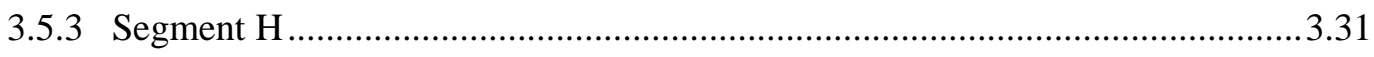




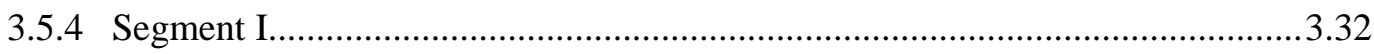

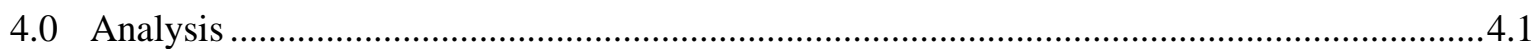

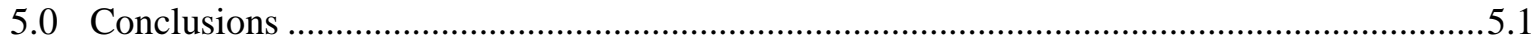

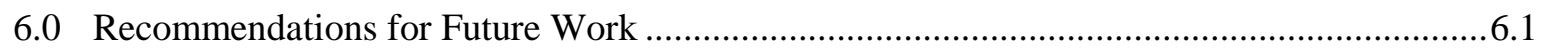

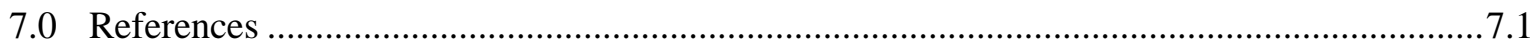




\section{Figures}

Figure 2.1. Typical U-Mo Monolithic Fuel Plate Cross-section (dimensions are in inches)..........2.1

Figure 2.2. In-cell Photographs of as-received Fuel Segments E (top), F (middle), and G (bottom). 2.3

Figure 2.3. In-cell Photographs of as-Received Fuel Segments H (top left), I (top right), and J (bottom) 2.5

Figure 2.4. Example Final Sectioning Diagram Used to Produce Multiple Samples from Segment F 2.6

Figure 2.5. Photograph of TF-LFA1, TF-DTA1, TF-OM1, and TF-DSC1 in a $250 \mathrm{~mL}$ Beaker

Containing the $\mathrm{NaOH}$ Aliquot at the Beginning of the Cladding Dissolution Process.....

Figure 2.6. Photograph of the TF-LFA1, TF-DTA1, TF-OM1, and TF-DSC1 Samples after the AA6061 Cladding Has Been Removed

Figure 3.1. Low Magnification Optical Microscopy Montages of the TE-OM1 (top) and TEOM2 (bottom) Samples

Figure 3.2. Graphical Representation of the Thickness Measurements Obtained from the TE-OM Samples

Figure 3.3. TE-OM1 (left) and TE-OM2 (right) Thickness Measurements for Each Layer as a Function of Measurement Location ...

Figure 3.4. $\quad$ Extended Depth of Focus Optical Microscopy Images of the Fuel-Zr Diffusion

Barrier Interface for Both TE-OM1 (left) and TE-OM2 (right) Samples..................................3.4

Figure 3.5. Higher Magnification EDF Images of the Irradiated Fuel for Both TE-OM1 (left) and TE-OM2 (right) Samples

Figure 3.6. Low Magnification Optical Microscopy Montages of the TF-OM1 (top) and TFOM2 (bottom) Samples

Figure 3.7. Graphical Representation of the Thickness Measurements Obtained from the TF-OM Samples

Figure 3.8. TF-OM1 (left) and TF-OM2 (right) Thickness Measurements for Each Layer as a Function of Approximate Measurement Location

Figure 3.9. Extended Depth of Focus Optical Microscopy Images of the Fuel-Zr Diffusion

Barrier Interface for Both TF-OM1 (left) and TF-OM2 (right) Samples

Figure 3.10. Higher Magnification EDF Images of the Irradiated Fuel for Both TF-OM1 (left) and TF-OM2 (right) Samples.

Figure 3.11. Low Magnification Optical Microscopy Montages of the TH-OM1 (top) and TH-OM2 (bottom) Samples 3.9

Figure 3.12. Graphical Representation of the Thickness Measurements Obtained from the TH-OM Samples

Figure 3.13. TH-OM1 (left) and TH-OM2 (right) Thickness Measurements for Each Layer as a Function of Approximate Measurement Location .....

Figure 3.14. Extended Depth of Focus Optical Microscopy Images of the Fuel-Zr Diffusion

Barrier Interface for Both TH-OM1 (left) and TH-OM2 (right) Samples ..............................3.12

Figure 3.15. Higher Magnification EDF Images of the Irradiated Fuel for Both TH-OM1 (top) and TH-OM2 (bottom) Samples 
Figure 3.16. Low Magnification Optical Microscopy Montages of the TI-OM1 (top) and TIOM2 (bottom) Samples

Figure 3.17. Graphical Representation of the Thickness Measurements Obtained from the TIOM Samples

Figure 3.18. TI-OM1 (left) and TI-OM2 (right) Thickness Measurements for Each Layer as a Function of Approximate Measurement Location....

Figure 3.19. Extended Depth of Focus Optical Microscopy Images of the Fuel-Zr Diffusion

Barrier Interface for Both TI-OM1 (left) and TI-OM2 (right) Samples

Figure 3.20. Higher Magnification EDF Images of the Irradiated Fuel for Both TI-OM1 (top) and TI-OM2 (bottom) Samples

Figure 3.21. GEA Results for Specific Nuclides as a Function of Calculated Segment Fission Density. Solid Markers Represent Moderate Surface Heat Flux Segments (A, B, C, and E) while Open Markers Represent High Surface Heat Flux Segments (F, H, and I)

Figure 3.22. Calculated Specific Heat Capacities of TE Fuel Samples (DSC2 and DSC3) as a Function of Temperature for Each Thermal Cycle ...................................................................2.

Figure 3.23. Calculated Specific Heat Capacities of TF Fuel Samples (DSC1 and DSC2) as a Function of Temperature for Each Thermal Cycle

Figure 3.24. Calculated Specific Heat Capacities of TH Fuel Samples (DSC1 and DSC2) as a Function of Temperature for Each Thermal Cycle...

Figure 3.25. Calculated Specific Heat Capacities of TI Fuel Samples (DSC1 and DSC2) as a Function of Temperature for Each Thermal Cycle.

Figure 3.26. Extracted U-Mo Specific Heat Capacity Obtained from the Composite Specific Heat Capacity Measurements and the Neumann-Kopp Approximation for Each Fuel Segment as a Function of Temperature

Figure 3.27. (A) Square Sapphire Window in the Sample Holder, (B) Sample in the Sample Holder on Top of the Sapphire Window, and (C) Assembled Sample Holder in the LFA Instrument 3.29

Figure 3.28. Composite Thermal Diffusivity as a Function of Temperature for Segment E.3.30 Figure 3.29. Composite Thermal Diffusivity as a Function of Temperature for Segment F ........3.31

Figure 3.30. Composite Thermal Diffusivity as a Function of Temperature for Segment H .......3.32

Figure 3.31. Composite Thermal Diffusivity as a Function of Temperature for Segment I..........3.33

Figure 3.32. Post-LFA Measurement Photograph of the TI-LFA2 Sample. Cracks originating at the edges of the sample and propagating through the interior are labeled.

Figure 4.1. Measured Composite, Calculated $\mathrm{Zr}+\mathrm{U}-\mathrm{Mo}$, and Calculated U-Mo Densities as a Function of Average Fission Density for Each Irradiated Fuel Segment Analyzed (Including FY13 Samples). Solid markers represent high surface heat flux samples while open markers represent moderate surface heat flux samples.

Figure 4.2. Decrease in Density from as-Fabricated Values as a Function of Average Fission Density for Each Fuel Segment (Including FY13 Samples). Solid markers represent high surface heat flux samples while open markers represent moderate surface heat flux samples.4.3

Figure 4.3. Calculated Specific Heat Capacity of the U-Mo Fuel at 100C, 200C, and 300C as a Function of Average Fission Density for Each Fuel Segment (Including FY13 Samples). Solid markers represent high surface heat flux samples while open markers represent moderate surface heat flux samples. 
Figure 4.4. Calculated Composite Thermal Conductivity At 100C, 200C, and 300C as a Function of Average Fission Density for Each Fuel Segment (Including FY13 Samples). Solid markers represent high surface heat flux samples while open markers represent moderate surface heat flux samples.

Figure 4.5. Extracted U-Mo Thermal Conductivity at $100{ }^{\circ} \mathrm{C}, 200{ }^{\circ} \mathrm{C}$, and $300{ }^{\circ} \mathrm{C}$ as a Function of Average Fission Density for Each Fuel Segment (Including FY13 Samples). Solid markers represent high surface heat flux samples while open markers represent moderate surface heat flux samples. 


\section{Tables}

Table 2.1. Pertinent Characteristics and Dimensions of the AFIP Experiments Analyzed as Part of This Work

Table 2.2. Summary of Physical Dimensions ${ }^{(a)}$ of as-Received Fuel Segments from Idaho

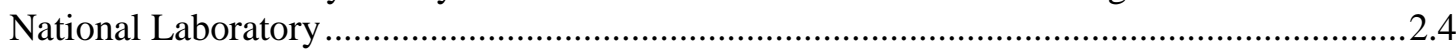

Table 2.3. Sample Masses Used to Conduct Analytical Chemistry Experiments..........................2.9

Table 3.1. Thickness Measurements Obtained from the Optical Microscopy Samples ${ }^{(\mathrm{a})}$................3.2

Table 3.2. Thickness Measurements Obtained from the TF Optical Microscopy Samples ${ }^{(a)}$..........3.6

Table 3.3. Thickness Measurements Obtained from the TH Optical Microscopy Samples ${ }^{(a)}$.........3.9

Table 3.4. Thickness Measurements Obtained from the TI Optical Microscopy Samples ${ }^{(a)}$...........13

Table 3.5. Uranium:Molybdenum Ratios of the Analytical Chemistry Samples Obtained

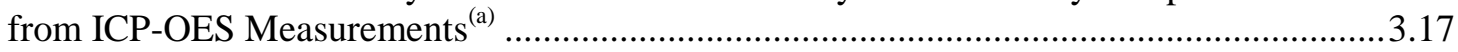

Table 3.6. Solid Fission Product Distribution of the Analytical Chemistry Samples

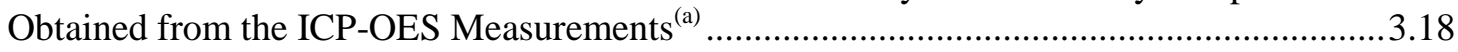

Table 3.7. Average Results from the TIMS U Analysis on Each Fuel Segment Investigated.......3.20

Table 3.8. Average Results from the TIMS Pu Analysis on Each Fuel Segment Investigated ....3.21

Table 3.9. Composite Density Measurements and Estimated Zr + U-Mo and U-Mo Density Measurements for Both Segment E LFA Samples (units are in $\mathrm{g}^{\bullet} \mathrm{cm}^{-3}$ ) .................................22

Table 3.10. Composite Density Measurements and Estimated Zr + U-Mo and U-Mo Density Measurements for Both Segment F LFA Samples (units are in $\mathrm{g}^{\bullet} \mathrm{cm}^{-3}$ ) ...............................2.22

Table 3.11. Composite Density Measurements and Estimated Zr + U-Mo and U-Mo Density Measurements for Both Segment H LFA Samples (units are in $\mathrm{g}^{\bullet} \mathrm{cm}^{-3}$ )..............................3.23

Table 3.12. Composite Density Measurements and Estimated Zr + U-Mo and U-Mo Density Measurements for Both Segment I LFA Samples (units are in $\mathrm{g}^{\bullet} \mathrm{cm}^{-3}$ ).

Table 4.1. Summary of Calculated Average Fission Density for Each Fuel Segment Analyzed in FY13 and FY14 


\subsection{Introduction}

The rate at which heat produced by fission can be dissipated from the fuel plate directly affects the fuel temperature. Thus, proper characterization of the thermal conductivity of a proposed fuel as a function of temperature and burnup allows for proper assessment of the safety margins and economics of a particular reactor with that fuel. For previous fuel development campaigns, most notably for low enriched $\mathrm{U}_{3} \mathrm{Si}_{2}$ dispersion fuel, thermal conductivity of irradiated samples was not performed (NRC 1988). For this particular fuel system and design (i.e., dispersion fuel), it was believed that the impact of irradiation on the thermal conductivity of the fuel meat ${ }^{1}$ was minimal. Dispersion fuel offers two advantages in thermal conductivity over a monolithic ${ }^{2}$ fuel design. First, thermal conductivity is essentially proportional to the amount of high thermal conductivity aluminum present in the matrix. Because a dispersion fuel design typically contains more matrix than dispersed fuel, the matrix will generally dissipate heat faster than the lower thermal conductivity fuel phase. Second, dispersion fuel often contains a certain amount of as-fabricated porosity, anywhere from 4-14 vol\%, depending upon the volume fraction of fuel. As fission products build up in the fuel particles, an outward pressure on the surrounding matrix is generated. However, the matrix cannot expand outward because of the constraint imparted by the clad, resulting in creep of the matrix into as-fabricated porosity during the initial stages of irradiation. This initial densification can result in a slight increase in fuel meat thermal conductivity, because the as-fabricated porosity is eliminated. However, the thermal conductivity of the dispersion fuel meat will gradually decrease beyond medium burnup once all as-fabricated porosity has been eliminated. At high burnup, fission gas bubbles will begin to precipitate and coalesce in the fuel particles and surrounding interaction regions because of recoil that degrades thermal conductivity more rapidly (NRC 1988).

In the case of the monolithic fuel design, there is no aluminum available as a matrix and no (intended) as-fabricated porosity. Thus, the thermal conductivity of a monolithic U-Mo fuel plate is at a maximum prior to irradiation, and will always be less than that of a dispersion fuel design because of the absence of a high thermal conductivity aluminum matrix. Thermal conductivity of the U-Mo system has stronger temperature dependence than currently qualified fuel alloys and is sensitive to the Mo concentration. The relative U-Mo ratio will decline with fuel depletion and is further enhanced by the fact that Mo is a fission product. The influence of porosity may also contribute to thermal conductivity degradation more rapidly in a monolithic fuel design. Because as-fabricated porosity is not typically present in a monolithic fuel design, density will decrease more rapidly as a result of fuel swelling and therefore decrease thermal conductivity sooner than in a dispersion fuel design, which implies that the monolithic fuel meat is not constrained to the same degree as the dispersion fuel meat. Finally, a $\mathrm{Zr}$ diffusion barrier (a lower conductivity material) is used between the U-Mo and aluminum alloy 6061 (AA6061) (Moore and Marshall 2010). Interaction between the $\mathrm{Zr}$ and U-Mo fuel alloy during fabrication results in a series of intermetallics (most notably $\delta$ - $\mathrm{UZr}_{2}$ and $\mathrm{Mo}_{2} \mathrm{Zr}$ ) that can be further enhanced during irradiation (Perez et al. 2010). Segregation effects resulting from $\gamma$-phase destabilization, as well as irradiation damage at the fuel-Zr interface (where gross porosity tends to agglomerate in the latter stages of irradiation), can also be detrimental to fuel conductivity during irradiation. Destabilization of the $\gamma$-phase can also result in

\footnotetext{
1 "Fuel meat" is a combination of fuel materials with a nonfissionable heat-conducting (matrix) material, confined inside a fuel plate.

${ }^{2}$ A monolithic fuel plate contains a solid piece of fuel material, i.e., nonfissionable heat-conducting (matrix) material is absent.
} 
formation of $\alpha$-U and $\mathrm{U}_{2}$ Mo intermetallic phases that have different thermal transport properties. Thus, it is apparent that thermal conductivity behavior of the low enriched uranium-molybdenum (LEU-Mo) monolithic fuel system must be well understood and validated before approvals to use the fuel can be expected.

The Office of Material Management and Minimization (M3) Reactor Conversion Fuel ThermoPhysical Characterization Project at Pacific Northwest National Laboratory (PNNL) is tasked with using PNNL facilities and processes to receive irradiated LEU-Mo fuel plate samples and perform analysis in support of the M3 Reactor Conversion Program. This work is in support of the M3 Reactor Conversion Fuel Development Pillar that is managed by Idaho National Laboratory (INL). The primary research scope is to determine the thermo-physical properties as a function of temperature and burnup, specifically the thermal conductivity by measuring the thermal diffusivity, density, and specific heat capacity of irradiated fuel specimens. This requires certain physical examinations of the fuel samples to determine cladding, foil, and $\mathrm{Zr}$ coating thicknesses, as well as any gross interaction layers and/or porosity that could significantly affect heat transport behavior. In addition, based upon early conversations with Fuel Development Pillar personnel, an option to investigate localized fuel mass loss and fission gas release characteristics of irradiated fuel samples has been pursued. However, the effort associated with the localized fuel mass loss and fission gas release characteristics will be documented in a separate report. The products of the research scope are validated temperature and burnup dependent property correlations with related uncertainties. These correlations are expected to support the LEU-Mo Base Fuel Qualification Report that is submitted to the U.S. Nuclear Regulatory Commission (NRC) and may also support specific research and test reactor safety analysis reports in determining safe operating margins for operation with the LEU-Mo monolithic fuel alloy.

This report documents additional measurements and analysis performed in Fiscal Year (FY) 2014. Four additional fuel segments were analyzed in FY14 to investigate the specific effects of fabrication history, surface heat flux during irradiation, burnup, and influence of cladding on thermal properties. New information is presented in this report and summarized with measurements conducted in FY13, which may be found in Burkes et al. 2013. 


\subsection{Experimental Processes, Methods, and Materials}

\subsection{Fuel System Description}

The Advanced Test Reactor (ATR) Full-size Plate In Center Flux Trap Position (AFIP) experiments were designed to evaluate the performance of monolithic fuels at a scale prototypic of research reactor fuel plates. The AFIP experimental fuel plates consisted of AA6061 clad monolithic fuel plates using a metallic foil of $U$ alloyed with nominally 10 weight percent molybdenum (U-10Mo) enriched to nominally $19.75 \%{ }^{235} \mathrm{U}$. The metallic fuel foils of interest for this study were prepared by hot co-rolling a U-10Mo alloy ingot with Zr on either side (Moore and Marshall 2010). The nominal thickness of the Zr was $25 \mu \mathrm{m}$ on either side of the foil and was introduced to minimize interaction between the U-10Mo fuel and the AA6061 cladding, thereby acting as a diffusion barrier. The foil was hermetically sealed and bound within the AA6061 cladding using a hot isostatic pressing (HIP) process (Park et al. 2010). A schematic representing a typical fuel plate cross-section is provided in Figure 2.1.

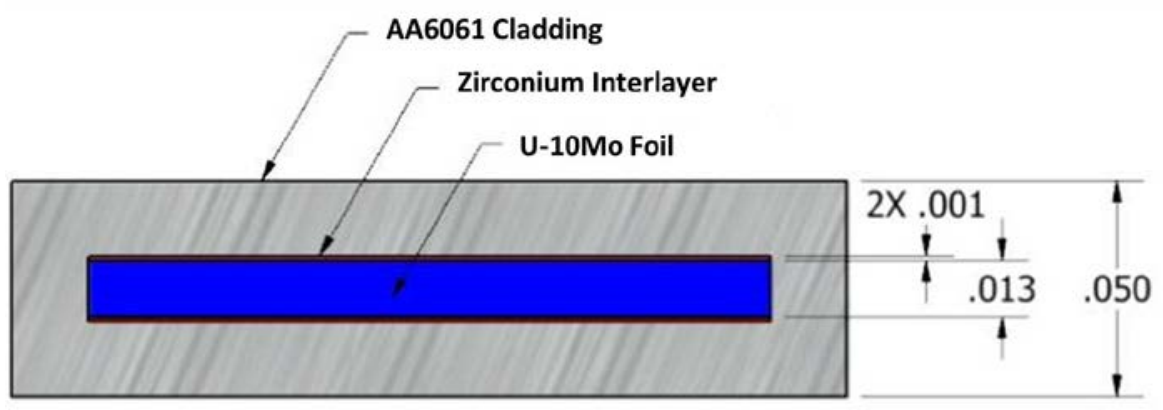

Figure 2.1. Typical U-Mo Monolithic Fuel Plate Cross-section (dimensions are in inches)

Fuel segments were provided for thermal property analysis from three separate AFIP-style fuel plates irradiated in the ATR. The fuel segments represented differences in processing parameters during fabrication of the fuel plates as well as differences in the irradiation conditions, most specifically the surface heat flux that each fuel plate experienced during irradiation. A summary of the pertinent characteristics of each fuel plate is provided in Table 2.1. Additional details on the various aspects of the AFIP experiments can be found in Keiser et al. (2011), Moore and Marshall (2011), Perez et al. (2012a), Perez et al. (2011a), and Perez et al. (2012b). 
Table 2.1. Pertinent Characteristics and Dimensions of the AFIP Experiments Analyzed as Part of This Work

\begin{tabular}{lcccc}
\hline \multicolumn{1}{c}{ Experiment } & AFIP-3BZ & AFIP-6 MkI & \multicolumn{2}{c}{ AFIP-6 MkII } \\
\hline Segment Identifier & $\mathrm{E}$ & $\mathrm{F}$ & $\mathrm{H}$ & $\mathrm{I}$ \\
${ }^{235} \mathrm{U}$ enrichment & $19.937 \%$ & $40.008 \%$ & $40.008 \%$ & $40.008 \%$ \\
${ }^{236} \mathrm{U}$ enrichment & $0.880 \%$ & $0.334 \%$ & $0.334 \%$ & $0.334 \%$ \\
Mo concentration & $10.3 \mathrm{wt} \%$ & $9.74 \%$ & $9.74 \%$ & $9.74 \%$ \\
Foil thickness & $437 \pm 16.1 \mu \mathrm{m}$ & $381 \mu \mathrm{m}$ & $381 \mu \mathrm{m}$ & $381 \mu \mathrm{m}$ \\
(including Zr) & & & & \\
Foil length & $51.0 \mathrm{~cm}$ & $56.8 \mathrm{~cm}$ & $57.2 \mathrm{~cm}$ & $57.2 \mathrm{~cm}$ \\
Foil width & $3.81 \mathrm{~cm}$ & $3.62 \mathrm{~cm}$ & $3.49 \mathrm{~cm}$ & $3.49 \mathrm{~cm}$ \\
Plate thickness & $1.26-1.28 \mathrm{~mm}$ & $1.30-1.32 \mathrm{~mm}$ & $1.32-1.35 \mathrm{~mm}$ & $1.32-1.35 \mathrm{~mm}$ \\
Plate length & $57.2 \mathrm{~cm}$ & $114 \mathrm{~cm}$ & $114 \mathrm{~cm}$ & $114 \mathrm{~cm}$ \\
Plate width & $5.61 \mathrm{~cm}$ & $5.68 \mathrm{~cm}$ & $5.67-5.68 \mathrm{~mm}$ & $5.67-5.68 \mathrm{~mm}$ \\
Irradiation length & $101.0 \mathrm{EFPD}{ }^{(\mathrm{a})}$ & $39.2 \mathrm{EFPD}^{(\mathrm{a})}$ & $56.1 \mathrm{EFPD}^{(\mathrm{a})}$ & $56.1 \mathrm{EFPD}^{(\mathrm{a})}$ \\
(a) Effective Full Power Days & & & \\
(EFPD) & & & & \\
\hline
\end{tabular}

\subsection{Fuel Segment Preparation}

Rectangular segments were prepared from the AFIP-3BZ, AFIP-6MkI, and AFIP-6MkII fuel plates at INL. The exact location of the fuel segments was not formally provided to PNNL, but the location can easily be estimated by comparing burnup values measured and reported from this work with Monte Carlo N-Particle (MCNP) calculations performed on each experiment by INL. The segments consisted of only the fueled region of the fuel plate, i.e., the AA6061 edges of the fuel plate and approximately outermost $5 \mathrm{~mm}$ of fuel on either side were trimmed away from the segment. The requested dimensions of the segments were $12.5 \mathrm{~mm}$ in length $\times 27 \mathrm{~mm}$ wide and were shipped to PNNL for thermal property measurements.

\subsection{As-received Fuel Segment Conditions}

Segments E, F, and G were received at the PNNL Radiochemical Processing Laboratory on February 3, 2014. The segments were removed from the shipping cask and an initial inspection of the conditions of the samples was performed. In general, the segments were in an acceptable condition and no observable delamination had occurred. Photographs of the as-received segments are provided in Figure 2.2. Table 2.2 summarizes the physical dimensions of the segments E, F, and G. Note that Segment G was AA6061 cladding only (no fuel) and the specific irradiation conditions of this sample were not provided. 

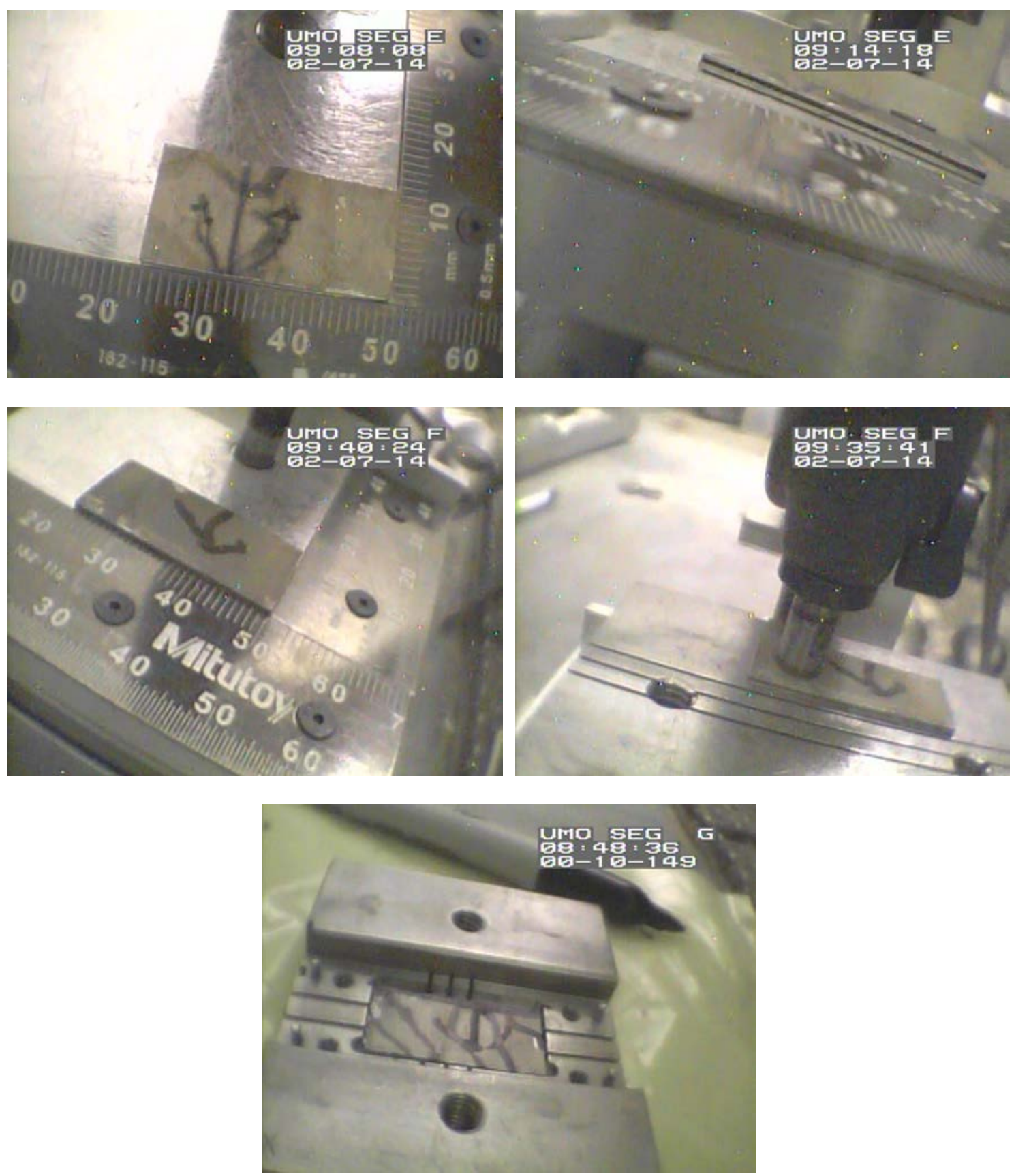

Figure 2.2. In-cell Photographs of as-received Fuel Segments E (top), F (middle), and G (bottom). 
Table 2.2. Summary of Physical Dimensions ${ }^{(a)}$ of as-Received Fuel Segments from Idaho National Laboratory

\begin{tabular}{ccccc}
\hline Fuel Segment & KGT Container & Measured Length & Measured Width & $\begin{array}{c}\text { Measured } \\
\text { Thickness }^{(b)}\end{array}$ \\
\hline E & 1581 & 26.0 & 12.0 & 1.378 \\
F & 1899 & 28.0 & 12.1 & 1.369 \\
G & 1900 & 27.0 & 13.0 & 1.307 \\
H & 1688 & 28.0 & 13.0 & 1.440 \\
I & 1676 & 27.0 & 13.0 & 1.524 \\
J & 1604 & 27.5 & 13.0 & 1.391 \\
\hline
\end{tabular}

(a) All dimensions are in $\mathrm{mm}$.

(b) Because of the bowing of the fuel segments, the measured thickness reported was obtained in approximately the middle of the fuel segment.

Segments H, I, and J were received at the Radiochemical Processing Laboratory on April 22, 2014. The fuel segments were removed from the shipping cask and an initial inspection of the conditions of the samples was performed. The $\mathrm{H}, \mathrm{I}$, and $\mathrm{J}$ segments were also received in an acceptable condition and no observable delamination had occurred. Photographs of the as-received fuel segments are provided in Figure 2.3. Table 2.2 also includes the physical dimensions of the as-received segments $\mathrm{H}$, I, and J. Note that Segment J was AA6061 cladding only (no fuel) and the specific irradiation conditions of this sample were not provided.

Fuel segments were stored under argon in a desiccator until distributed for further segmentation. Similarly, fuel samples obtained after segmentation were stored under argon when not in use, both before and after the various property measurements. All fuel segments were slated for thermo-physical property measurements, i.e., pycnometry, optical microscopy (OM), differential scanning calorimetry, laser flash analysis, and analytical chemistry. However, due to efficiencies gained over time, two samples for fission gas release measurements, i.e., thermogravimetric — differential thermal analysis/mass spectroscopy, were also harvested in addition to one or two spare samples. Fuel segments for thermo-physical property analysis are denoted by a "T" followed by the segment identification letter; e.g., "TE” is fuel segment $\mathrm{E}$ allocated for thermo-physical property measurement. 

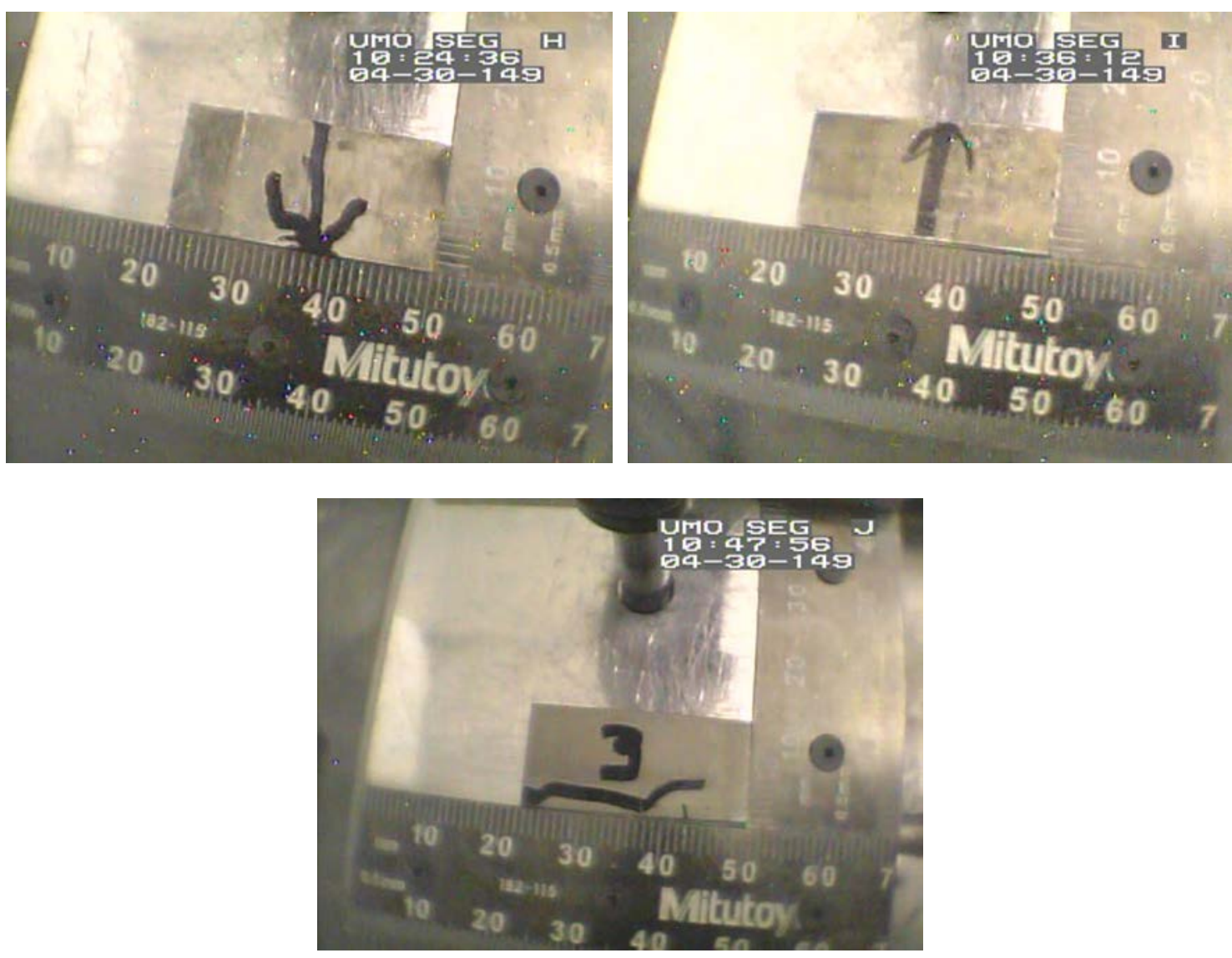

Figure 2.3. In-cell Photographs of as-Received Fuel Segments H (top left), I (top right), and J (bottom)

Note that Segments G and J were provided to assess impacts of irradiation on behavior of the AA6061 cladding. Limited measurements were performed on samples prepared from Segment G. The results indicated no significant deviation from assumed unirradiated thermal properties for AA6061 cladding. This work was not pursued further based on focusing priority and resources on the irradiated samples. Thus, thermal property measurements made on Segments G and J are not included in this report but may be provided in a separate letter report upon request.

\subsection{Fuel Sample Preparation}

The fuel segments were sectioned further to produce samples for various compositional, thermal, and physical measurements. The sectioning was accomplished with a specialized low-speed saw with a Buehler diamond-wafering blade. Multiple cuts made under an inert argon environment were performed according to the sectioning diagram to transform the as-received fuel segment into duplicate samples for laser flash analysis and gas pycnometry, analytical chemistry, differential scanning calorimetry, OM, and fission gas analysis. Additional samples for either differential scanning calorimetry or to be held in reserve for other measurements were also prepared.

An example of a sectioning diagram used to produce the various samples from the fuel segments is provided in Figure 2.4 (Segment F). Included on the final sectioning diagram are the approximate length and width dimensions (in $\mathrm{mm}$ ) for each sample. The nomenclature identified in this example final 
sectioning diagram was used to identify samples throughout this report. Note that each sample is denoted by a " $T$ " indicating that the sample was used for thermal property analysis followed by the segment identifier, in this case Segment F resulting in a identification of "TF", followed by the specific method the sample was analyzed by. Also note that the laser flash apparatus (LFA) and pycnometry samples are the same, although labeled in the diagrams solely as LFA. Samples labeled "Spare" were held in reserve for additional duplicate measurements or for Differential Thermal Analysis, which is discussed in a separate report.

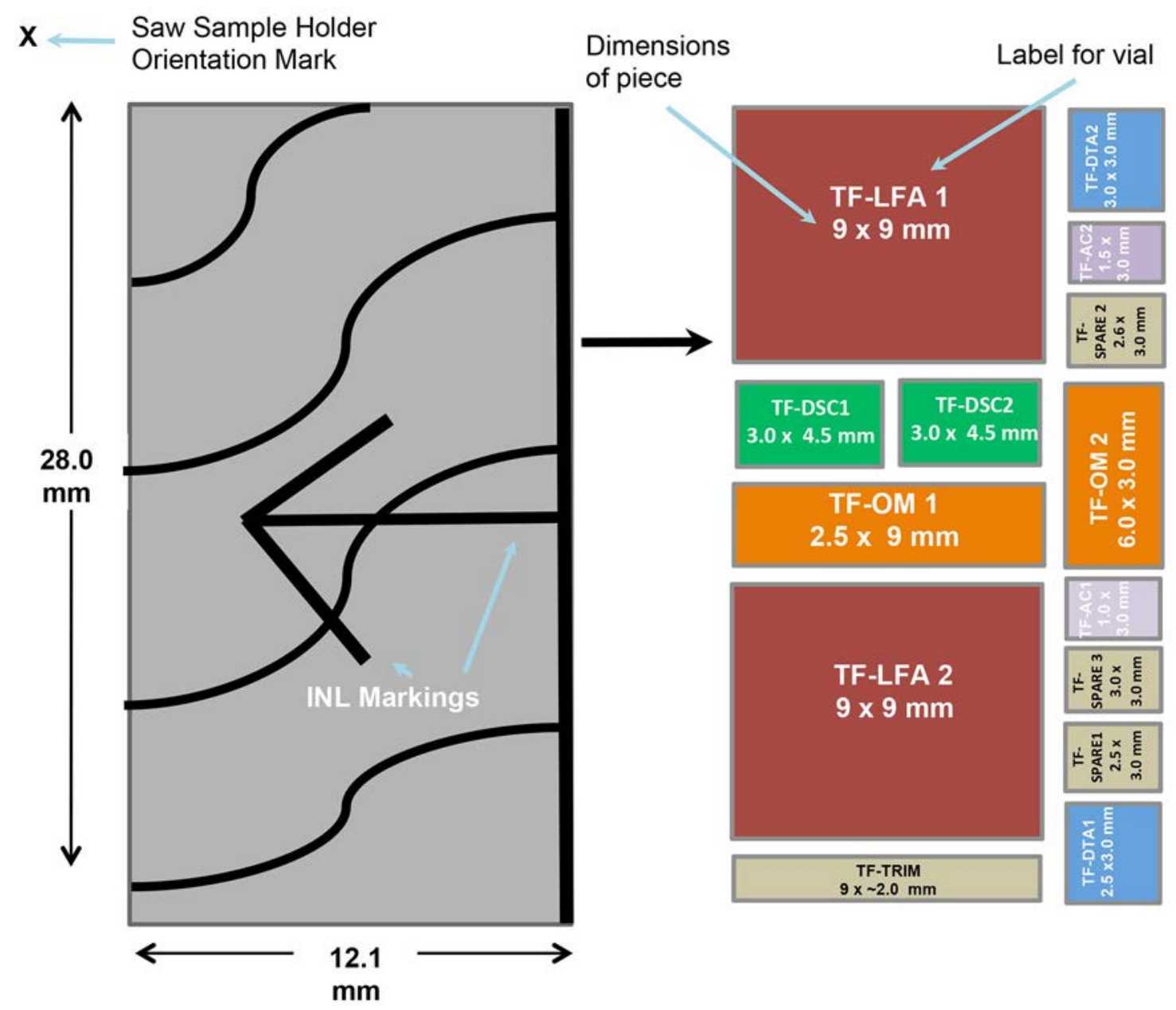

Figure 2.4. Example Final Sectioning Diagram Used to Produce Multiple Samples from Segment F

\subsection{Cladding Dissolution}

To investigate the influence of cladding on the monolithic fuel plate design on thermal properties, the AA6061 cladding was removed from samples prepared from Segment TF. To accomplish this, the LFA, differential scanning calorimetry (DSC), OM, and DTA samples were placed in a $50 \mathrm{~mL}$ aliquot of $5 \mathrm{M}$ $\mathrm{NaOH}$ contained in a $250 \mathrm{~mL}$ beaker. The beaker was placed on a hot plate maintained at $40{ }^{\circ} \mathrm{C}$ to accelerate the cladding dissolution reaction. Once the reaction was completed (evidenced by the lack of bubbles), the beaker was left on the hot plate for an additional thirty minutes. The beaker was then removed from the hot plate and the solution was allowed to cool. Approximately $25 \mathrm{~mL}$ of de-ionized 
water (DIW) was added to a clean $100 \mathrm{~mL}$ beaker. The $\mathrm{NaOH}$ solution from the $250 \mathrm{~mL}$ beaker was carefully removed and placed into a waste collection bottle using a pipette. The $\mathrm{Zr}+\mathrm{U}-\mathrm{Mo}$ samples were removed from the $250 \mathrm{~mL}$ beaker and placed in the $100 \mathrm{~mL}$ beaker containing DIW. A second $100 \mathrm{~mL}$ beaker containing approximately $25 \mathrm{~mL}$ of DIW was prepared, and samples were removed from the first $100 \mathrm{~mL}$ beaker and placed into this second beaker. This process was continued three times, cleaning each $100 \mathrm{~mL}$ beaker with DIW between each transfer, for a total of six DIW rinses. The samples were then removed from the beaker and placed on a clean paper towel to blot dry. The samples were then placed in appropriately labeled sample vials and distributed to the respective measurement stations or placed in storage for further use. A photograph of the samples located in the $250 \mathrm{~mL}$ beaker containing the $\mathrm{NaOH}$ aliquot is provided in Figure 2.5. Photographs of the thermal property samples following cladding removal are provided in Figure 2.6.

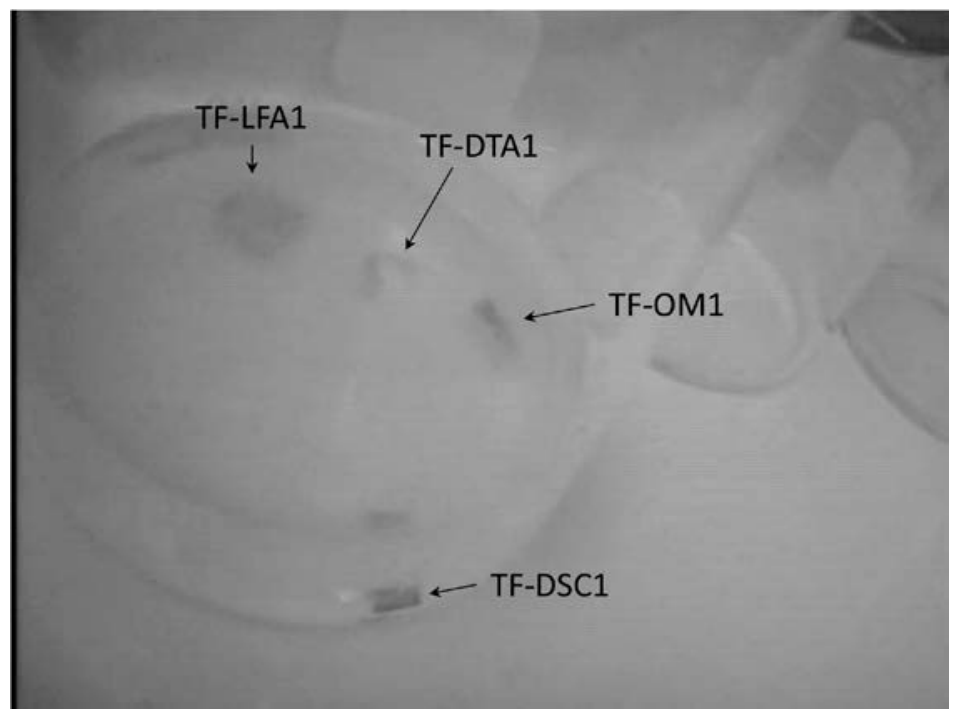

Figure 2.5. Photograph of TF-LFA1, TF-DTA1, TF-OM1, and TF-DSC1 in a $250 \mathrm{~mL}$ Beaker Containing the $\mathrm{NaOH}$ Aliquot at the Beginning of the Cladding Dissolution Process

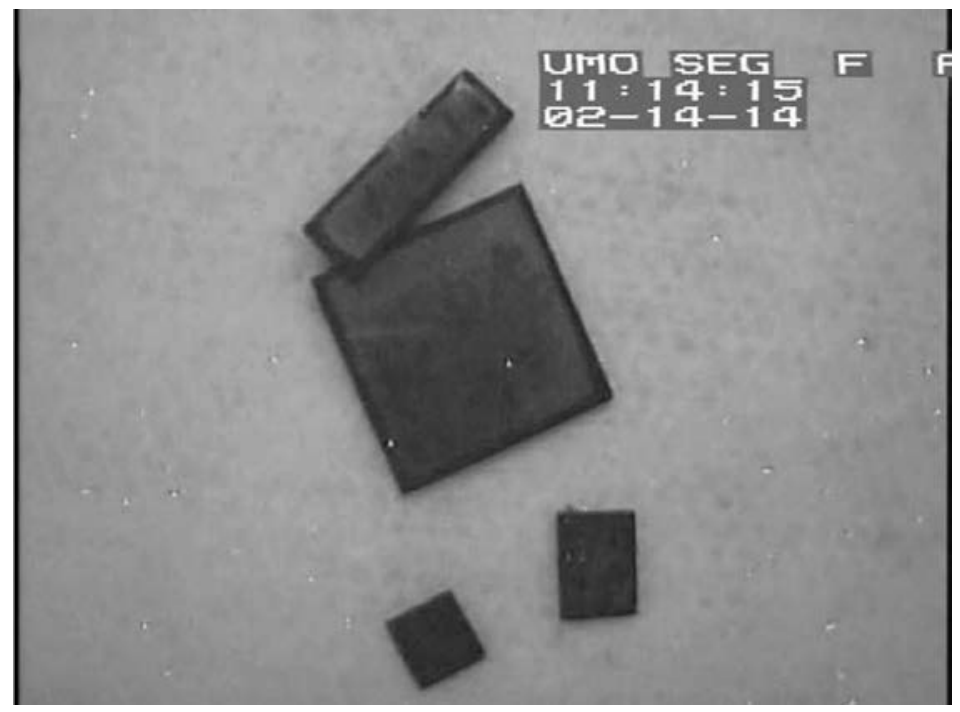

Figure 2.6. Photograph of the TF-LFA1, TF-DTA1, TF-OM1, and TF-DSC1 Samples after the AA6061 Cladding Has Been Removed 


\subsection{Optical Microscopy}

OM analysis was conducted to provide values for the internal dimensions, including component layer thicknesses and variability across the longitudinal (OM1) and transverse (OM2) directions of the fuel plate. Samples were prepared by mounting in epoxy (VariDur Acrylic from Buehler), segmented using an Isomet low-speed saw to obtain the desired edge, and then polished. All polishing operations were conducted with a Buehler Minimet polisher using exchangeable pads. The samples were initially roughed to an 800-grit finish producing images that could be used to extract thickness measurements. The images of the $\mathrm{Zr}$ /fuel interface and other regions were obtained after regrinding the samples starting with 400-grit abrasive discs, increasing to 1200 grit over various steps, followed by polishing cloths with diamond suspension solutions starting at $9 \mu \mathrm{m}$ and polishing stepwise down to $0.02 \mu \mathrm{m}$.

Samples were examined with a Nikon MA200 inverted optical microscope using polarized light, cross-polars, and $1 / 4$ wave-plate compensator to improve the visibility of features when necessary. The Nikon MA200 was installed into the hot cell equipped with remote control of $x-y$ translation, $z$-focus, illumination intensity, and the objective lens turret. Communication cables were extended and modifications to the microscope made so that a majority of the electronics were located outside the hot cell. To make the overall operation of the microscope easier and more efficient, the system was connected to the internal laboratory network, allowing it to be operated from any location. An extended depth-of-focus (EDF) module in the microscope software enabled the automatic acquisition of images at different focal planes (z-stack) to produce an image that had all regions of the specimen in focus. The images were recorded using a Nikon Digital Camera and Elements software package. The microscope images were calibrated using the SRM-2400 length standard purchased from the National Institute of Standards and Technology (NIST). After the analysis was completed, the specimen was removed from the hot cell as quickly as possible to minimize potential damage to the digital camera.

\subsection{Analytical Chemistry}

Analytical chemistry samples were acid-extracted in heated nitric acid using a temperature-controlled heat block. The initial extraction used approximately $15 \mathrm{~mL}$ of $8 \mathrm{M} \mathrm{HNO}_{3}$ heated to $95{ }^{\circ} \mathrm{C}$ for 6 hours. After this initial extraction, the two cladding layers were visible in the extraction tube. The initial extraction acid was collected, fresh $8 \mathrm{M} \mathrm{HNO}_{3}$ was added, and the fuel samples were heated again for an additional 4 hours at $95^{\circ} \mathrm{C}$. The second batch of acid extraction solution was removed and collected. Fresh $8 \mathrm{M} \mathrm{HNO}_{3}$ was then added to each sample as a rinse, with the rinse combined with the previous two acid extraction solutions. The final rinse of the samples was performed with DIW and combined with the previous acid extraction and rinse solutions. The extraction and rinse solutions were collected in 100 $\mathrm{mL}$ volumetric flasks. DIW was used for the final volume adjustment for the combined solutions in the volumetric flasks.

Masses used to process the analytical chemistry samples are provided in Table 2.3. Portions of the AA6061 cladding, Zr diffusion barrier, and potentially U-Zr intermetallic reaction product were not completely dissolved in the nitric acid solution. In this case, the residual material was dried in a Blue $\mathrm{M}$ drying oven at $105{ }^{\circ} \mathrm{C}$ for a total of 5 days. The residuals were weighed periodically to obtain a constant weight using a Sartorius MSG 234 balance so that a mass balance check could be performed. The residuals were stored in a glass vial once the constant weight had been obtained. 
Table 2.3. Sample Masses Used to Conduct Analytical Chemistry Experiments

\begin{tabular}{lccc}
\hline \multicolumn{1}{c}{ Sample } & Sample Mass (g) & Undissolved residual Mass (g) & Dissolved Mass Analyzed (g) \\
\hline TE-AC1 & 0.1265 & 0.0068 & 0.1197 \\
TE-AC2 & 0.1078 & 0.0051 & 0.1027 \\
TF-AC1 & 0.0342 & 0.0012 & 0.0330 \\
TF-AC2 & 0.0465 & 0.0020 & 0.0445 \\
TH-AC1 & 0.1340 & 0.0054 & 0.1286 \\
TH-AC2 & 0.1600 & 0.0059 & 0.1541 \\
TI-AC1 & 0.1060 & 0.0038 & 0.1022 \\
TI-AC2 & 0.1564 & 0.0057 & 0.1507 \\
\hline
\end{tabular}

Inductively coupled plasma-optical emission spectroscopy (ICP-OES) analysis was performed to determine the elemental composition of the dissolved fuel meat. Calibration of the PerkinElmer 5300DV ICP-OES was performed following the manufacturer's recommended calibration procedure using multianalyte custom standard solutions traceable to NIST. Midrange calibration verification standards were used to verify acceptance of the two-point calibration curves obtained for each analyte and for continuing calibration verification. A preparation blank and blank spike quality control samples were processed with the samples during dissolution and extraction. A replicate analysis was conducted on one sample for each fuel segment analysis in lieu of a prepared duplicate. Post-spike analyses were conducted on the samples. Of specific interest to the ICP-OES analysis were concentrations of $\mathrm{Al}, \mathrm{Mo}, \mathrm{U}$, and $\mathrm{Zr}$ in the solution. Values of $\mathrm{U}$ and Mo were used to determine $\mathrm{U}: \mathrm{Mo}$ ratio and values of $\mathrm{Al}$ and $\mathrm{Zr}$ to evaluate the cladding and diffusion barrier dissolution. Other nontarget analytes were also reported including the concentrations of the rare earths/measurable fission products (Ce, $\mathrm{Eu}, \mathrm{La}, \mathrm{Nd}, \mathrm{Ru}$, and $\mathrm{Sr}$ ) in the samples. Note that for the 93-3-1 DU-10Mo surrogate samples, only ICP-OES was performed.

Gamma energy analysis (GEA) was performed to determine the identity and quantity of gamma emitters present in the samples. Gamma detectors were calibrated using multi-isotope standards that are NIST-traceable and prepared in the identical counting geometry to samples for all detectors. Control sources containing ${ }^{241} \mathrm{Am},{ }^{137} \mathrm{Cs}$, and ${ }^{60} \mathrm{Co}$ were analyzed daily before the use of each detector. Background counts, which were subtracted from all sample counts, were performed on all gamma detectors at least weekly for either an overnight or weekend count. Canberra Genie 2000 software was used to compile the total counts of ${ }^{106} \mathrm{RuRh},{ }^{125} \mathrm{Sb},{ }^{134} \mathrm{Cs},{ }^{137} \mathrm{Cs},{ }^{144} \mathrm{Ce},{ }^{154} \mathrm{Eu}$, and ${ }^{155} \mathrm{Eu}$.

Analysis of $\mathrm{U}$ and $\mathrm{Pu}$ isotopic abundance of the samples was measured using thermal ionization mass spectrometry (TIMS). The separated $\mathrm{U}$ and Pu sample fractions contained approximately $30 \mu \mathrm{g}$ of $\mathrm{U}$ and approximately $0.3 \mu \mathrm{g}$ of Pu. The separated $\mathrm{U}$ fractions were diluted in $1 \mathrm{~mL}$ of $4 \mathrm{M} \mathrm{HNO}_{3}$. The separated Pu fractions were diluted with $25 \mu \mathrm{L}$ of $4 \mathrm{M} \mathrm{HNO}_{3}$. Five to 10 microliters of each solution were pipetted onto rhenium filaments, and then dried by warming the filament electrically. The dried sample was then installed in the TIMS for analysis. The CEC Model 21-703 TIMS was calibrated by running NIST-traceable U-100 isotopic abundance standard and Pu-946 isotopic abundance standard to check the mass calibration and mass discrimination correction. 


\subsection{Density}

An AccuPyc 1300 gas expansion pycnometer was used for density determination. The instrument consists of a sample chamber and an expansion chamber separated by an expansion valve. After inserting a sample into the sample chamber, the sample chamber is filled with helium. The helium is discharged into an expansion chamber having a known internal volume. The pressure difference between the isolated sample chamber and that of the sample chamber and expansion chamber combined is used to calculate volume displacement using Boyle's Law:

$$
p V=k
$$

where $p$ denotes the pressure of the system, $V$ is the volume of the gas, and $k$ is a constant value representative of the pressure and volume of the system. Rearranging Equation 1 to fit the current system gives (Lowell et al. 2004):

$$
V_{S}=V_{C}+\frac{V_{R}}{1-\frac{p_{1}}{p_{2}}}
$$

where $V_{S}$ is the sample volume, $V_{C}$ is the volume of the empty sample chamber, $V_{R}$ is the reference volume, $p_{1}$ is the first pressure (in the sample chamber only) and $p_{2}$ is the second pressure after expansion of the gas into the combined volumes of sample chamber and reference chamber. $V_{S}$ is then used with the pre-determined mass of the sample $(m)$ to obtain the sample density $(\rho)$ :

$$
\rho=\frac{m}{V_{S}}
$$

The balance calibration was verified by weighing standard weights between $1 \mathrm{~g}$ and $30 \mathrm{~g}$ and was considered acceptable if the measured values of the standard weights were within $\pm 1.0 \%$ of the standard values. The AccuPyc 1330 was calibrated per the manufacturer's instructions and confirmed before and after sample analysis with a verified standard. The gas pycnometer calibration standard was run multiple times during instrument operation and was considered acceptable if the measured volume was within $\pm 1.0 \%$ of the certified value. The samples were placed in a tared $1-\mathrm{cm}^{3}$ pycnometer sample cup and weighed. The pycnometer cup and sample were placed in the AccuPyc 1330 sample chamber and the chamber cap was fastened securely. Each sample was analyzed 10 times using ultra-high purity helium; the results were averaged and the density with standard deviation was recorded.

\subsection{Differential Scanning Calorimetry}

A Perkin Elmer Pyris 1 power-compensated DSC was used to perform specific heat capacity measurements on the fuel samples as a function of temperature. A constant flow of inert argon gas was purged through the system during operation to minimize sample oxidation and ensure a consistent sampling environment. Flow rate through the instrument was verified by a flow meter attached to the argon source external to the hot cell and a flow meter attached to the purge-gas exit line from the DSC 
interior to the hot cell. A chiller unit housed outside the hot cell that used a mixture of 80/20 propylene glycol/water set to $-5^{\circ} \mathrm{C}$ provided cooling capacity to the instrument.

Prior to testing, the DSC was balance- and slope-corrected, and then temperature was calibrated over the range of $156.6{ }^{\circ} \mathrm{C}(\mathrm{In})$ to $419.5{ }^{\circ} \mathrm{C}(\mathrm{Zn})$ using In, $\mathrm{Sn}, \mathrm{Pb}$, and $\mathrm{Zn}$ standard materials. Melt checks using two or more of the standard materials were performed before the actual sample run and after the sample run was complete. Melt onset temperatures were determined by calculating the intersection of two slopes that compose the melt curve, and the enthalpy of fusion was determined by the integrated curve. The instrument was considered to be within tolerance if the melt onset temperature was within $\pm 0.3{ }^{\circ} \mathrm{C}$ and the enthalpy of fusion was within $\pm 5 \%$ of the reported standard values.

Three separate runs using the same sample and reference pans with identical temperature profiles were performed: a baseline run with two empty $\mathrm{Al}$ pans, a reference run with a sapphire standard placed in the sample $\mathrm{Al}$ pan, and a sample run with the fuel sample placed in the sample $\mathrm{Al}$ pan. The same series of three runs was made for each fuel sample investigated. To ensure maximum contact with the heating stage, the flattest of the two large sample faces was selected for face-down placement in the Al sample pan (i.e., the four edges were not considered). Samples were loaded and centered in the aluminum sample pan that was subsequently centered in the platinum crucible (i.e., DSC sample holder).

For each irradiated fuel sample, data were obtained from two separate thermal profiles in order to avoid premature delamination and loss of the sample. Unless noted otherwise, five low temperature cycles were conducted from $40{ }^{\circ} \mathrm{C}$ to $170{ }^{\circ} \mathrm{C}$ using a constant ramp rate of $10^{\circ} \mathrm{C} \cdot \mathrm{min}^{-1}$. The low temperature cycles were followed by five high temperature cycles, from $180{ }^{\circ} \mathrm{C}$ to $370{ }^{\circ} \mathrm{C}$, also using a constant ramp rate of $10{ }^{\circ} \mathrm{C} \cdot \mathrm{min}^{-1}$. A 10-minute isotherm was conducted at the beginning and end of each thermal cycle. Data were collected upon both heating and cooling. The total cycle time for each irradiated fuel sample was approximately nine hours.

Specific heat capacity of each sample is typically determined using the ratio method. The key assumption for using the ratio method is that the experimental conditions for each of the three runs (i.e., baseline, reference, and sample) are the same; as such, any baseline shift that may have occurred in between any of the runs is unaccounted for. Therefore, to correct for potential baseline shift, specific heat capacity of each sample was calculated by employing a modified version of the ratio method presented in Equation 4 (Shaw and Carrol 1998). In Equation $4, C_{P}$ is the specific heat capacity in $\mathrm{J}^{\circ} \mathrm{g}^{-1} \bullet \mathrm{C}^{-1}, T$ is the temperature in ${ }^{\circ} \mathrm{C}, m$ is the mass in $\mathrm{mg}, \Delta V$ is the vertical displacement between the measured heat flow curve and the baseline, the superscripts + and - represent the heating and cooling runs respectively, and the subscripts $R$ and $S$ represent the reference (sapphire) and sample.

$$
C_{P}^{S_{P}+}(T)=C_{P}^{S_{-}-}(T)=\frac{m_{R}}{m_{S}}\left(\frac{\Delta V_{S}^{+}-\Delta V_{S}^{-}}{\Delta V_{R}^{+}-\Delta V_{R}^{-}}\right) C_{P}^{R}(T)
$$

\subsection{Laser Flash Analysis}

Thermal diffusivity measurements were performed using a Netzsch LFA 457 MicroFlash ${ }^{\circledR}$ Laser Flash Apparatus. The same samples used for density measurements were also subjected to laser flash analysis. A sapphire support was specially fabricated to accommodate the precise sample orientation necessary for proper laser flash analysis. The support was required in order to configure the sample in an 
orientation that allowed full laser irradiation of the sample side facing the laser, while also preventing any fine fuel fragments that may have separated from the sample during analysis from falling down into the instrument. Sapphire was specifically selected because of its transparency to laser light in the energy range of the laser used and also based on reports of successful use (Sheindlin et al. 1998). A vacuum of approximately 100 mtorr was applied to the closed sample chamber after the sample was loaded. Once under vacuum, a He purge was initiated and the vacuum pump shut off to allow for a He environment in the chamber. To minimize sample oxidation and ensure a consistent sampling environment, this process was repeated a second time. Once the chamber was refilled with He at approximately atmospheric pressure, the chamber was sealed and the purge gas shut off. Helium gas was selected because this allowed for better temperature control in the instrument at lower temperatures.

Before and after sample measurements, thermal diffusivity of a NIST-traceable iron standard was measured over the temperature range of interest. The instrument was considered in calibration if the iron standard measurements were within $\pm 5 \%$ of the expected values. Before laser flash measurements, the samples were coated with a thin layer of graphite (Graphit 33 from CRC Industries Deutschland).

For the irradiated fuel samples, data were obtained from two separate thermal profiles in order to avoid premature delamination and loss of the sample. A low-temperature cycle was conducted from $25{ }^{\circ} \mathrm{C}$ to $150{ }^{\circ} \mathrm{C}$, followed by a high-temperature cycle from $200{ }^{\circ} \mathrm{C}$ to $350{ }^{\circ} \mathrm{C}$. One minute was allowed between each shot to allow the sample to return to the prescribed temperature. Data were collected upon both heating and cooling that resulted in an approximately eight-hour cycle time.

ASTM E1461 (ASTM 2011) was used as a reference to perform the thermal diffusivity measurements. NETZSCH Proteus software ${ }^{3}$ was used to calculate thermal diffusivity using the CapeLehman + pulse correction model (Cape and Lehman 1963) that accounts for any heat transfer from the sample to the measurement environment and for finite pulse width effects (given the relative thinness of the samples). The Cape-Lehman model was selected because thermal diffusivity values reported for the Fe standard were also calculated using this mode, and based upon recommendations by the equipment manufacturer.

\footnotetext{
${ }^{3}$ Netzsch Proteus LFA Analysis, Version 6.0.0, May 7, 2012.
} 


\subsection{Results}

The results presented in this section are organized according to optical metallography, analytical chemistry, density, DSC, and laser flash analysis.

\subsection{Optical Metallography}

The optical metallography results presented in this section are organized according to fuel segment identification.

\subsubsection{Segment E}

Example OM montages of the TE-OM1 (longitudinal to the rolling direction) and TE-OM2 (transverse to the rolling direction) samples are provided in Figure 3.1. These montages were used to obtain thickness measurements over the sample length. The U-Mo sandwiched between AA6061 clad can be clearly observed in Figure 3.1.

Optical microscopy thickness measurements on the two samples are provided in Table 3.1, along with an average thickness for each constituent layer. The summation of each average layer thickness is assumed to represent the overall thickness of the segment for the calculations that follow. The data presented in Table 3.1 are also shown graphically in Figure 3.2. 

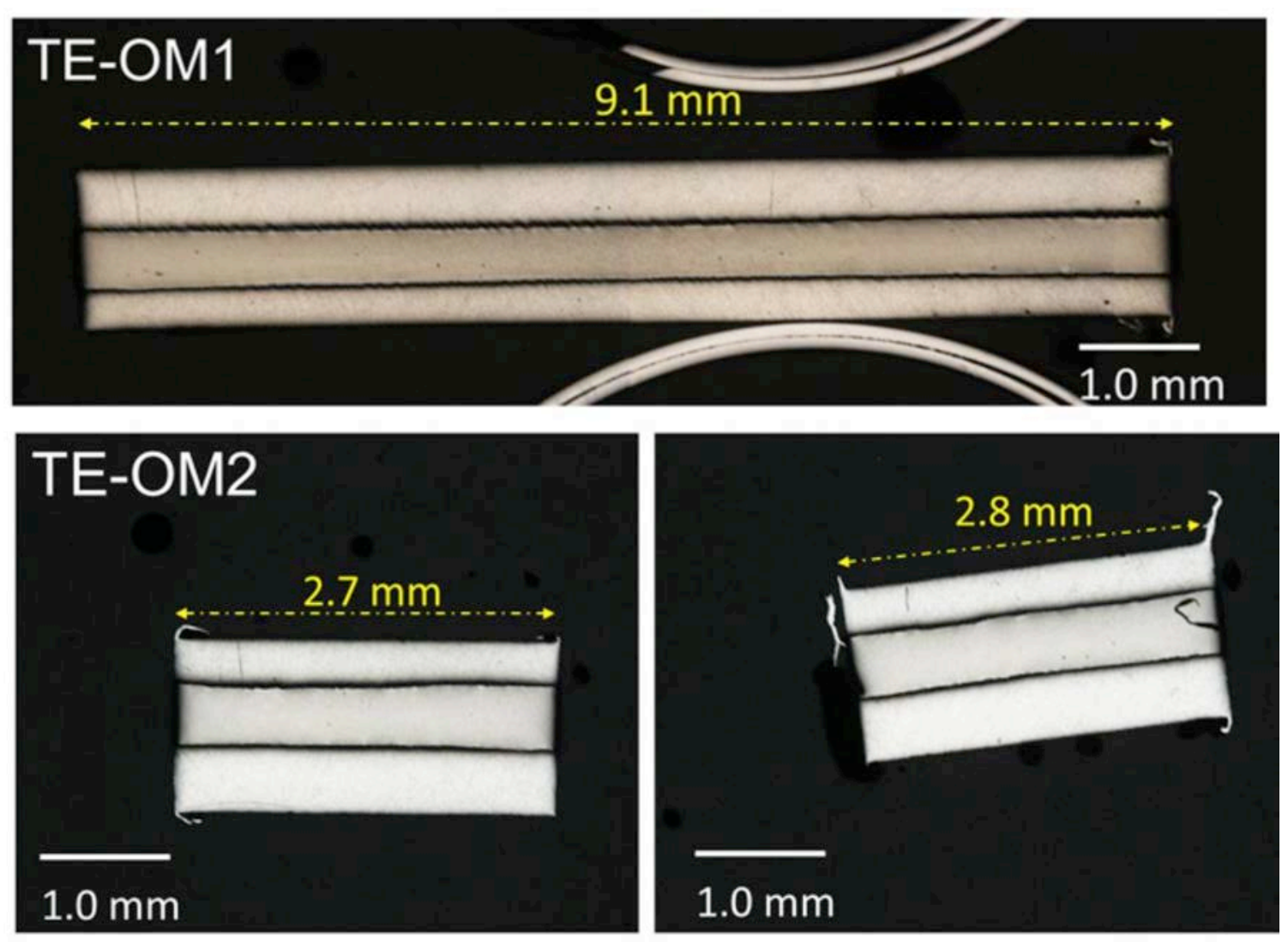

Figure 3.1. Low Magnification Optical Microscopy Montages of the TE-OM1 (top) and TE-OM2 (bottom) Samples

Table 3.1. Thickness Measurements Obtained from the Optical Microscopy Samples ${ }^{(a)}$

\begin{tabular}{lccc}
\hline & TE-OM1 & TE-OM2 & Overall \\
\hline Layer & Thickness, $\mu \mathrm{m}$ & Thickness, $\mu \mathrm{m}$ & Thickness, $\mu \mathrm{m}$ \\
Aluminum (upper) & $336 \pm 7.08(202)$ & $340 \pm 12.1(124)$ & $337 \pm 9.50(326)$ \\
Zirconium (upper) & $40.0 \pm 7.40(642)$ & $35.8 \pm 6.28(349)$ & $38.5 \pm 7.31(991)$ \\
U-10Mo & $419 \pm 18.5(428)$ & $438 \pm 20.7(195)$ & $425 \pm 21.1(623)$ \\
Zirconium (lower) & $34.8 \pm 8.45(521)$ & $35.0 \pm 6.95(297)$ & $34.8 \pm 7.94(818)$ \\
Aluminum (lower) & $477 \pm 12.2(220)$ & $482 \pm 10.0(77)$ & $478 \pm 11.8(297)$ \\
\hline Total Plate & $1320 \pm 11.5(140)$ & $1332 \pm 6.48(81)$ & $1324 \pm 11.6(221)$ \\
\hline
\end{tabular}

(a) Data presented are average values with standard deviation taken from the number of measurements reported within parentheses. 


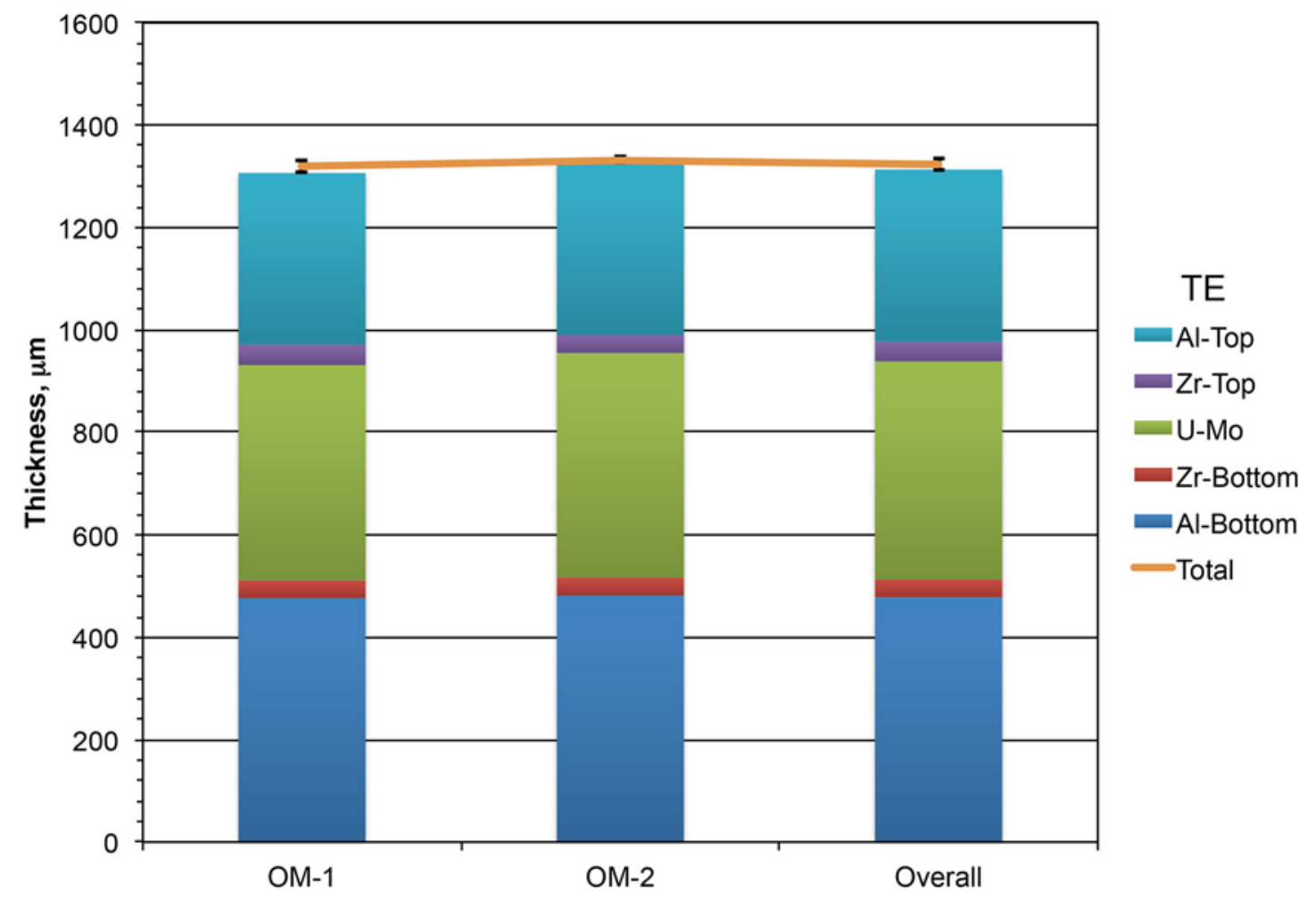

Figure 3.2. Graphical Representation of the Thickness Measurements Obtained from the TE-OM Samples

Overall, the layer thicknesses of each sample are relatively consistent with one another. The $\mathrm{Zr}$ thickness in each sample is, on average, much thicker than the nominal thickness of $25.4 \mu \mathrm{m}$.

Furthermore, based on the standard deviation of the Zr layer thickness measurements, it is apparent that this layer is variable, but perhaps not as variable as that observed with the AFIP-2BZ fuel segments analyzed in FY13. Thicknesses of the top and bottom portions of the AA6061 clad are in good agreement with one another for both samples. However, one side of the AA6061 clad is consistently thicker than the other side (lower compared to upper). This is believed to result from the foil retention pocket that is machined into one of the AA6061 clad plates to house the monolithic fuel foil before the bonding process (Moore 2010). The summation of each average layer thickness is in reasonably good agreement with the average of the thickness measurements taken over the entire length of the cross section, represented by the line in Figure 3.2. Thickness measurements as a function of position across the length of the sample are presented in Figure 3.3 for TC-OM1 and TC-OM2. This figure illustrates the variability in sample thicknesses for each of the constituent layers. 

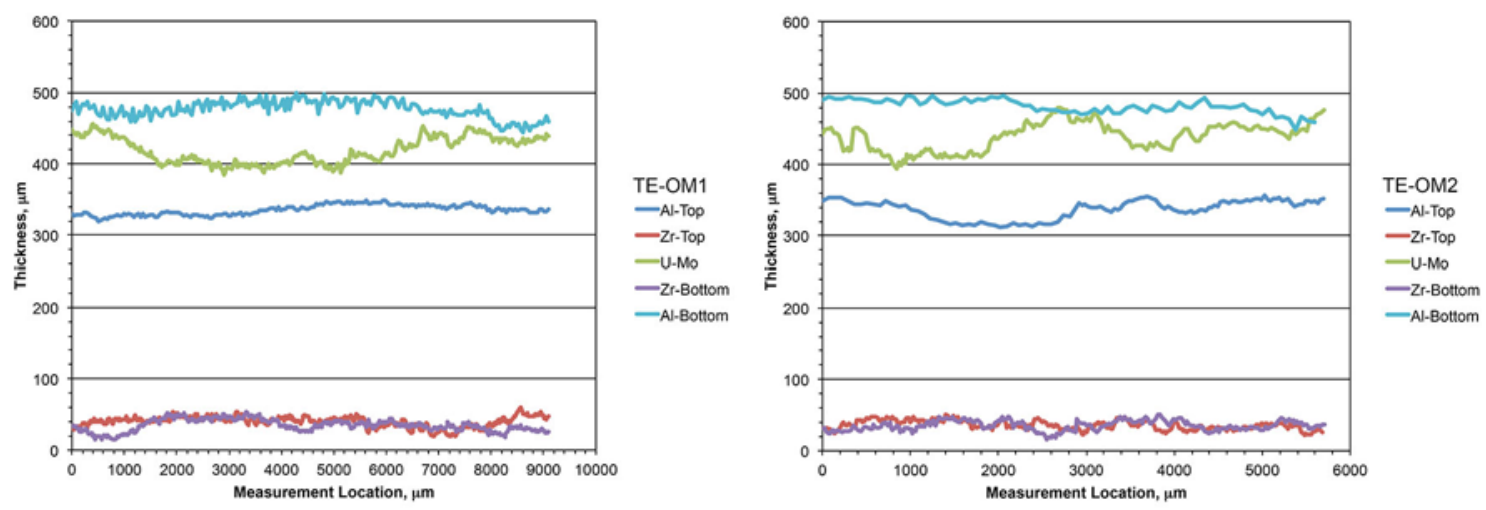

Figure 3.3. TE-OM1 (left) and TE-OM2 (right) Thickness Measurements for Each Layer as a Function of Measurement Location

Higher magnification optical images of the fuel-Zr diffusion barrier interface and fuel are provided in Figure 3.4 and Figure 3.5 for both TE-OM1 and TE-OM2 samples. The metallographs clearly shows a wide distribution of grain size within the U-Mo fuel, evidenced by the fine, rather uniform fission gas bubbles that begin to nucleate along the boundaries. More elongated grains are present in the TE-OM2 samples compared to samples analyzed in FY13, which could be the result of a slightly different rolling process (e.g., reduction schedule) used to fabricate the AFIP-3BZ foil. Recrystallization of the grain structure has clearly been initiated but has not yet reached completion as a result of the coarser, more elongated grains present in this fuel segment. There are also darker regions sporadically observed along the fuel-Zr interface (Figure 3.4). However, in this particular fuel segment, these features appear to be gross porosity located at the fuel-Zr interface, whereas in segments analyzed in FY13, such features were not necessarily present. Rather, it was hypothesized that the darker, more uniform features randomly oriented at the fuel-Zr interface were intermetallics (e.g., $\mathrm{Mo}_{2} \mathrm{Zr}$ ). Evidence of a hypothesized $\mathrm{UZr}_{2}$ layer (Perez et al. 2010) is still present in these samples represented by the lighter region immediately adjacent to the fuel. This layer possesses much greater contrast than that observed with the fuel segments analyzed in FY13. It is noted that this finding may be the result of improvements made in imaging and polishing, or this contrast could be compositionally driven. However, this distinction cannot be made without additional analysis by scanning electron microscopy (SEM).
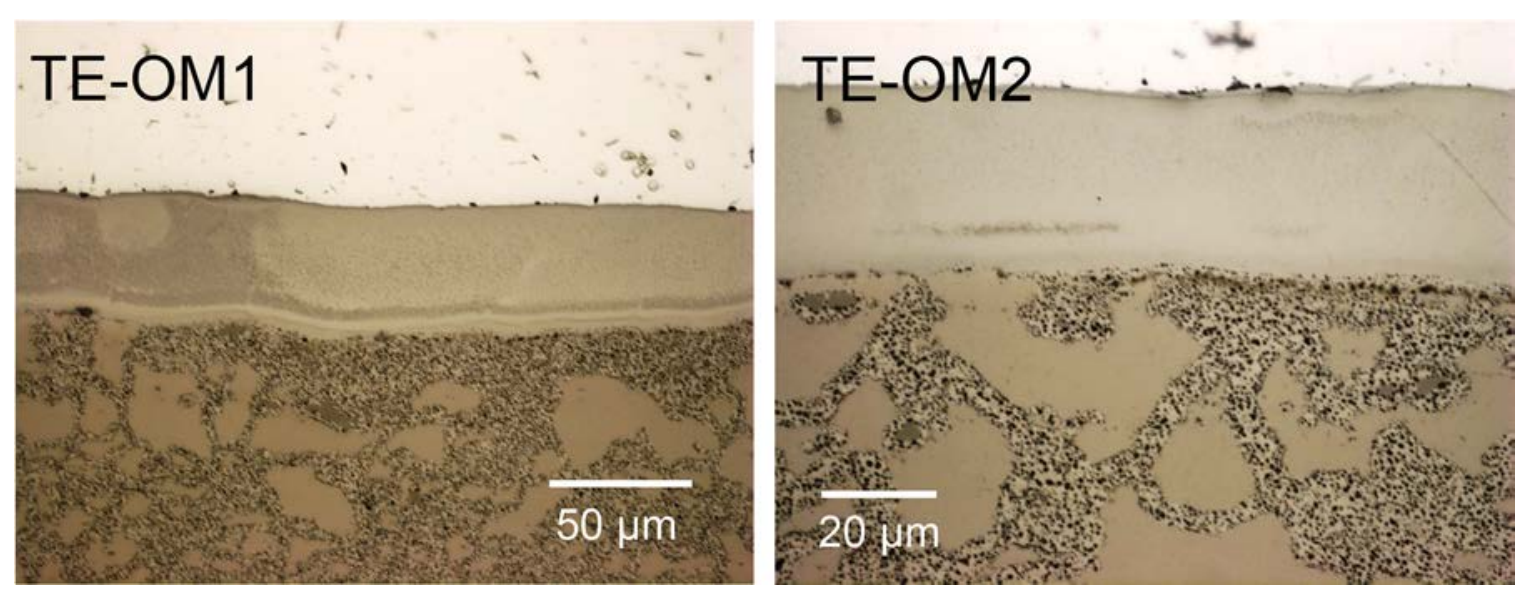

Figure 3.4. Extended Depth of Focus Optical Microscopy Images of the Fuel-Zr Diffusion Barrier Interface for Both TE-OM1 (left) and TE-OM2 (right) Samples 

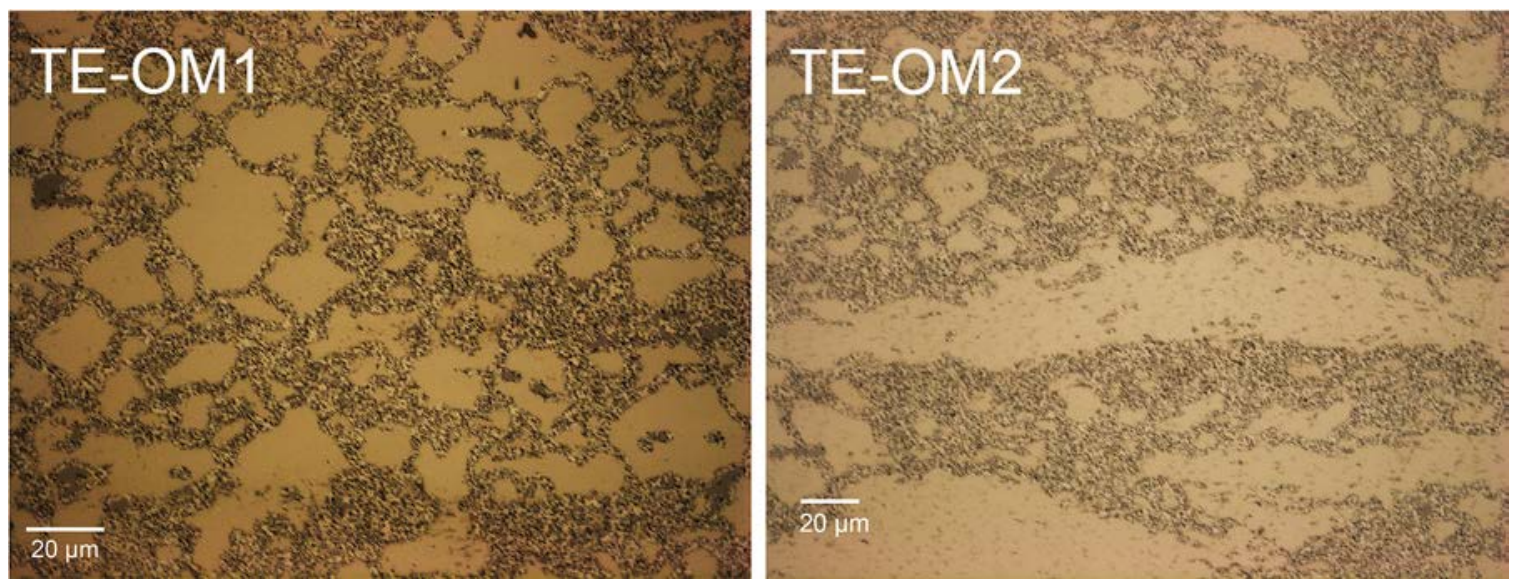

Figure 3.5. Higher Magnification EDF Images of the Irradiated Fuel for Both TE-OM1 (left) and TEOM2 (right) Samples

\subsubsection{Segment F}

Example OM montages of the TF-OM1 (longitudinal) and TF-OM2 (transverse) samples are provided in Figure 3.6. These montages were used to obtain thickness measurements over the entire sample length at approximately equidistantly spaced locations.

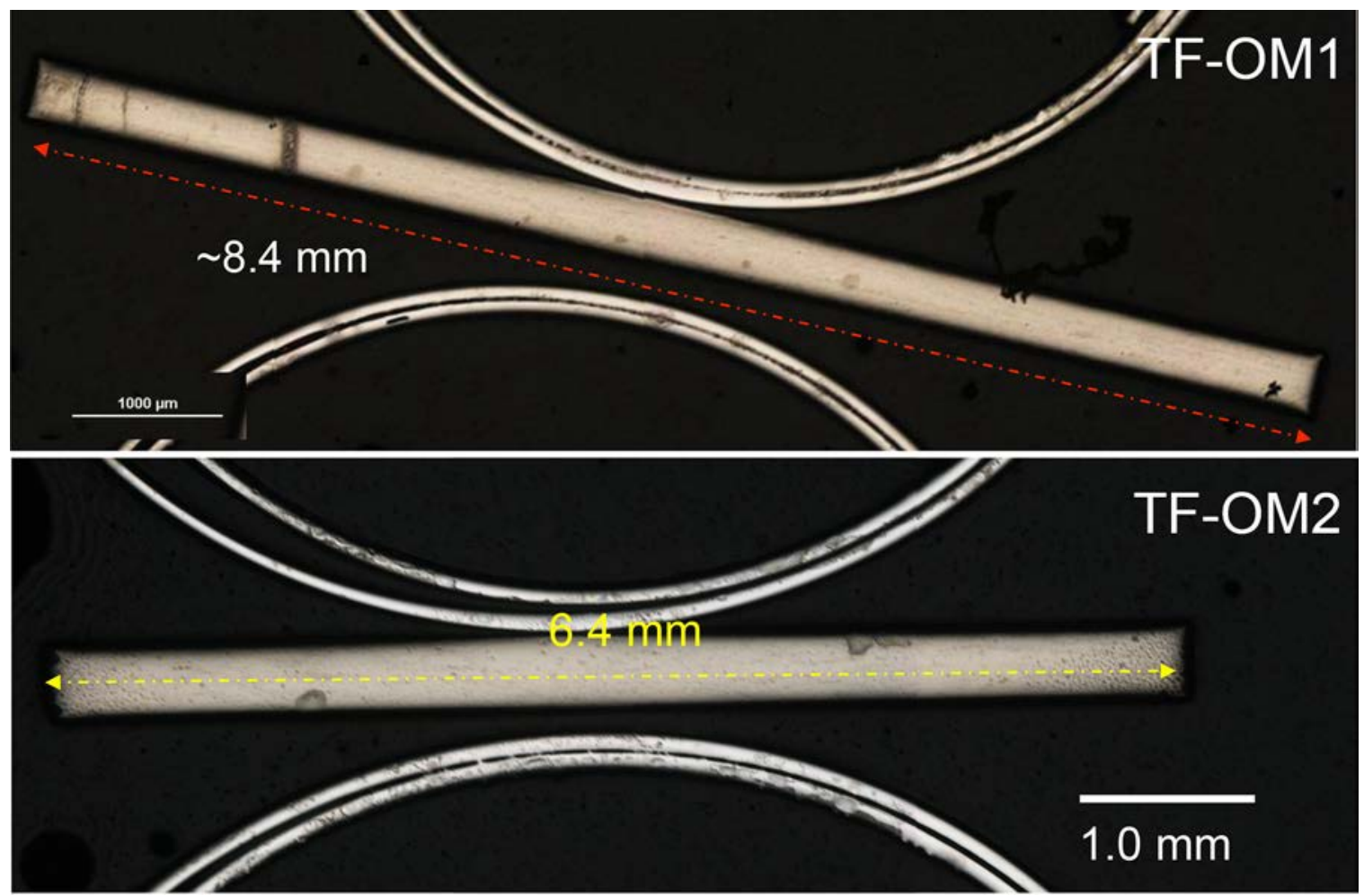

Figure 3.6. Low Magnification Optical Microscopy Montages of the TF-OM1 (top) and TF-OM2 (bottom) Samples

Optical microscopy thickness measurements on the two samples are provided in Table 3.2, along with an average thickness for each constituent layer. The summation of each average layer thickness is 
assumed to represent the overall thickness of the segment for the calculations that follow. The data presented in Table 3.2 are also shown graphically in Figure 3.7.

Table 3.2. Thickness Measurements Obtained from the TF Optical Microscopy Samples ${ }^{(a)}$

\begin{tabular}{lccc}
\hline & TF-OM1 & TF-OM2 & Overall \\
\hline Layer & Thickness, $\mu \mathrm{m}$ & Thickness, $\mu \mathrm{m}$ & Thickness, $\mu \mathrm{m}$ \\
Zirconium (upper) & $22.7 \pm 4.36(475)$ & $22.8 \pm 5.16(369)$ & $22.7 \pm 4.72(844)$ \\
U-10Mo & $390 \pm 7.24(399)$ & $390 \pm 7.51(254)$ & $390 \pm 7.34(653)$ \\
Zirconium (lower) & $23.3 \pm 4.15(571)$ & $23.7 \pm 4.77(406)$ & $23.5 \pm 4.42(977)$ \\
\hline
\end{tabular}

(a) Data presented are average values with standard deviation taken from the number of measurements reported within parentheses.

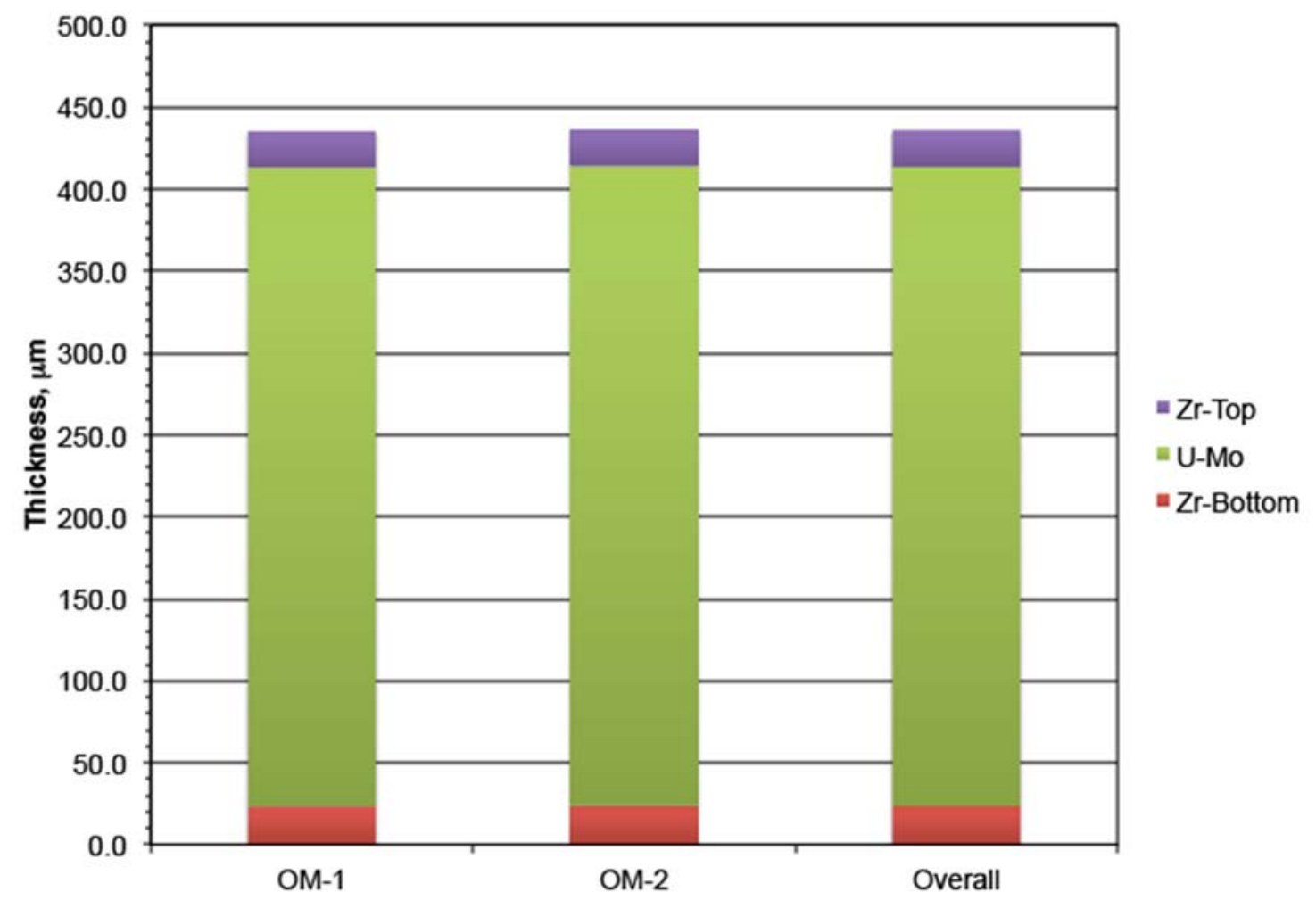

Figure 3.7. Graphical Representation of the Thickness Measurements Obtained from the TF-OM Samples

Overall, the layer thicknesses of each sample are relatively consistent with one another. The $\mathrm{Zr}$ thicknesses in each sample were, on average, much closer to the nominal thickness of $25.4 \mu \mathrm{m}$ and appeared to have slightly less variability than any of the AFIP-2BZ or AFIP-3BZ samples. This result could again be indicative of improvements made to the rolling process used to fabricate U-Mo fuel foils for later experiments, because these foils were likely processed according to very different parameters than those fabricated for earlier irradiation experiments. 
Thickness measurements as a function of position across the length of the sample are presented in Figure 3.8 for TF-OM1 and TF-OM2. This figure illustrates the variability in sample thicknesses for each of the constituent layers.
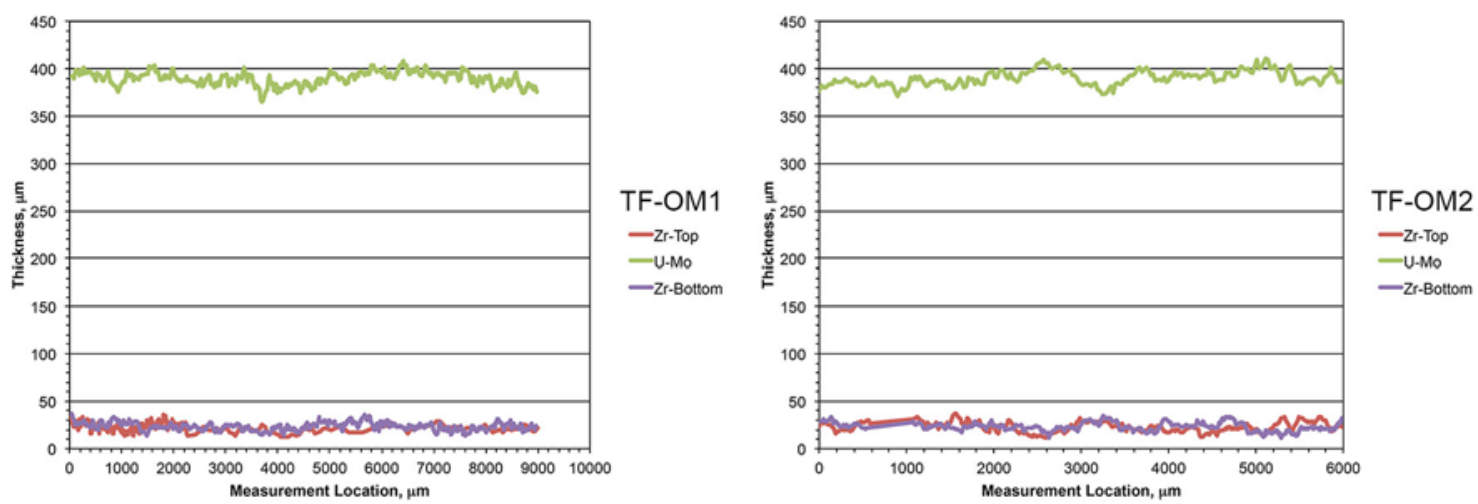

Figure 3.8. TF-OM1 (left) and TF-OM2 (right) Thickness Measurements for Each Layer as a Function of Approximate Measurement Location

Extended depth of focus (EDF) OM images of the fuel-Zr diffusion barrier interface are provided in Figure 3.9 for both TF-OM1 and TF-OM2 samples. Higher magnification EDF OM images of the fuel are provided in Figure 3.10. The metallographs show less distribution of grain size within the U-Mo fuel than observed for other fuel segments. In addition, there appear to be fewer bubbles along the grain boundaries, but the bubbles that are present appear to be larger in size compared to the AFIP-2BZ and AFIP-3BZ samples, especially for the TF-OM1 sample (Figure 3.9). As with previous samples, there are features observed along the fuel-Zr diffusion barrier interface, specifically the thin, lighter, uniform layer believed to be $\mathrm{UZr}_{2}$ and the darker features that decorate portions of the interface. It is not clear from these metallographs whether the darker features are porosity, similar to those observed in Segment TE, or $\mathrm{Mo}_{2} \mathrm{Zr}$ intermetallics, similar to those observed for samples analyzed in FY13. An increased number of darker features are observed throughout the fuel zone (Figure 3.9). It is not clear from the techniques authorized in this work scope what these features are, i.e., decomposition product, carbides, other impurities, etc. It is very interesting to note that a number of these darker features within the fuel zone contain black spots, which could be indicative of porosity, particularly in the TF-OM2 sample. These black features are much larger in size than anything analyzed previously. 

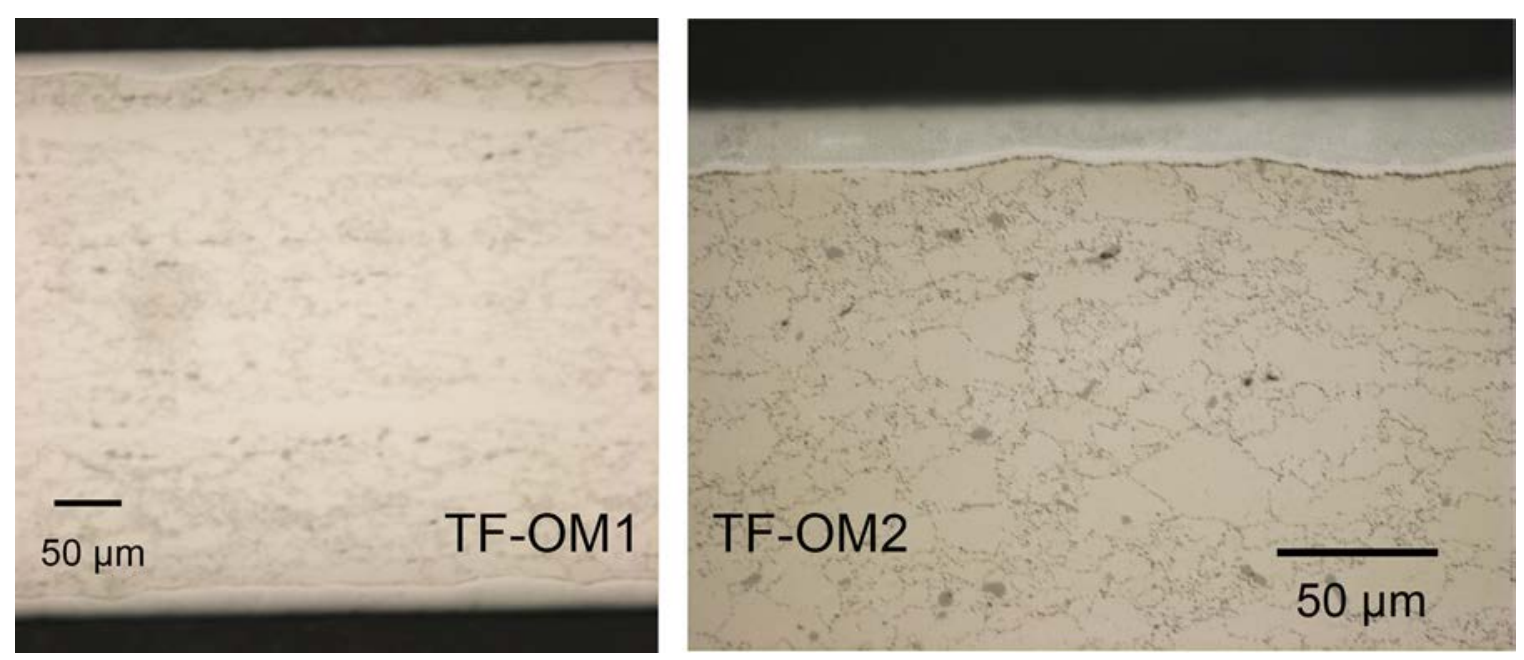

Figure 3.9. Extended Depth of Focus Optical Microscopy Images of the Fuel-Zr Diffusion Barrier Interface for Both TF-OM1 (left) and TF-OM2 (right) Samples
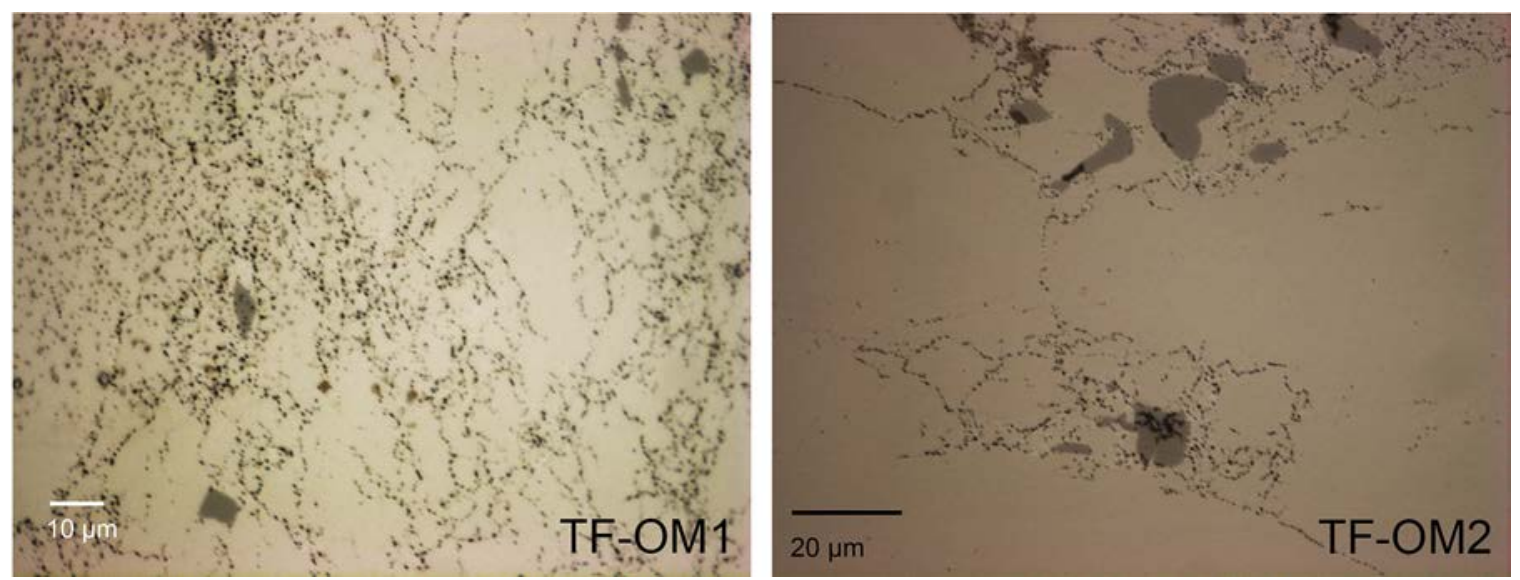

Figure 3.10. Higher Magnification EDF Images of the Irradiated Fuel for Both TF-OM1 (left) and TFOM2 (right) Samples

\subsubsection{Segment $\mathrm{H}$}

Optical microscopy montages of the TH-OM1 (longitudinal) and TH-OM2 (transverse) samples are provided in Figure 3.11. These montages were used to obtain thickness measurements over the entire sample length at approximately equidistantly spaced locations. The multiple layers of the composite can be observed in Figure 3.11.

Optical microscopy thickness measurements on the two samples are provided in Table 3.3, along with an average thickness for each constituent layer. The summation of each average layer thickness is assumed to represent the overall thickness of the segment for the calculations that follow. The data presented in Table 3.3 are also shown graphically in Figure 3.12. 

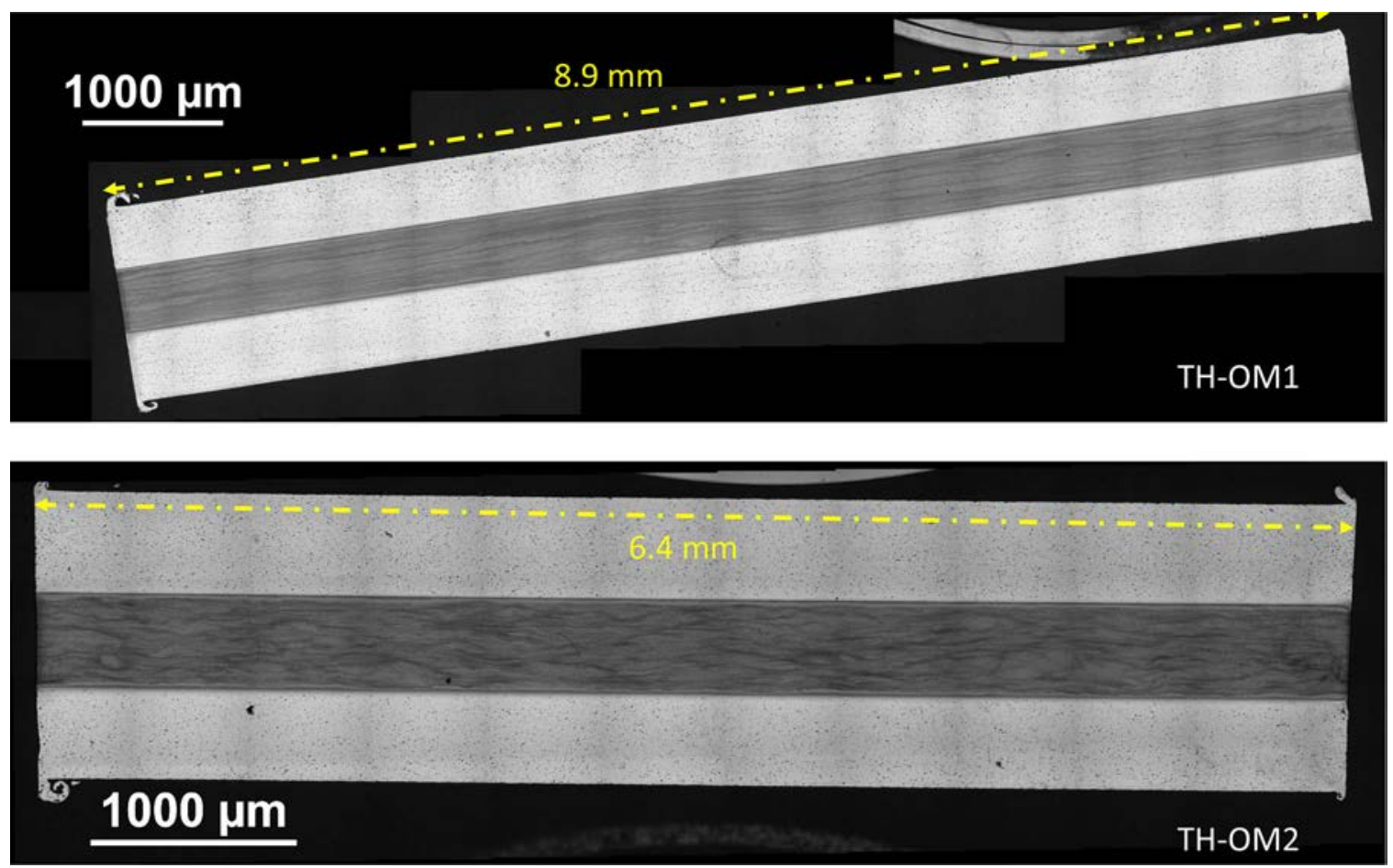

Figure 3.11. Low Magnification Optical Microscopy Montages of the TH-OM1 (top) and TH-OM2 (bottom) Samples

Table 3.3. Thickness Measurements Obtained from the TH Optical Microscopy Samples ${ }^{(a)}$

\begin{tabular}{lccc}
\hline & TH-OM1 & TH-OM2 & Overall \\
\hline Layer & Thickness, $\mu \mathrm{m}$ & Thickness, $\mu \mathrm{m}$ & Thickness, $\mu \mathrm{m}$ \\
Aluminum (upper) & $485 \pm 4.39(54)$ & $489 \pm 2.46(40)$ & $487 \pm 4.03(94)$ \\
Zirconium (upper) & $25.6 \pm 4.26(461)$ & $26.6 \pm 5.02(144)$ & $25.8 \pm 4.47(605)$ \\
U-10Mo & $415 \pm 6.70(434)$ & $417 \pm 6.49(136)$ & $415 \pm 6.74(570)$ \\
Zirconium (lower) & $23.6 \pm 4.60(492)$ & $25.0 \pm 4.75(204)$ & $24.0 \pm 4.68(696)$ \\
Aluminum (lower) & $440 \pm 4.59(57)$ & $438 \pm 2.64(52)$ & $439 \pm 3.97(109)$ \\
\hline Total Plate & $1392 \pm 5.06(90)$ & $1391 \pm 2.43(28)$ & $1392 \pm 4.59(118)$ \\
\hline (a) Data presented are average values with standard deviation taken from the number of measurements reported \\
within parentheses.
\end{tabular}




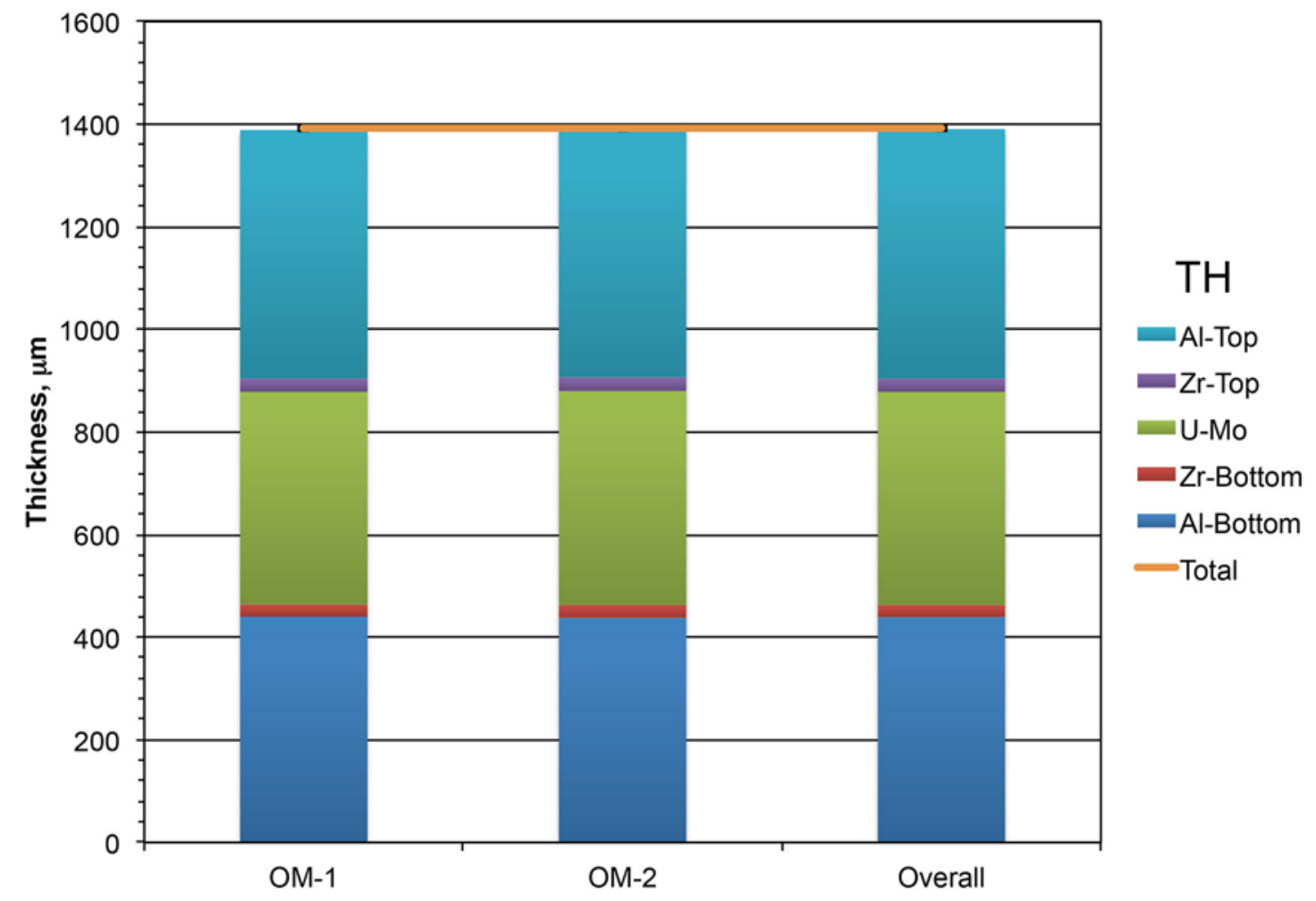

Figure 3.12. Graphical Representation of the Thickness Measurements Obtained from the TH-OM Samples

Overall, the layer thicknesses of each sample are very consistent with one another. Similar to OM measurements on the TF sample, the $\mathrm{Zr}$ thickness in each TH sample is on average very close to the nominal thickness of $25.4 \mu \mathrm{m}$. While there is still some difference in the AA6061 cladding thickness between the top and bottom, the variation is not as extensive as that observed for the other HIP plate analyzed in this work (Segment TE). The summation of each average layer thickness is in very good agreement with the average of the thickness measurements taken over the entire length of the crosssection, represented by the line in Figure 3.12.

Thickness measurements as a function of approximate position across the length of the sample are presented in Figure 3.13 for TH-OM1 and TH-OM2. This figure illustrates the lower variability in sample thicknesses observed for each of the constituent layers compared to the samples analyzed previously. 

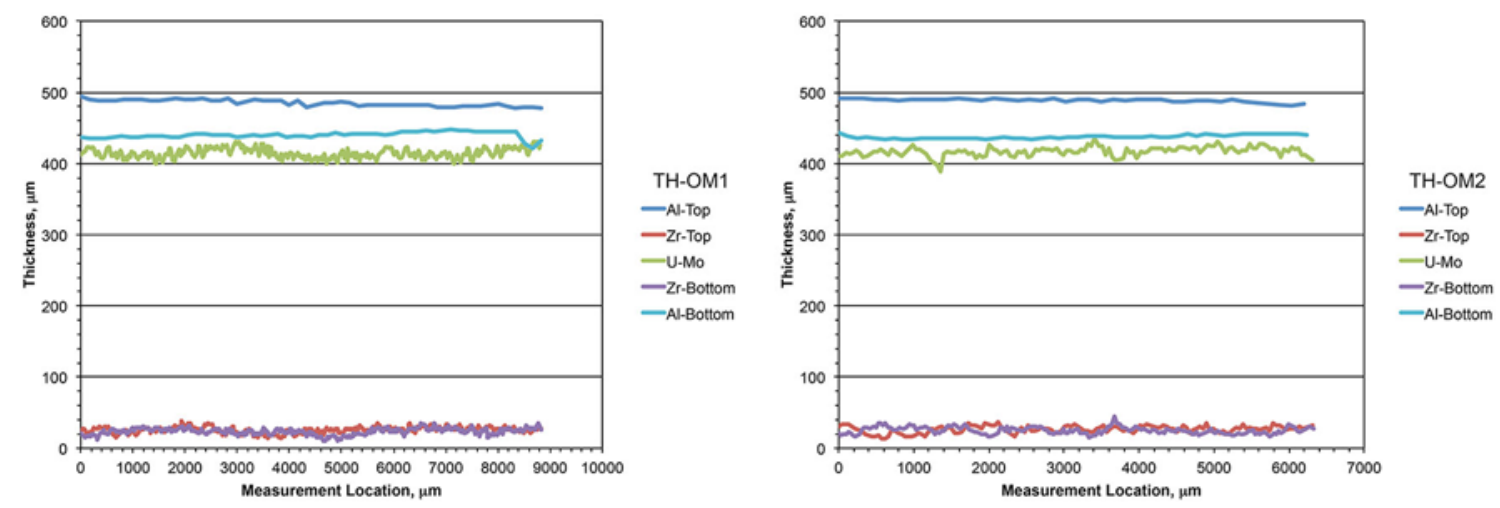

Figure 3.13. TH-OM1 (left) and TH-OM2 (right) Thickness Measurements for Each Layer as a Function of Approximate Measurement Location

Extended depth of focus OM images of the fuel-Zr diffusion barrier interface and fuel are provided in Figure 3.14 and Figure 3.15 for both TH-OM1 and TH-OM2 samples. The TH metallographs show that recrystallization of the microstructure is clearly occurring, and only coarse U-Mo grains remain. The thin, uniform layer believed to be $\mathrm{UZr}_{2}$ along the fuel-Zr diffusion barrier interface present in previous samples is not as clear in these metallographs, and the Zr layer appears to be much more blotchy (in terms of grayscale) than previously observed. There are still dark precipitates along portions of the Zr-fuel interface, although these features are not present along the entire length of the interface shown in the metallograph. Again, it is not clear from the images whether these features are porosity or $\mathrm{Mo}_{2} \mathrm{Zr}$ intermetallics, but they are much more closely spaced than any of the samples analyzed previously. The intermetallics are known to form in unirradiated materials, but the influence of irradiation conditions on the characteristics (i.e., amophorization, compositional changes, etc.) is not well understood or documented. The higher magnification images of the fuel reveal a heavily banded microstructure. Fission gas bubbles appear to be much more concentrated in the darker bands than in the lighter bands. Furthermore, it appears that the darker bands consist of finer grains than the lighter bands, which could indicate that lighter bands are enriched in Mo as opposed to the darker bands. The same darker features randomly located throughout the fuel in Figure 3.15 that were observed for Segment TF are present in these samples. Similarly, much of these darker features contain large, non-uniform black spots that are hypothesized to represent porosity, although a definitive conclusion cannot be drawn from basic optical metallography. 

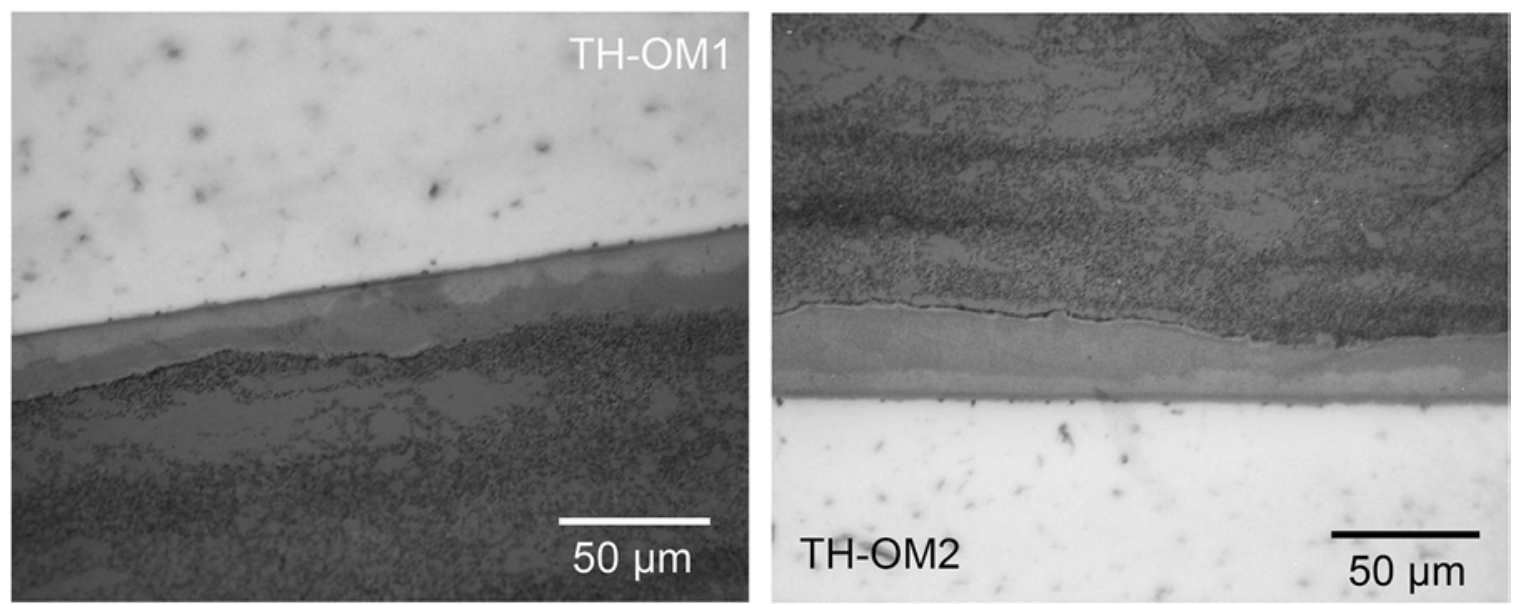

Figure 3.14. Extended Depth of Focus Optical Microscopy Images of the Fuel-Zr Diffusion Barrier Interface for Both TH-OM1 (left) and TH-OM2 (right) Samples
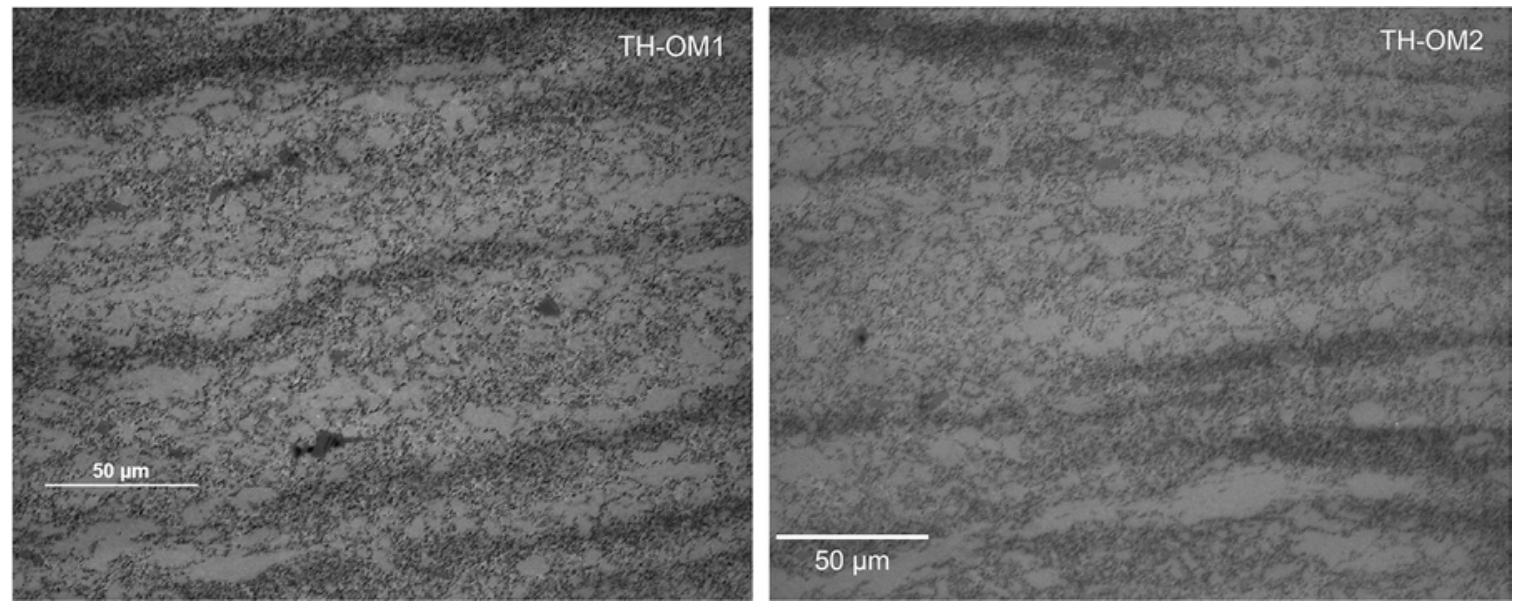

Figure 3.15. Higher Magnification EDF Images of the Irradiated Fuel for Both TH-OM1 (top) and THOM2 (bottom) Samples

\subsubsection{Segment I}

Optical microscopy montages of the TI-OM1 (longitudinal) and TI-OM2 (transverse) samples are provided in Figure 3.16. These montages were used to obtain thickness measurements over the entire sample length at approximately equidistantly spaced locations. The multiple layers of the composite can be observed in Figure 3.16.

Optical microscopy thickness measurements on the two samples are provided in Table 3.4, along with an average thickness for each constituent layer. The summation of each average layer thickness is assumed to represent the overall thickness of the segment for the calculations that follow. The data presented in Table 3.4 are also shown graphically in Figure 3.17. 

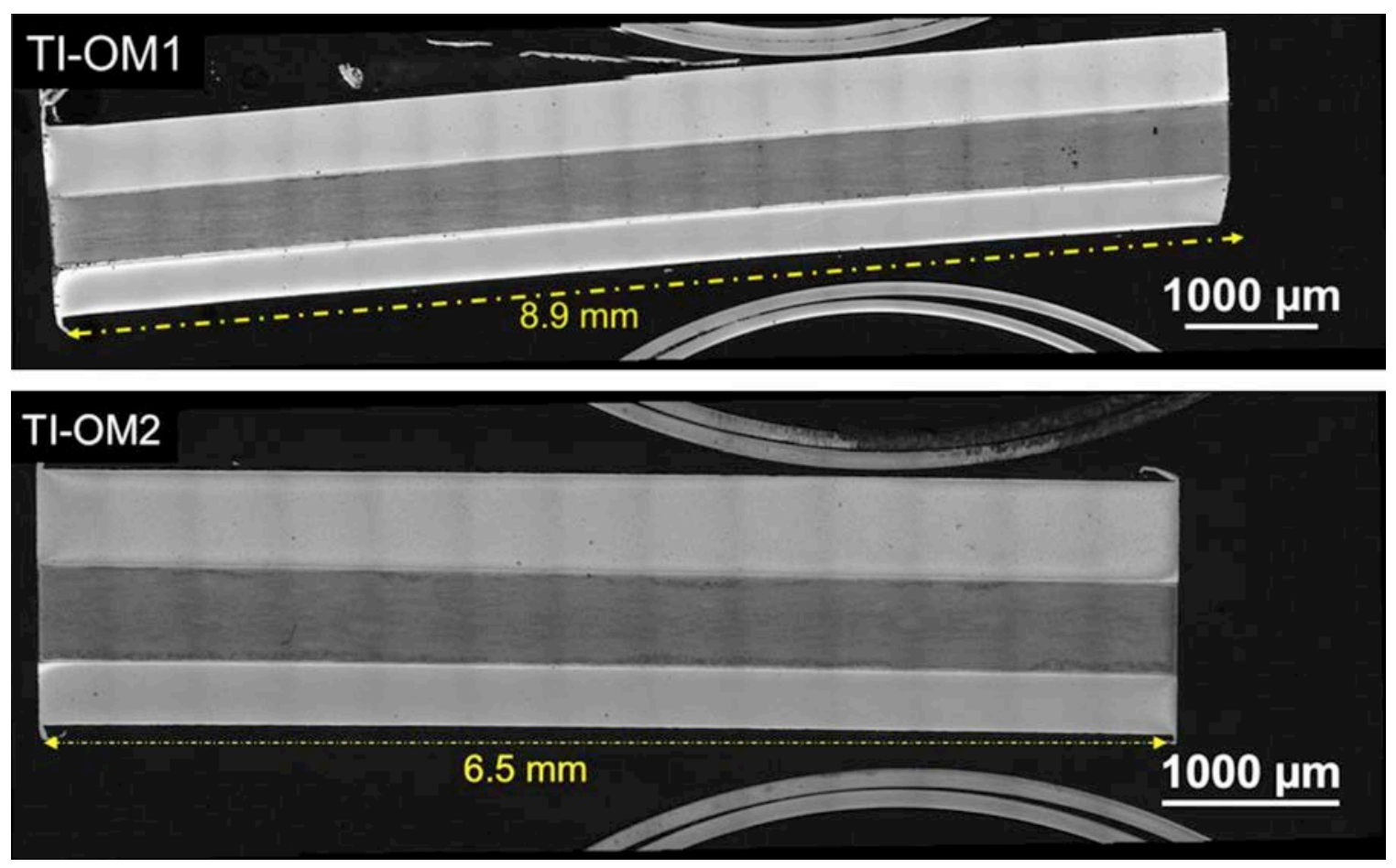

Figure 3.16. Low Magnification Optical Microscopy Montages of the TI-OM1 (top) and TI-OM2 (bottom) Samples

Table 3.4. Thickness Measurements Obtained from the TI Optical Microscopy Samples ${ }^{(a)}$

\begin{tabular}{lccc}
\hline & TI-OM1 & TI-OM2 & Overall \\
\hline Layer & Thickness, $\mu \mathrm{m}$ & Thickness, $\mu \mathrm{m}$ & Thickness, $\mu \mathrm{m}$ \\
Aluminum (upper) & $520 \pm 11.0(34)$ & $559 \pm 10.3(71)$ & $546 \pm 21.2(105)$ \\
Zirconium (upper) & $23.8 \pm 4.80(913)$ & $24.8 \pm 6.81(272)$ & $24.0 \pm 5.34(1185)$ \\
U-10Mo & $500 \pm 7.64(309)$ & $494 \pm 11.2(172)$ & $498 \pm 9.44(481)$ \\
Zirconium (lower) & $26.5 \pm 4.49(509)$ & $24.3 \pm 4.89(202)$ & $25.9 \pm 4.71(711)$ \\
Aluminum (lower) & $358 \pm 5.08(44)$ & $337 \pm 8.98(84)$ & $345 \pm 12.7(128)$ \\
\hline Total Plate & $1422 \pm 15.9(33)$ & $1431 \pm 5.68(45)$ & $1427 \pm 11.8(78)$ \\
\hline
\end{tabular}

(a) Data presented are average values with standard deviation taken from the number of measurements reported within parentheses. 


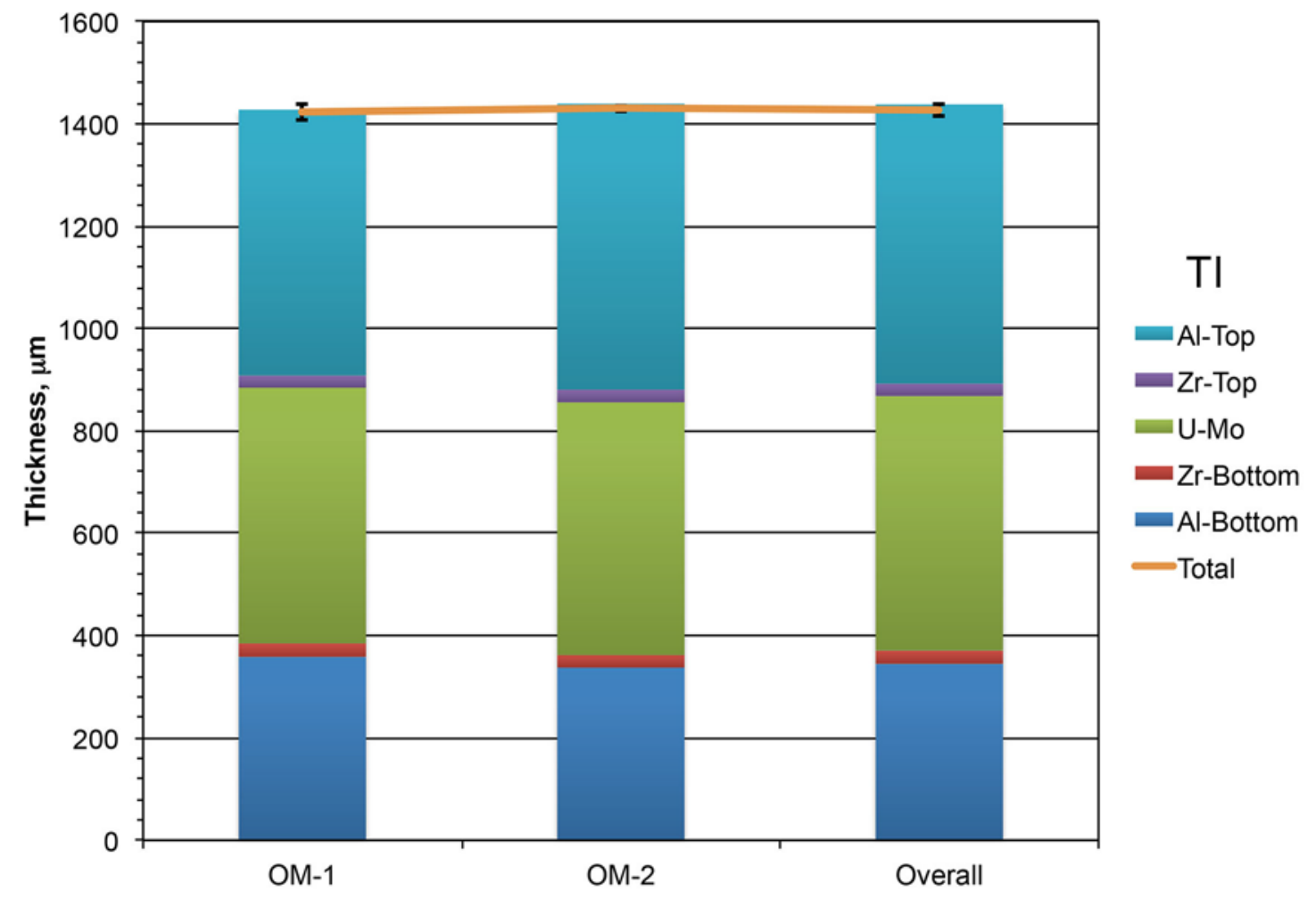

Figure 3.17. Graphical Representation of the Thickness Measurements Obtained from the TI-OM Samples

Overall, the layer thicknesses of each sample are relatively consistent with one another. The $\mathrm{Zr}$ thickness in each TI sample is, on average, very close to the nominal thickness of $25.4 \mu \mathrm{m}$. However, similar to OM measurements made on previous samples, one side of the AA6061 clad is consistently thinner than the other (lower vs. upper). This is very different from Segment TH that was harvested from the same fuel plate. While a potential reason for the difference in thickness has been offered previously (refer to Section 3.1.1), it is not clear why there would be so much discrepancy within a given fuel plate, especially for a uniform bonding process such as HIP. Thickness measurements obtained on the TI-OM transverse and longitudinal samples are in very good agreement with one another, and the summation of each average layer thickness is in very good agreement with the average of the thickness measurements taken over the entire length of the cross-section, represented by the line in Figure 3.17.

Thickness measurements as a function of approximate position across the length of the sample are presented in Figure 3.18 for TI-OM1 and TI-OM2. This figure illustrates the relative similarity in sample thicknesses for each of the constituent layers. 

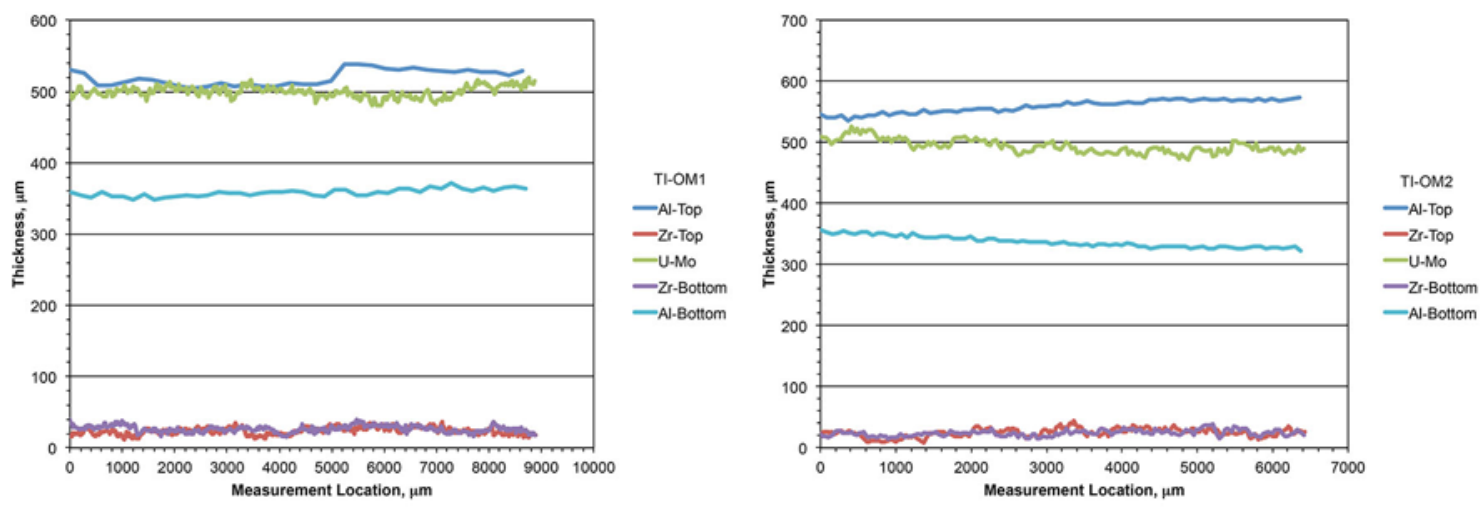

Figure 3.18. TI-OM1 (left) and TI-OM2 (right) Thickness Measurements for Each Layer as a Function of Approximate Measurement Location

Extended depth of focus OM images of the fuel-Zr diffusion barrier interface are provided in Figure 3.19 for both TI-OM1 and TI-OM2 samples. These metallographs clearly show a contrast with any other sample analyzed previously. The hypothesized $\mathrm{UZr}_{2}$ layer present at the $\mathrm{Zr}$-fuel interface is once again not as clear as it has been in other samples. It is not clear if this layer was just not present in these particular samples, or if the layer was damaged as a result of the more intense irradiation conditions. There are a number of dark features decorating the Zr-fuel interface, which are too large to be considered $\mathrm{Mo}_{2} \mathrm{Zr}$ precipitates. These features are likely regions of gross porosity that have coalesced at the interface. In fact, dark features located within approximately $50 \mu \mathrm{m}$ of the fuel-Zr interface are also present, which has not been observed previously (Figure 3.19 right). These particular features have a peculiar shape and a brief search of literature does not show similar features being observed previously. Higher-magnification EDF OM images of the TI-OM1 and TI-OM2 fuel zones are provided in Figure 3.20. These metallographs suggest that recrystallization of the initial microstructure is nearly complete, as many of the original grains are no longer discernible. The fuel is laced with fission gas bubbles that range in size. Many of the bubbles are the largest that have been observed in any of the samples analyzed to date. The chemical banding that was observed in the TH samples is not observed in the TI samples, but this could be the effect of greater gas bubble density.
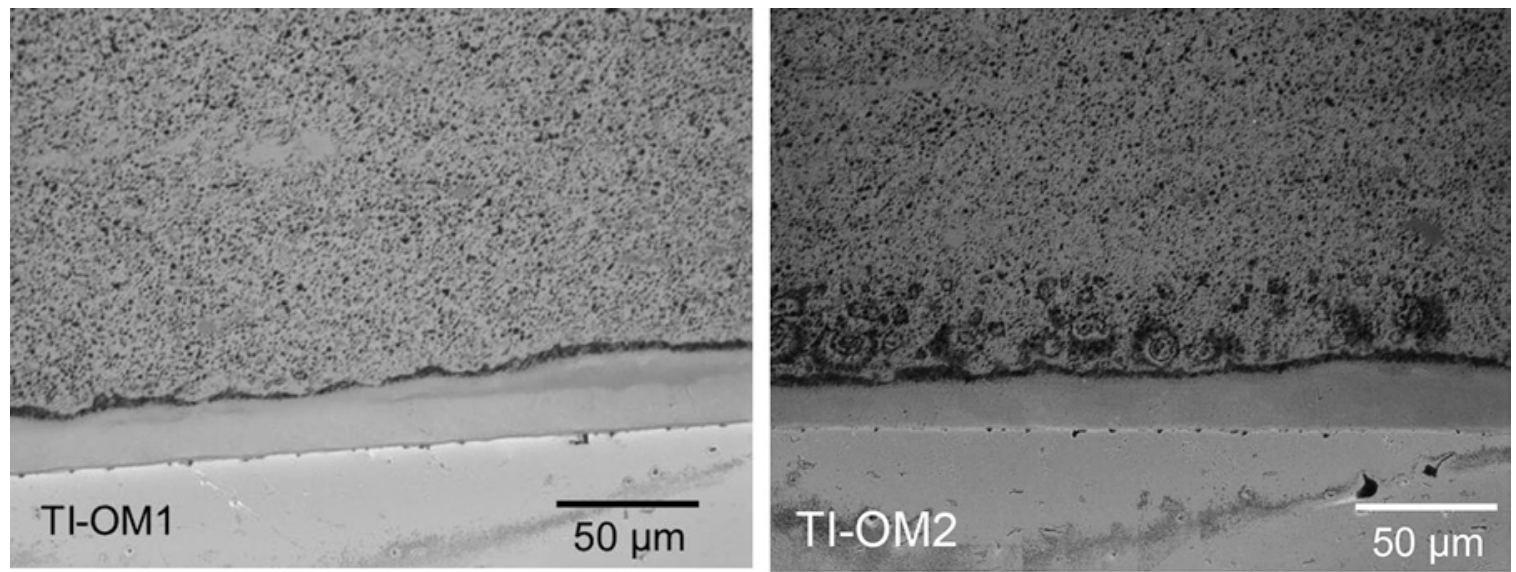

Figure 3.19. Extended Depth of Focus Optical Microscopy Images of the Fuel-Zr Diffusion Barrier Interface for Both TI-OM1 (left) and TI-OM2 (right) Samples 

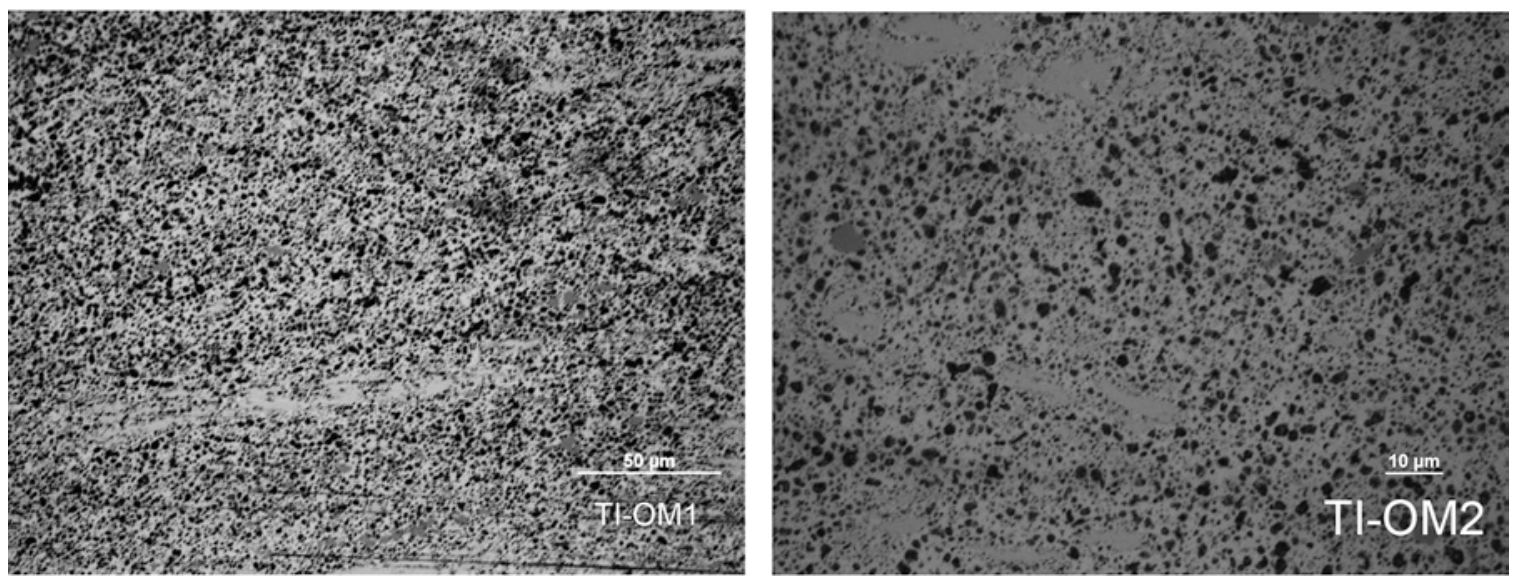

Figure 3.20. Higher Magnification EDF Images of the Irradiated Fuel for Both TI-OM1 (top) and TIOM2 (bottom) Samples

\subsection{Analytical Chemistry}

The analytical chemistry results presented in this section are organized according to the method of measurement.

\subsubsection{Inductively Coupled Plasma-Optical Emission Spectroscopy}

Uranium:molybdenum ratios obtained from the ICP-OES analysis are provided in Table 3.5. The results in Table 3.5 suggest that, based on the amount of irradiated fuel alloy dissolved, the mass composition of the dissolved Mo component ranges from $10.9 \mathrm{wt} \%$ to $12.7 \mathrm{wt} \%$, with the balance being dissolved U. The reported as-fabricated Mo concentration in the AFIP-3BZ fuel foil (Segment TE) was 10.3 wt.\% Mo, and was 9.74 wt\% Mo in the AFIP-6MkI (Segment TF) and AFIP-6MkII (Segments TH and TI) fuel foils. Thus, the change in fuel composition from the as-fabricated value with irradiation ranges between $12 \%$ and $26 \%$. This behavior is expected because the relative ratio of $U$ to Mo will decline with ${ }^{235} \mathrm{U}$ depletion during irradiation, in effect resulting in an enrichment of the Mo concentration in the alloy. This is further enhanced by the fact that Mo isotopes represent a relatively significant percentage of the fission products produced during irradiation. It should be noted that approximately $5 \%$ of the dissolved samples remained as residual solids that could be enriched or depleted in particular fission product elements. There will also be a minor depletion in ${ }^{238} \mathrm{U}$ because of activation and conversion to $\mathrm{Pu}$. The enrichment in Mo for the TE, TH, and TI fuel segments is comparable to those measured for samples in FY13. However, the Mo enrichment for Segment TF is minimal in comparison but could result from the significantly shorter irradiation time for the AFIP-6MkI experiment from which the segment was harvested. Other typical solid fission products observed from the ICP-OES analysis are summarized in Table 3.6. There is a clear increase in the amount of solid fission products present in the analytical chemistry samples with increased burnup. Uncertainty of all ICP-OES results is $\pm 15 \%$. 
Table 3.5. Uranium:Molybdenum Ratios of the Analytical Chemistry Samples Obtained from ICP-OES Measurements $^{(a)}$

\begin{tabular}{|c|c|c|c|c|}
\hline Segment & Sample ID & \% Dissolved & U, wt. $\%^{(\mathrm{b})}$ & Mo, wt.\% ${ }^{(\mathrm{c})}$ \\
\hline \multirow{4}{*}{$\mathrm{TE}$} & AC1 & 94.6 & 87.2 & 12.8 \\
\hline & AC1 (rep) & 94.6 & 87.0 & 13.0 \\
\hline & AC2 & 95.3 & 87.5 & 12.5 \\
\hline & Average & 94.8 & 87.3 & 12.7 \\
\hline \multirow{4}{*}{$\mathrm{TF}$} & AC1 & 96.6 & 89.1 & 10.9 \\
\hline & AC2 & 95.7 & 89.1 & 10.9 \\
\hline & AC2 (rep) & 95.7 & 89.1 & 10.9 \\
\hline & Average & 96.0 & 89.1 & 10.9 \\
\hline \multirow{4}{*}{$\mathrm{TH}$} & AC1 & 96.0 & 88.4 & 11.6 \\
\hline & AC1 (rep) & 96.0 & 88.4 & 11.6 \\
\hline & AC2 & 96.3 & 88.3 & 11.7 \\
\hline & Average & 96.1 & 88.3 & 11.7 \\
\hline \multirow{4}{*}{$\mathrm{TI}$} & AC1 & 96.5 & 87.8 & 12.2 \\
\hline & AC1 (rep) & 96.5 & 87.9 & 12.1 \\
\hline & AC2 & 96.3 & 87.7 & 12.3 \\
\hline & Average & 96.4 & 87.8 & 12.2 \\
\hline \multicolumn{5}{|c|}{$\begin{array}{l}\text { (b) Calculated as the wt.\% of } \mathrm{U} \text { to } \mathrm{U}+\mathrm{Mo} \\
\text { (c) Calculated as the wt.\% of Mo to U+Mo }\end{array}$} \\
\hline
\end{tabular}


Table 3.6. Solid Fission Product Distribution of the Analytical Chemistry Samples Obtained from the ICP-OES Measurements ${ }^{(a)}$

\begin{tabular}{cllcccccc}
\hline Segment & \multicolumn{1}{c}{ Sample } & $\mathrm{Ce}$ & $\mathrm{Eu}$ & $\mathrm{La}$ & $\mathrm{Nd}$ & $\mathrm{Ru}$ & $\mathrm{Sr}$ & $\mathrm{Y}$ \\
\hline \multirow{5}{*}{$\mathrm{TE}$} & AC1 & $\mathrm{NM}$ & 240 & 3200 & 11000 & $\mathrm{NM}$ & 2360 & 1340 \\
& AC1 (rep) & $\mathrm{NM}$ & 320 & 3100 & 11000 & $\mathrm{NM}$ & 2370 & 1250 \\
& AC2 & $\mathrm{NM}$ & 200 & 3300 & 10000 & $\mathrm{NM}$ & 2430 & 1340 \\
& Average & $\mathrm{NM}$ & 253 & 3200 & 10667 & $\mathrm{NM}$ & 2387 & 1310 \\
& AC1 & $\mathrm{NM}$ & 79 & 2000 & 6300 & $\mathrm{NM}$ & 1540 & 829 \\
& AC2 & $\mathrm{NM}$ & 100 & 2000 & 6500 & $\mathrm{NM}$ & 1570 & 800 \\
$\mathrm{TF}$ & AC2 (rep) & $\mathrm{NM}$ & 68 & 2000 & 6200 & $\mathrm{NM}$ & 1580 & 829 \\
& Average & $\mathrm{NM}$ & 82 & 2000 & 6333 & $\mathrm{NM}$ & 1563 & 819 \\
& AC1 & 4300 & 150 & 2540 & 7600 & 3300 & 2130 & 1140 \\
& AC1 (rep) & 4200 & 130 & 2530 & 7900 & 3200 & 2180 & 1150 \\
$\mathrm{~T}$ & AC2 & 4500 & 130 & 2520 & 7800 & 3300 & 2170 & 1140 \\
& Average & 4333 & 137 & 2530 & 7767 & 3267 & 2160 & 1143 \\
& AC1 & 3200 & 150 & 2840 & 9100 & 3700 & 2460 & 1270 \\
& AC2 & 4400 & 152 & 2810 & 9200 & 3700 & 2430 & 1270 \\
& AC2 (rep) & 4600 & 140 & 2810 & 8800 & 3400 & 2420 & 1270 \\
& Average & 4067 & 147 & 2820 & 9033 & 3600 & 2437 & 1270 \\
\hline
\end{tabular}

(a) Units are in $\mu \mathrm{g} / \mathrm{g}$ fuel

\subsubsection{Gamma Energy Analysis}

Results from GEA as a function of calculated fission density for each fuel segment analyzed are provided graphically in Figure 3.21. Included on the graph are results obtained from measurements in FY13 (Segments TA, TB, and TC). The open symbols on the graph represent the high surface heat flux samples that were analyzed (i.e., Segments TF, TH, and TI), while the closed symbols on the graph represent the moderate surface heat flux samples that were analyzed (i.e., TA, TB, TC, and TE). In order to make useful comparisons, the GEA data were corrected for decay from the time of measurement to the time when irradiation of the respective fuel plate ceased (refer to Perez et al. 2011b for Segments TA, TB, and TC; Perez et al. 2012a for Segment TE; Perez et al. 2011a for Segment TF; and Perez et al. 2012b for Segments TH and TI). In general, nuclide activity increases as the fission density of the sample increases. There is minimal apparent influence of surface heat flux on ${ }^{154} \mathrm{Eu},{ }^{134} \mathrm{Cs}$, and ${ }^{106} \mathrm{RuRh}$ nuclide activity. However, the higher surface heat flux of Segments TF, TH, and TI results in slightly higher nuclide inventories for ${ }^{125} \mathrm{Sb},{ }^{137} \mathrm{Cs}$, and ${ }^{144} \mathrm{Ce}$. 


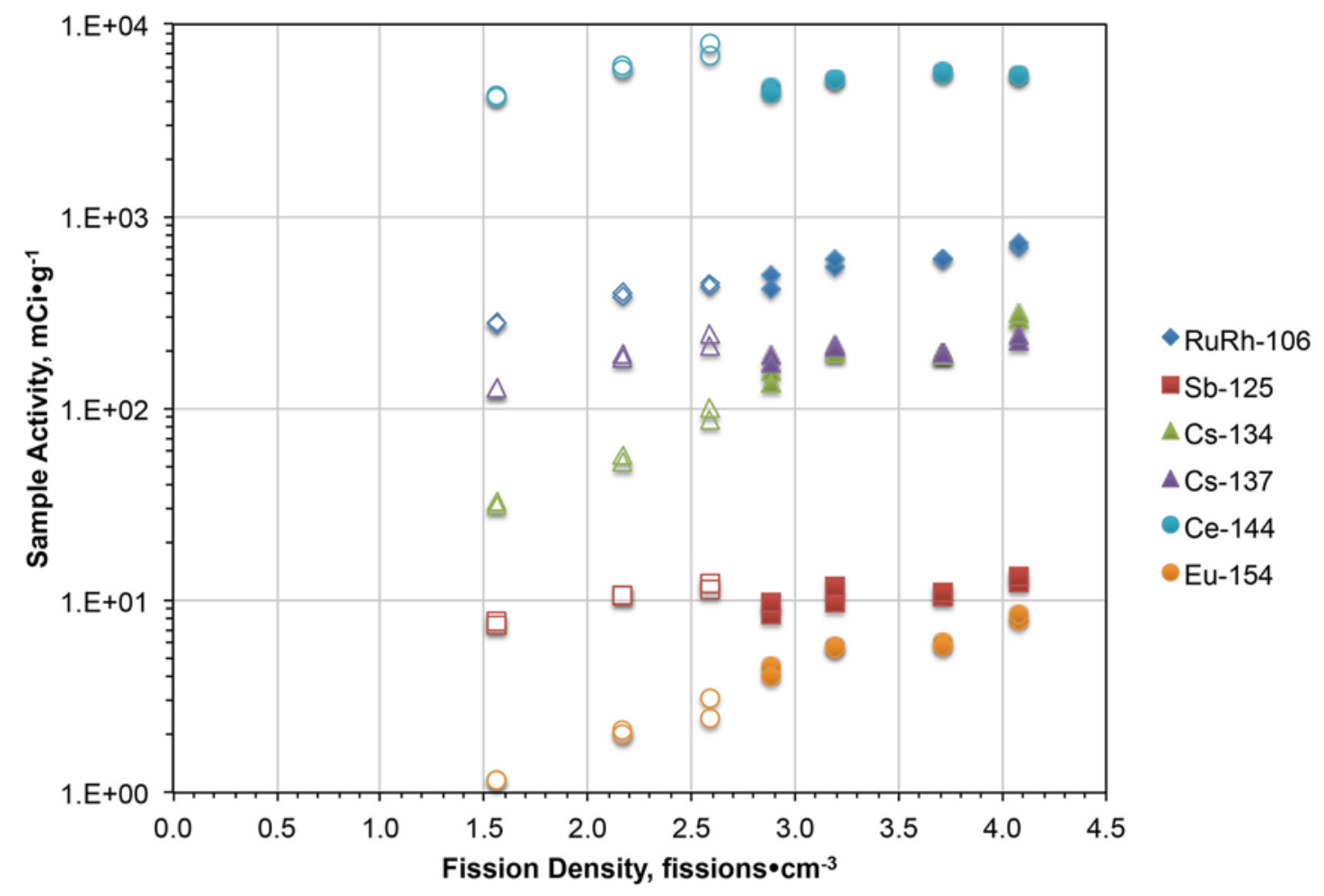

Figure 3.21. GEA Results for Specific Nuclides as a Function of Calculated Segment Fission Density. Solid Markers Represent Moderate Surface Heat Flux Segments (A, B, C, and E) while Open Markers Represent High Surface Heat Flux Segments (F, H, and I)

\subsubsection{Thermal Ionization Mass Spectroscopy}

Average results from the TIMS $U$ analysis are provided in Table 3.7. The average burnup $(B)$ for each fuel segment was determined on a mass basis using the as-fabricated enrichments summarized in Table 2.1 (BOL) and the overall average TIMS U results provided in Table 3.7 (EOL) represented by Equation 5. Use of Equation 5 assumes that the ${ }^{238} \mathrm{U}$ content did not change significantly during irradiation, which was justified based on the number of ${ }^{239} \mathrm{Pu}$ atoms measured by TIMS and discussed below.

$B=\frac{U_{B O L}^{235}-\left[U_{E O L}^{235}+\left(U_{E O L}^{236}-U_{B O L}^{236}\right)\right]}{U_{B O L}^{235}}$ 
Table 3.7. Average Results from the TIMS U Analysis on Each Fuel Segment Investigated

\begin{tabular}{clccccc}
\hline Segment & \multicolumn{1}{c}{ Sample } & ${ }^{234} \mathrm{U}$ & ${ }^{235} \mathrm{U}$ & ${ }^{236} \mathrm{U}$ & ${ }^{238} \mathrm{U}$ & Burnup \\
\hline \multirow{4}{*}{ TE } & AC1 & $0.160 \pm 0.019$ & $6.62 \pm 0.064$ & $2.49 \pm 0.313$ & $90.7 \pm 0.270$ & \\
& AC1 (rep) & $0.176 \pm 0.004$ & $6.68 \pm 0.148$ & $2.69 \pm 0.053$ & $90.5 \pm 0.105$ & \\
& AC2 & $0.177 \pm 0.006$ & $6.80 \pm 0.078$ & $2.65 \pm 0.013$ & $90.4 \pm 0.064$ & \\
& Average & $0.174 \pm 0.012$ & $6.73 \pm 0.113$ & $2.62 \pm 0.158$ & $90.5 \pm 0.199$ & $55.1 \%$ \\
& AC1 & $0.240 \pm 0.004$ & $33.5 \pm 0.186$ & $2.08 \pm 0.004$ & $64.1 \pm 0.190$ & \\
& AC1 (rep) & $0.236 \pm 0.011$ & $33.3 \pm 0.467$ & $2.08 \pm 0.025$ & $64.4 \pm 0.438$ & \\
TF & AC2 & $0.228 \pm 0.004$ & $33.5 \pm 0.244$ & $2.09 \pm 0.015$ & $64.2 \pm 0.261$ & \\
& AC2 (rep) & $0.236 \pm 0.009$ & $33.4 \pm 0.524$ & $2.10 \pm 0.027$ & $64.4 \pm 0.497$ & \\
& Average & $0.235 \pm 0.008$ & $33.4 \pm 0.329$ & $2.09 \pm 0.018$ & $64.2 \pm 0.318$ & $12.0 \%$ \\
& AC1 & $0.240 \pm 0.005$ & $31.0 \pm 0.071$ & $2.76 \pm 0.007$ & $66.1 \pm 0.071$ & \\
& AC1 (rep) & $0.237 \pm 0.004$ & $31.0 \pm 0.071$ & $2.75 \pm 0.007$ & $66.1 \pm 0.141$ & \\
TH & AC2 & $0.237 \pm 0.005$ & $30.9 \pm 0.058$ & $2.78 \pm 0.036$ & $66.1 \pm 0.100$ & \\
& AC2 (rep) & $0.235 \pm 0.013$ & $30.8 \pm 0.058$ & $2.77 \pm 0.040$ & $66.2 \pm 0.058$ & \\
& Average & $0.237 \pm 0.007$ & $30.9 \pm 0.074$ & $2.76 \pm 0.029$ & $66.1 \pm 0.088$ & $16.6 \%$ \\
& AC1 & $0.234 \pm 0.004$ & $29.2 \pm 0.000$ & $3.17 \pm 0.010$ & $67.4 \pm 0.058$ & \\
& AC1 (rep) & $0.239 \pm 0.004$ & $29.1 \pm 0.058$ & $3.20 \pm 0.021$ & $67.4 \pm 0.058$ & \\
TI & AC2 & $0.237 \pm 0.007$ & $29.1 \pm 0.173$ & $3.19 \pm 0.021$ & $67.5 \pm 0.173$ & \\
& AC2 (rep) & $0.237 \pm 0.004$ & $29.2 \pm 0.058$ & $3.18 \pm 0.023$ & $67.4 \pm 0.058$ & \\
& Average & $0.237 \pm 0.004$ & $29.2 \pm 0.098$ & $3.19 \pm 0.020$ & $67.4 \pm 0.103$ & $19.8 \%$ \\
\hline
\end{tabular}

Average results from the TIMS Pu analysis are summarized in Table 3.8. As expected, more ${ }^{239} \mathrm{Pu}$ is present in the lower burnup samples (i.e., Segments F, H, and I), while there are more ${ }^{238} \mathrm{Pu},{ }^{240} \mathrm{Pu},{ }^{241} \mathrm{Pu}$, and ${ }^{242} \mathrm{Pu}$ in the higher burnup sample analyzed (i.e., Segment E). 
Table 3.8. Average Results from the TIMS Pu Analysis on Each Fuel Segment Investigated

\begin{tabular}{clccccc}
\hline Segment & Sample & ${ }^{238} \mathrm{Pu}$ & ${ }^{239} \mathrm{Pu}$ & ${ }^{240} \mathrm{Pu}$ & ${ }^{241} \mathrm{Pu}$ & ${ }^{242} \mathrm{Pu}$ \\
\hline \multirow{6}{*}{ TE } & AC1 & $2.36 \pm 0.636$ & $68.9 \pm 0.537$ & $17.3 \pm 0.262$ & $8.33 \pm 0.007$ & $3.09 \pm 0.163$ \\
& AC1 (rep) & $1.96 \pm 0.281$ & $68.3 \pm 0.358$ & $17.6 \pm 0.552$ & $9.00 \pm 0.555$ & $3.12 \pm 0.115$ \\
& AC2 & $2.31 \pm 0.562$ & $68.8 \pm 0.584$ & $17.6 \pm 0.480$ & $8.21 \pm 0.479$ & $3.09 \pm 0.233$ \\
& AC2 (rep) & $2.04 \pm 0.887$ & $68.6 \pm 0.797$ & $18.0 \pm 0.289$ & $8.23 \pm 0.112$ & $3.16 \pm 0.114$ \\
& Average & $2.15 \pm 0.592$ & $68.6 \pm 0.585$ & $17.7 \pm 0.434$ & $8.42 \pm 0.475$ & $3.12 \pm 0.149$ \\
& AC1 & $0.471 \pm 0.109$ & $90.0 \pm 0.108$ & $7.42 \pm 0.074$ & $1.93 \pm 0.046$ & $0.143 \pm 0.038$ \\
& AC1 (rep) & $0.280 \pm 0.004$ & $90.4 \pm 0.070$ & $7.53 \pm 0.050$ & $1.70 \pm 0.026$ & $0.103 \pm 0.006$ \\
TF & AC2 & $0.276 \pm 0.001$ & $90.2 \pm 0.120$ & $7.69 \pm 0.106$ & $1.74 \pm 0.014$ & $0.105 \pm 0.001$ \\
& AC2 (rep) & $0.319 \pm 0.023$ & $90.0 \pm 0.177$ & $7.72 \pm 0.283$ & $1.83 \pm 0.106$ & $0.145 \pm 0.020$ \\
& Average & $0.344 \pm 0.103$ & $90.2 \pm 0.192$ & $7.57 \pm 0.168$ & $1.80 \pm 0.109$ & $0.124 \pm 0.029$ \\
& AC1 & $0.487 \pm 0.009$ & $86.5 \pm 0.141$ & $9.96 \pm 0.064$ & $2.82 \pm 0.021$ & $0.258 \pm 0.004$ \\
& AC1 (rep) & $0.519 \pm 0.008$ & $86.4 \pm 0.141$ & $9.95 \pm 0.078$ & $2.86 \pm 0.078$ & $0.269 \pm 0.005$ \\
TH & AC2 & $0.663 \pm 0.039$ & $86.1 \pm 0.265$ & $10.0 \pm 0.251$ & $2.94 \pm 0.075$ & $0.290 \pm 0.003$ \\
& AC2 (rep) & $0.536 \pm 0.023$ & $86.2 \pm 0.252$ & $10.1 \pm 0.341$ & $2.90 \pm 0.051$ & $0.265 \pm 0.030$ \\
& Average & $0.561 \pm 0.076$ & $86.3 \pm 0.244$ & $10.0 \pm 0.210$ & $2.89 \pm 0.070$ & $0.272 \pm 0.020$ \\
& AC1 & $0.636 \pm 0.031$ & $84.2 \pm 0.356$ & $11.2 \pm 0.287$ & $3.60 \pm 0.131$ & $0.375 \pm 0.008$ \\
& AC1 (rep) & $0.620 \pm 0.017$ & $84.2 \pm 0.100$ & $11.2 \pm 0.058$ & $3.62 \pm 0.031$ & $0.381 \pm 0.009$ \\
TI & AC2 & $0.688 \pm 0.026$ & $84.0 \pm 0.386$ & $11.3 \pm 0.271$ & $3.67 \pm 0.100$ & $0.370 \pm 0.008$ \\
& AC2 (rep) & $0.733 \pm 0.050$ & $84.0 \pm 0.208$ & $11.2 \pm 0.115$ & $3.63 \pm 0.127$ & $0.390 \pm 0.026$ \\
& Average & $0.668 \pm 0.053$ & $84.1 \pm 0.288$ & $11.2 \pm 0.204$ & $3.63 \pm 0.100$ & $0.378 \pm 0.014$ \\
\hline
\end{tabular}

\subsection{Density}

Density measurements obtained on laser flash analysis samples are provided in Table 3.9 through Table 3.12 for each fuel segment analyzed. Included in each table is the estimated density of the $\mathrm{Zr}+\mathrm{U}-$ Mo fuel layer and the U-Mo fuel determined using the rule of mixtures. Volume fractions of the AA6061, Zr, and U-Mo fuel were determined from the average constituent layer thickness measurements obtained from OM (provided in Table 3.1, Table 3.2, Table 3.3, and Table 3.4) for each respective fuel segment. A density of $2.70 \mathrm{~g} \bullet \mathrm{cm}^{-3}$ was used for the AA6061 (ASM 1990) and $6.51 \mathrm{~g}^{\bullet} \mathrm{cm}^{-3}$ for the $\mathrm{Zr}$ (ASM 1990). The density of these components was assumed to be unaffected by irradiation. 
Table 3.9. Composite Density Measurements and Estimated Zr + U-Mo and U-Mo Density Measurements for Both Segment E LFA Samples (units are in $\mathrm{g} \mathrm{cm}^{-3}$ )

\begin{tabular}{cccccc}
\hline \multicolumn{5}{c}{ LFA1 } & \multicolumn{3}{c}{ LFA2 } \\
\hline Composite & Zr + U-Mo & U-Mo & Composite & Zr + U-Mo & U-Mo \\
\hline 6.38 & 12.4 & 13.4 & 6.29 & 12.2 & 13.2 \\
6.39 & 12.4 & 13.5 & 6.31 & 12.2 & 13.2 \\
6.38 & 12.4 & 13.4 & 6.31 & 12.2 & 13.2 \\
6.41 & 12.5 & 13.5 & 6.31 & 12.2 & 13.2 \\
6.39 & 12.4 & 13.5 & 6.31 & 12.2 & 13.2 \\
6.40 & 12.4 & 13.5 & 6.33 & 12.3 & 13.3 \\
6.40 & 12.5 & 13.5 & 6.32 & 12.2 & 13.2 \\
6.39 & 12.4 & 13.5 & 6.31 & 12.2 & 13.2 \\
6.37 & 12.4 & 13.4 & 6.34 & 12.3 & 13.3 \\
6.39 & 12.4 & 13.4 & 6.32 & 12.3 & 13.2 \\
$6.39 \pm 0.010$ & $12.4 \pm 0.028$ & $13.5 \pm 0.033$ & $6.32 \pm 0.011$ & $12.2 \pm 0.032$ & $13.2 \pm 0.037$ \\
\hline
\end{tabular}

Table 3.10. Composite Density Measurements and Estimated Zr + U-Mo and U-Mo Density Measurements for Both Segment F LFA Samples (units are in $\mathrm{g} \mathrm{cm}^{-3}$ )

\begin{tabular}{cccccc}
\hline LFA1 & \multicolumn{3}{c}{ LFA2 } \\
\hline Composite & Zr + U-Mo & U-Mo & Composite & Zr + U-Mo & U-Mo \\
\hline 14.6 & 15.6 & 14.4 & 15.3 \\
14.6 & 15.6 & 14.5 & 15.4 \\
14.6 & 15.5 & 14.4 & 15.4 \\
14.5 & 15.5 & 14.4 & 15.3 \\
14.5 & 15.4 & 14.5 & 15.4 \\
14.5 & 15.5 & 14.4 & 15.3 \\
14.5 & 15.5 & 14.5 & 15.4 \\
14.6 & 15.5 & 14.5 & 15.5 \\
14.5 & 15.4 & 14.4 & 15.3 \\
& & 14.5 & 15.4 \\
& $14.5 \pm 0.053$ & $15.5 \pm 0.059$ & $14.4 \pm 0.054$ & $15.4 \pm 0.064$ \\
\hline
\end{tabular}


Table 3.11. Composite Density Measurements and Estimated Zr + U-Mo and U-Mo Density Measurements for Both Segment H LFA Samples (units are in $\mathrm{g}^{\bullet} \mathrm{cm}^{-3}$ )

\begin{tabular}{cccccc}
\hline \multicolumn{5}{c}{ LFA1 } & \multicolumn{3}{c}{ LFA2 } \\
\hline Composite & Zr + U-Mo & U-Mo & Composite & Zr + U-Mo & U-Mo \\
\hline 6.96 & 15.5 & 16.5 & 6.97 & 15.5 & 16.5 \\
6.99 & 15.5 & 16.6 & 6.99 & 15.5 & 16.6 \\
6.98 & 15.5 & 16.6 & 7.00 & 15.6 & 16.6 \\
6.98 & 15.5 & 16.6 & 7.02 & 15.6 & 16.7 \\
7.00 & 15.6 & 16.7 & 6.99 & 15.5 & 16.6 \\
6.99 & 15.5 & 16.6 & 7.01 & 15.6 & 16.7 \\
6.98 & 15.5 & 16.6 & 7.00 & 15.6 & 16.7 \\
6.99 & 15.5 & 16.6 & 7.00 & 15.6 & 16.6 \\
7.00 & 15.5 & 16.6 & 7.01 & 15.6 & 16.7 \\
6.98 & 15.5 & 16.6 & 7.00 & 15.6 & 16.7 \\
$6.98 \pm 0.010$ & $15.5 \pm 0.032$ & $16.6 \pm 0.036$ & $7.00 \pm 0.013$ & $15.6 \pm 0.041$ & $16.6 \pm 0.046$ \\
\hline
\end{tabular}

Table 3.12. Composite Density Measurements and Estimated Zr + U-Mo and U-Mo Density Measurements for Both Segment I LFA Samples (units are in $g^{\bullet} \mathrm{cm}^{-3}$ )

\begin{tabular}{cccccc}
\hline \multicolumn{1}{c}{ LFA1 } & \multicolumn{5}{c}{ LFA2 } \\
\hline Composite & Zr + U-Mo & U-Mo & Composite & Zr + U-Mo & U-Mo \\
\hline 6.69 & 13.2 & 13.9 & 6.65 & 13.1 & 13.7 \\
6.72 & 13.3 & 13.9 & 6.65 & 13.1 & 13.7 \\
6.73 & 13.3 & 14.0 & 6.65 & 13.1 & 13.7 \\
6.75 & 13.3 & 14.0 & 6.67 & 13.1 & 13.8 \\
6.70 & 13.2 & 13.9 & 6.62 & 13.0 & 13.7 \\
6.73 & 13.3 & 14.0 & 6.65 & 13.1 & 13.7 \\
6.72 & 13.3 & 13.9 & 6.67 & 13.1 & 13.8 \\
6.72 & 13.3 & 13.9 & 6.66 & 13.1 & 13.8 \\
6.73 & 13.3 & 14.0 & 6.66 & 13.1 & 13.7 \\
6.73 & 13.3 & 14.0 & 6.67 & 13.1 & 13.8 \\
$6.72 \pm 0.016$ & $13.3 \pm 0.045$ & $13.9 \pm 0.049$ & $6.65 \pm 0.012$ & $13.1 \pm 0.034$ & $13.7 \pm 0.037$ \\
\hline
\end{tabular}

Density will decrease as a function of temperature. No effort has been made to develop a correlation to derive density as a function of temperature (based on coefficient of thermal expansion). While it is relatively straightforward to develop a simple correlation, there are very little data for the correlation to be validated. Thus, density is assumed to be constant based on the room temperature values measured and calculated here for all ensuing thermal property calculations. 


\subsection{Differential Scanning Calorimetry}

Results in this section are organized by Segment identification. Specific heat capacity of each irradiated fuel sample as a function of temperature was determined from the DSC signal and Equation 4. Data are presented for each thermal cycle (both low and high temperature) and both fuel samples over the prescribed temperature ranges, i.e. $50-150{ }^{\circ} \mathrm{C}$ and $200-350{ }^{\circ} \mathrm{C}$. Note that because of the low temperature standard used to calibrate the instrument (i.e., In; m.p. $156.6{ }^{\circ} \mathrm{C}$ ), data below $150{ }^{\circ} \mathrm{C}$ can't be bounded by a reference standard and are presented for information only.

\subsubsection{Segment E}

The calculated composite specific heat capacities of the TE irradiated fuel samples as a function of temperature are provided in Figure 3.22. The specific heat capacity of the samples increases linearly with temperature. The deviation in specific heat capacity for the first high temperature cycle of each sample that was consistently observed with previous samples was not observed for the TE samples. Both samples showed very consistent and repeatable behavior with one another.

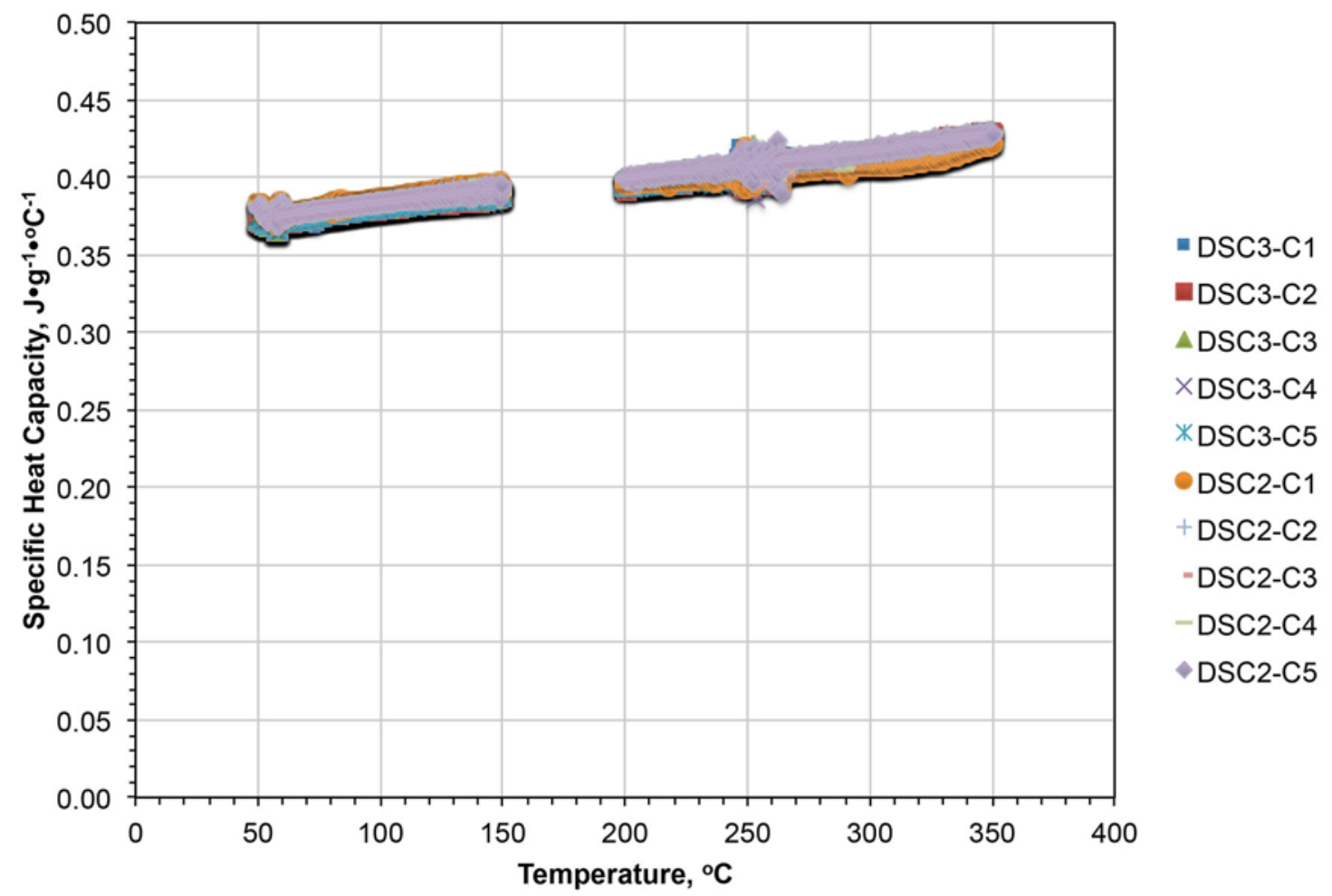

Figure 3.22. Calculated Specific Heat Capacities of TE Fuel Samples (DSC2 and DSC3) as a Function of Temperature for Each Thermal Cycle

\subsubsection{Segment $F$}

The calculated specific heat capacities of the TF irradiated fuel samples as a function of temperature are provided in Figure 3.23. The specific heat capacity of the samples increases nearly linearly with temperature. There are two instances in which this is not the case. First, the slight deviation in each 
specific heat capacity calculation at approximately $117^{\circ} \mathrm{C}$ is believed to be the result of the faster heating rate that was employed for these samples (i.e., $40^{\circ} \mathrm{C} \cdot \mathrm{min}^{-1}$ ) due to the absence of AA6061 cladding. The instrument struggled to maintain pace with the prescribed cooling rate resulting in slight deviations between the sample and reference profiles. Because the calculation of specific heat capacity involves both heating and cooling curves, the slight deviation results in the observed spike at this temperature. This anomaly does not adversely affect the specific heat capacity measurements that were used to calculate thermal conductivity. The second instance of non-linearity is the decrease in specific heat capacity for the first high temperature cycle for sample TF-DSC2, beginning at approximately $250{ }^{\circ} \mathrm{C}$. Measurements conducted in FY13 revealed a similar feature, albeit at slightly higher temperatures. The lower onset of specific heat capacity degradation for the TF sample is likely explained by the higher heating rate used for these measurements (i.e., $40{ }^{\circ} \mathrm{C} \cdot \mathrm{min}^{-1}$ v. $10^{\circ} \mathrm{C} \cdot \mathrm{min}^{-1}$ ). However, the reason that the decrease was observed for the DSC2 sample only and not the DSC1 sample is not clear at this time. The end result is slightly higher errors in overall specific heat capacity measurement at temperatures above $250{ }^{\circ} \mathrm{C}$.

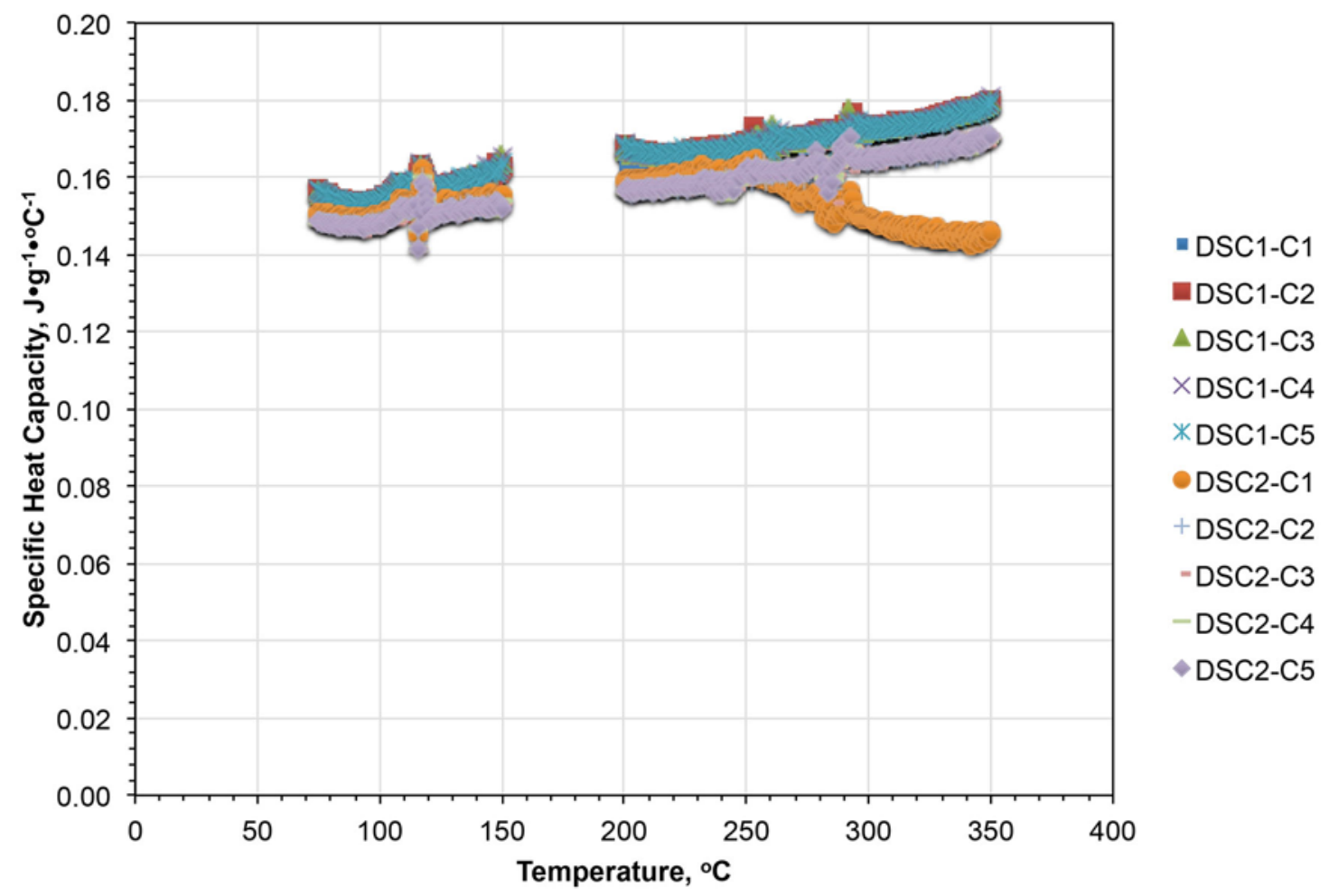

Figure 3.23. Calculated Specific Heat Capacities of TF Fuel Samples (DSC1 and DSC2) as a Function of Temperature for Each Thermal Cycle

\subsubsection{Segment $\mathrm{H}$}

The calculated specific heat capacities of the TH irradiated fuel samples as a function of temperature are provided in Figure 3.24. The specific heat capacity of the samples increases linearly with temperature, very similar to behavior observed for the TE irradiated fuel samples. There is a very slight deviation in specific heat capacity for the first high temperature cycle of each sample beginning around $250{ }^{\circ} \mathrm{C}$, similar to the behavior observed for the TF-DSC2 irradiated fuel sample. The drop in specific 
heat capacity was not as significant as that observed for the TF-DSC2 irradiated fuel sample, but this difference could be influenced by the fact that the TH-DSC irradiated fuel samples were clad in AA6061 while the TF-DSC irradiated fuel samples were not. Regardless, both samples showed very consistent and repeatable behavior with one another.

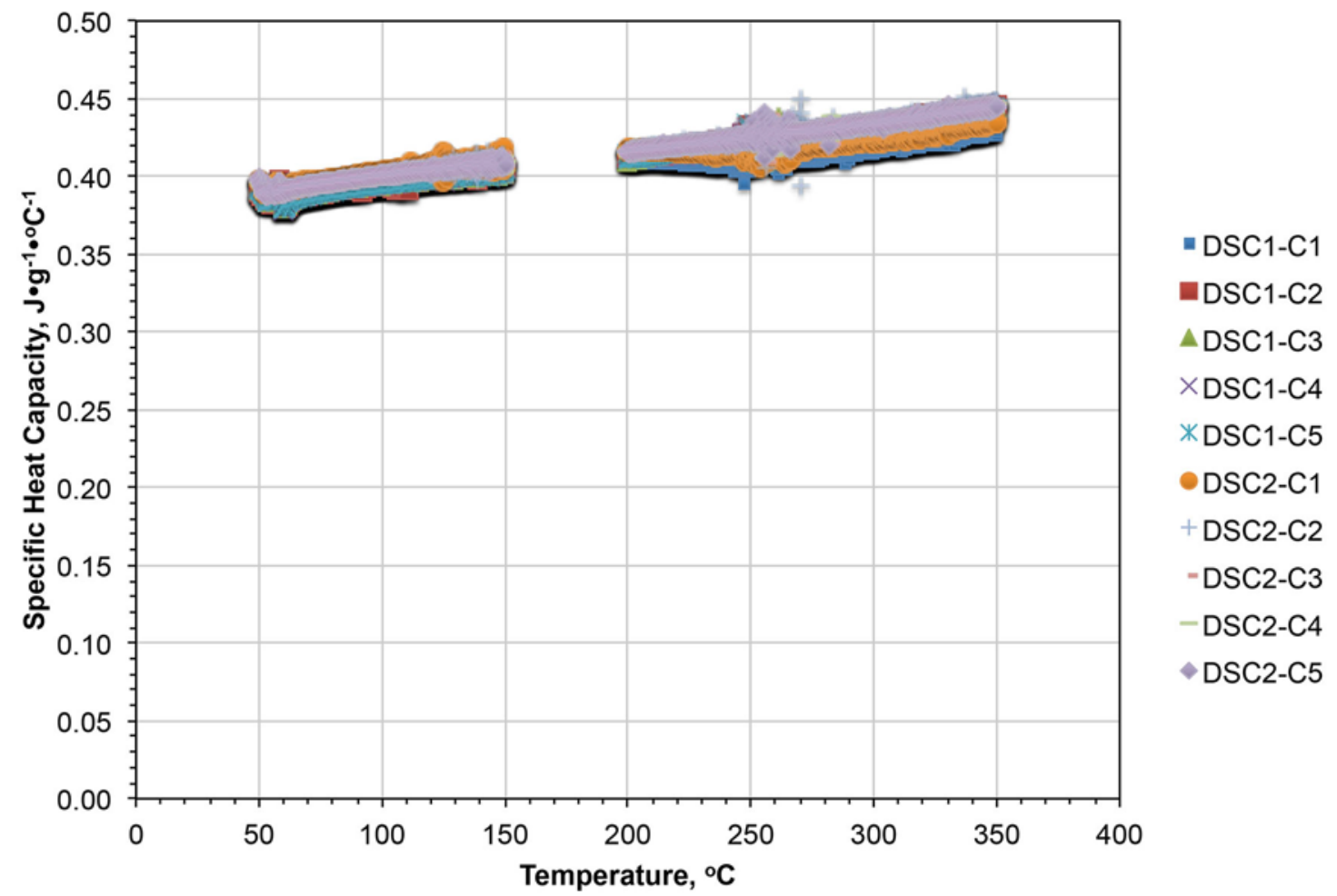

Figure 3.24. Calculated Specific Heat Capacities of TH Fuel Samples (DSC1 and DSC2) as a Function of Temperature for Each Thermal Cycle

\subsubsection{Segment I}

The calculated specific heat capacities of the TI irradiated fuel samples as a function of temperature are provided in Figure 3.25. Similar to behavior observed for the TE and TH irradiated fuel samples, the specific heat capacity of the samples increases linearly with temperature. The very slight deviation in specific heat capacity for the first high temperature cycle beginning around $250{ }^{\circ} \mathrm{C}$ was not necessarily observed for either TI irradiated fuel sample. The reason for this is not clear at this time. Both samples showed very consistent and repeatable behavior with one another. 


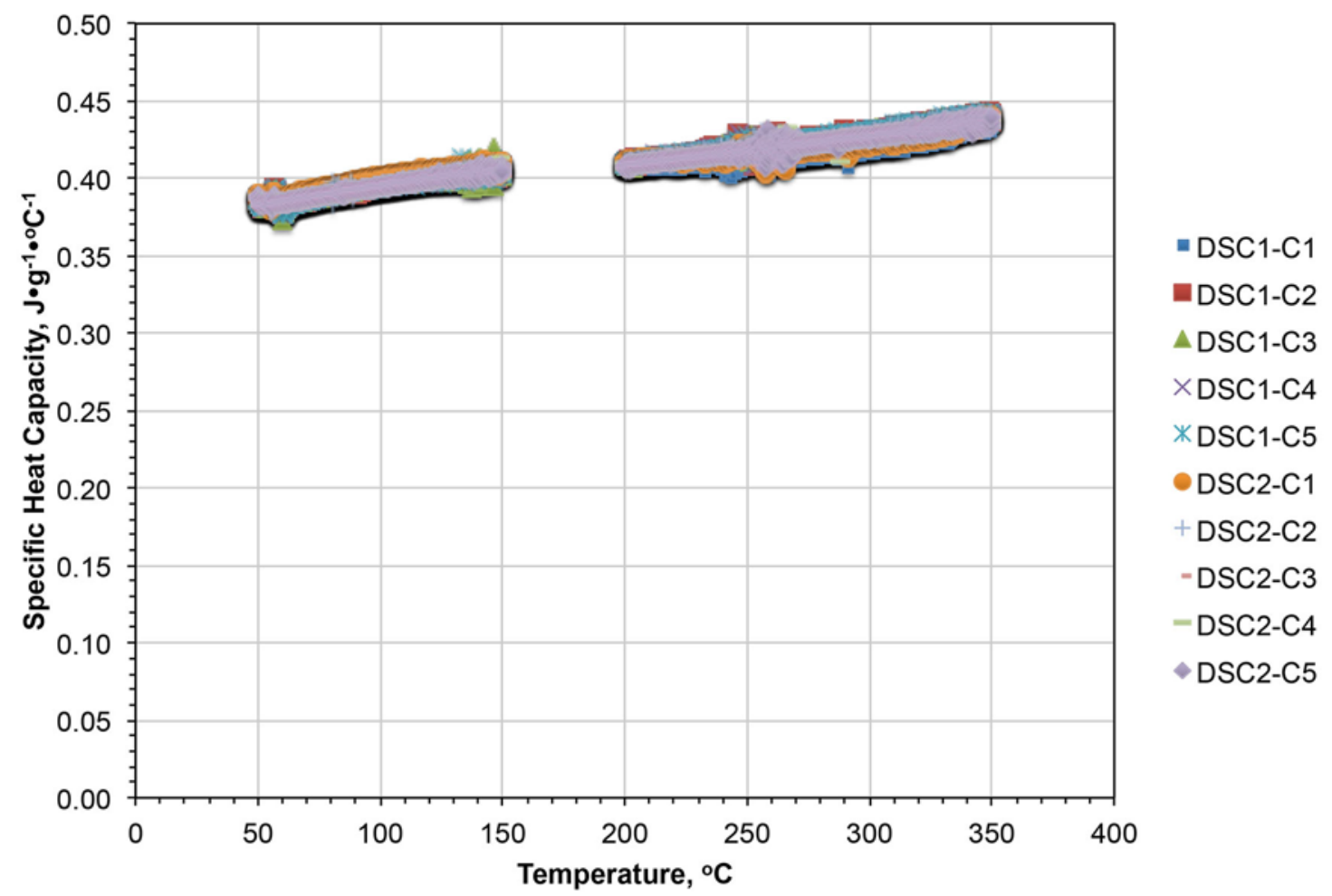

Figure 3.25. Calculated Specific Heat Capacities of TI Fuel Samples (DSC1 and DSC2) as a Function of Temperature for Each Thermal Cycle

As noted in Burkes et al. 2013, the decrease in the specific heat capacity around $250{ }^{\circ} \mathrm{C}$ could be attributed to the recovery from the as-irradiated condition, such as a release of the residual energy stored in the irradiated fuel segment, an annealing out of the radiation damage, and/or a recovery of a distorted lattice structure, similar to observations reported for U-60 wt.\% Zr fuel (Lee et al. 2007). Another potential driver could be precipitation of gaseous fission products from the solid solution and coalescence into larger fission gas bubbles (Golosov et al. 2008). If precipitation and coalescence occurred near the edges of the sample (which is exposed) and the gas products were discharged into the environment, they could create a temporary heat sink that results in a differential signal. The differential signal would not be expected on subsequent reheat cycles unless the temperature of the sample was raised (e.g., above $300{ }^{\circ} \mathrm{C}$ ) resulting in further precipitation, coalescence, and release.

\subsubsection{Calculated Specific Heat Capacity of U-Mo}

The specific heat capacity of the U-Mo fuel meat can be extracted from the composite measurements presented in Sections 3.4.1 through 3.4.4 using the Neumann-Kopp approximation, defined in Equation 6 below. For these extractions, the temperature-dependent specific heat capacities of the AA6061 cladding $\left(C p_{A A 6061}\right.$; Mills 2002) and $\mathrm{Zr}$ diffusion barrier $\left(C p_{Z r}\right.$; Fink and Leibowitz 1995) are assumed to be unaffected by irradiation. Although there will be minor modifications to the chemical composition of these constituents as a function of irradiation, e.g., transmutation of silicon in the AA6061, the influence of these modifications on specific heat capacity behavior is likely very minor and well within the uncertainty associated with the measurements. Thus, the U-Mo fuel meat $\left(C p_{U-M o}\right)$ extractions consider that any specific heat capacity change in the measured composite is because of a change in the fuel meat 
itself. The mass fraction of each constituent $\left(x_{A A 6061}, x_{Z r}\right.$, and $\left.x_{U-M o}\right)$ was determined from layer thicknesses reported in Section 3.1 and the average density of each constituent layer reported in Section 3.3 .

$$
C p_{\text {composite }}=x_{A 46061} \cdot C p_{A A 6061}+x_{Z r} \cdot C p_{Z r}+x_{U-M o} \cdot C p_{U-M o}
$$

A simple linear regression was performed on data from each thermal cycle and both samples after the U-Mo specific heat capacity was extracted from the composite measurements. Data were averaged at temperatures in $50{ }^{\circ} \mathrm{C}$ increments (over the $50-350{ }^{\circ} \mathrm{C}$ temperature range) for each sample, consisting of five measurements each and ten total measurements for both samples. The average calculated U-Mo specific heat capacities for the irradiated fuel samples as a function of temperature is provided in Figure 3.26, with error bars representing the standard deviation of each data set. Included in Figure 3.26 are specific heat capacity data available from literature on unirradiated U-Mo alloys with similar composition (dotted and dashed lines). The error associated with each fuel segment is relatively small, owing to the high reproducibility of the measurement for each thermal cycle and both irradiated fuel samples.

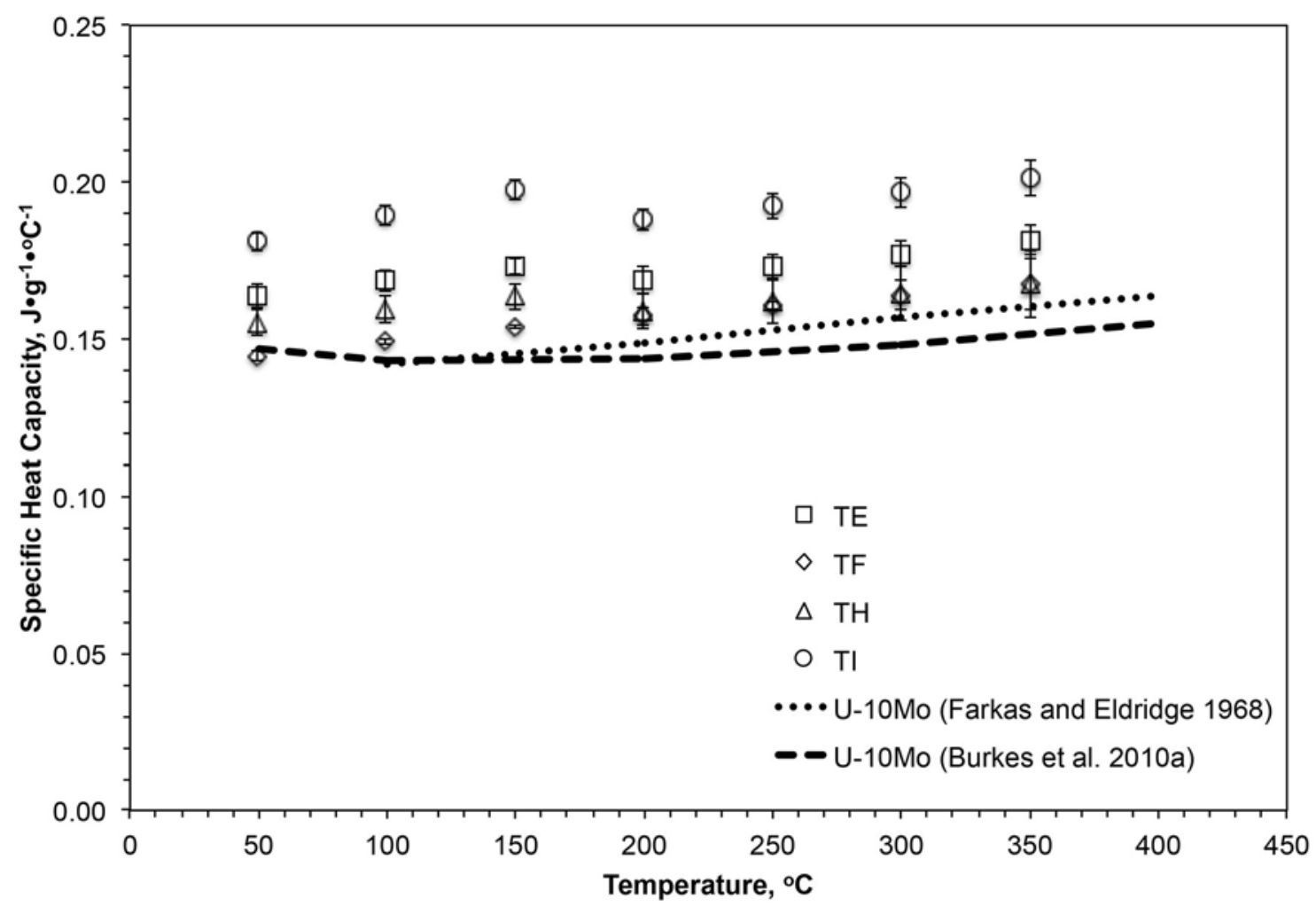

Figure 3.26. Extracted U-Mo Specific Heat Capacity Obtained from the Composite Specific Heat Capacity Measurements and the Neumann-Kopp Approximation for Each Fuel Segment as a Function of Temperature

In general, the specific heat capacity of the monolithic U-Mo fuel meat appears to increase with irradiation when compared to available specific heat capacity values for an unirradiated U-10Mo alloy. The calculated U-Mo specific heat capacity of Segments TF and TH are comparable, especially at temperatures above $200{ }^{\circ} \mathrm{C}$. Calculated U-Mo specific heat capacity for Segment TE is greater than that calculated for Segments TF and TH, likely resulting from the increased Mo concentration in the alloy due 
to significantly higher burnup. The calculated specific heat capacity of Segment TI is even greater than that of Segment TE, even though the increased Mo concentration in the alloys due to increased burnup (compared to Segments TF and TH) are comparable.

\subsection{Laser Flash Analysis}

Results in this section are organized by Segment identification. The data presented in each section are averages of the five shots at each temperature obtained upon both heating and cooling for each sample reported with standard deviation. The raw laser flash data (obtained using the Cowan model; Cowan 1963) has been corrected for the average total sample thickness summed from the individual constituent layers determined from OM for each respective fuel segment reported in Sections 3.1.1 through 3.1.4 using the Cape-Lehman model. Example photographs of the sapphire window, a sample, and the assembled sample holder in the LFA instrument are provided in Figure 3.27.

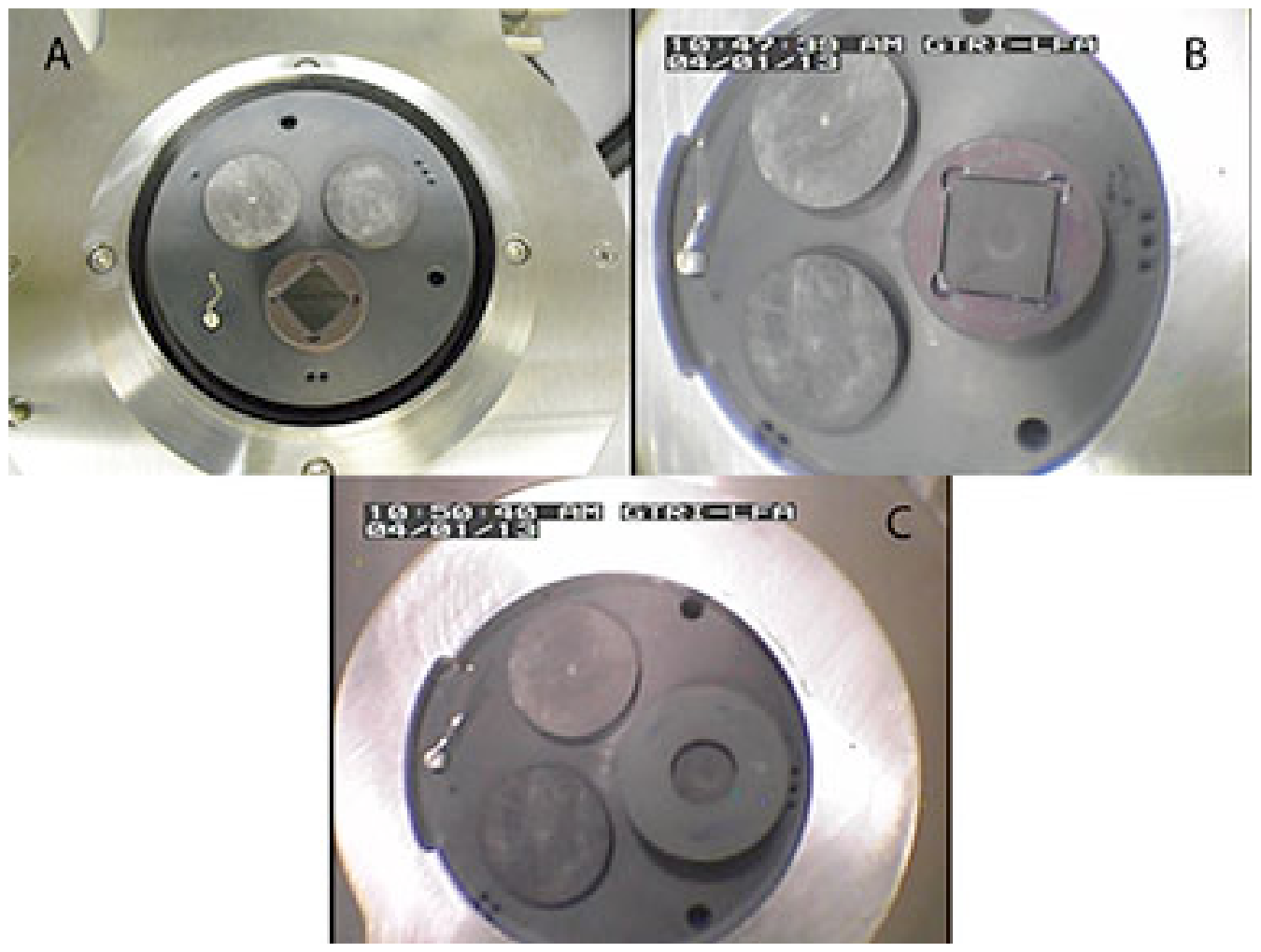

Figure 3.27. (A) Square Sapphire Window in the Sample Holder, (B) Sample in the Sample Holder on Top of the Sapphire Window, and (C) Assembled Sample Holder in the LFA Instrument

\subsubsection{Segment E}

Thermal diffusivity as a function of temperature for Segment $\mathrm{E}$ is provided in Figure 3.28. As observed in Figure 3.28, the thermal diffusivity of both Segment E samples increased nearly linearly with increasing temperature. In addition, the thermal diffusivity is similar for each sample and highly reproducible, as evidenced by the small error bars. The slight discrepancy between each sample (i.e., TELFA1 and TE-LFA-2) likely indicates minor property variations from sample to sample. 


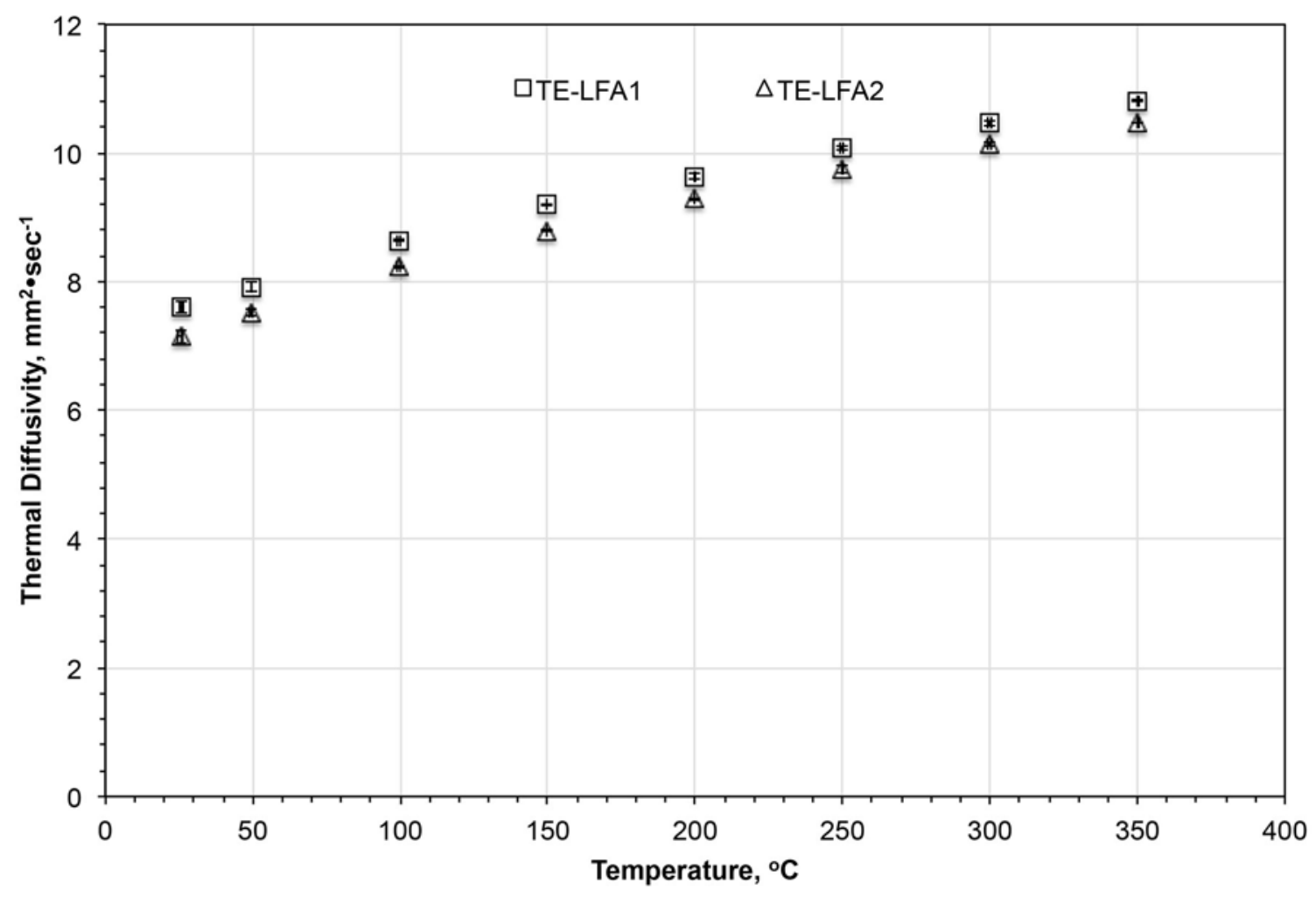

Figure 3.28. Composite Thermal Diffusivity as a Function of Temperature for Segment E

\subsubsection{Segment F}

Thermal diffusivity as a function of temperature for Segment $\mathrm{F}$ is provided in Figure 3.29. Similar to the other irradiated fuel samples analyzed, the thermal diffusivity of both Segment F LFA samples increases nearly linearly as a function of temperature. Both samples show similar thermal diffusivity behavior, and the measurements made at each temperature are highly reproducible. Consistent with Segment E measurements, there is a slight discrepancy between the two samples, i.e., LFA2 has a lower composite thermal diffusivity compared to LFA1. The slight discrepancy between the two samples again likely indicates minor property variations from sample to sample but can't be conclusively determined without performing additional post-measurement analysis (e.g., SEM). The absence of cladding results in thermal diffusivity values that are roughly half of that measured with cladding (e.g., Segment TH LFA samples). 


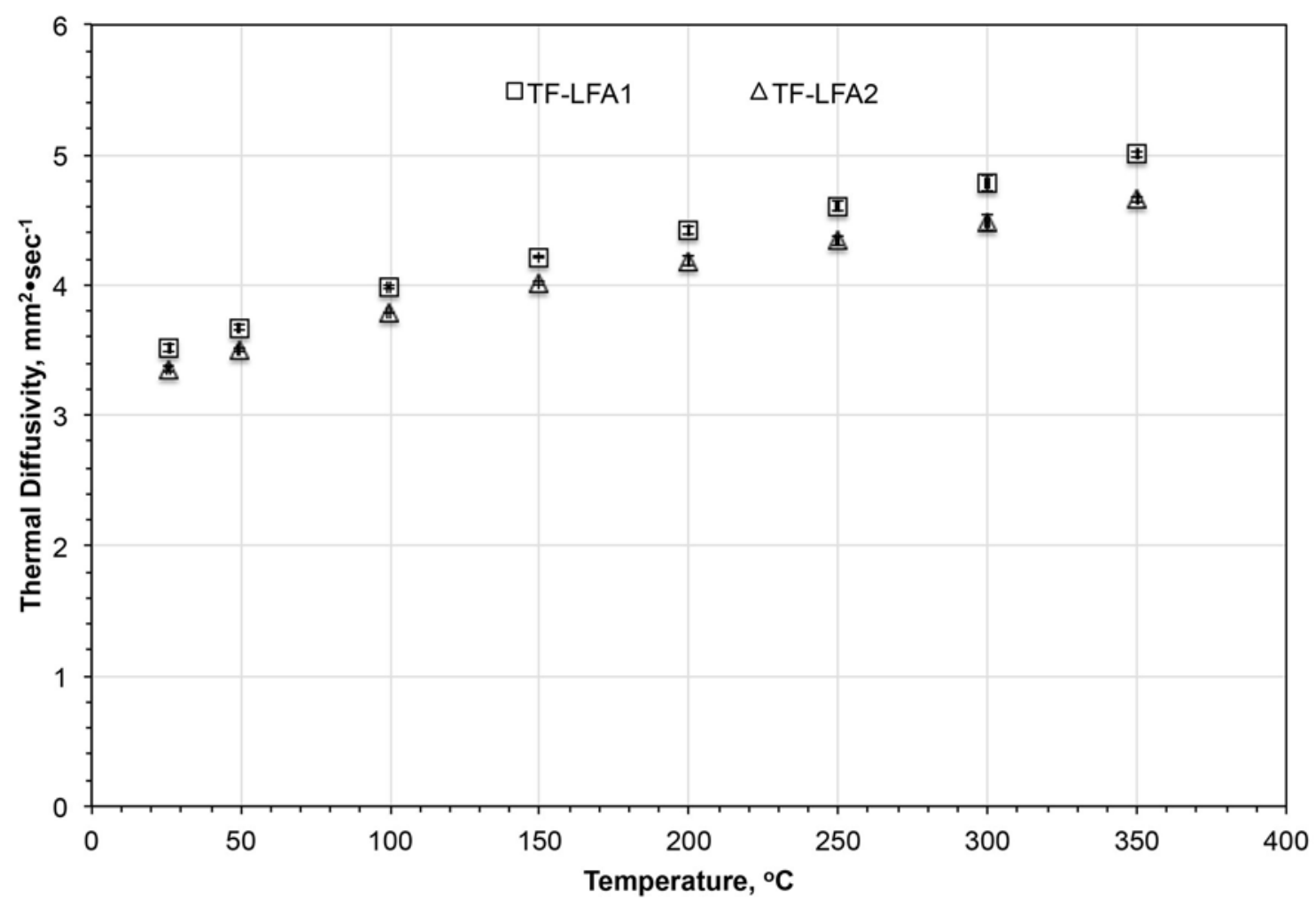

Figure 3.29. Composite Thermal Diffusivity as a Function of Temperature for Segment F

\subsubsection{Segment $\mathrm{H}$}

Thermal diffusivity as a function of temperature for Segment $\mathrm{H}$ is provided in Figure 3.30. Thermal diffusivity increases nearly linearly with temperature. Both samples show very similar behavior to one another and measurements are highly reproducible at each temperature. As observed previously, the LFA2 sample has a slightly lower composite thermal diffusivity than the LFA1 sample. Thermal diffusivity values are slightly higher than those measured for the moderate surface heat flux sample (i.e., Segment TE), likely the result of the lower burnup achieved with these samples. Thermal diffusivity was more than twice that of the Segment TF samples again showing the influence of AA6061 cladding on the composite fuel sample behavior. 


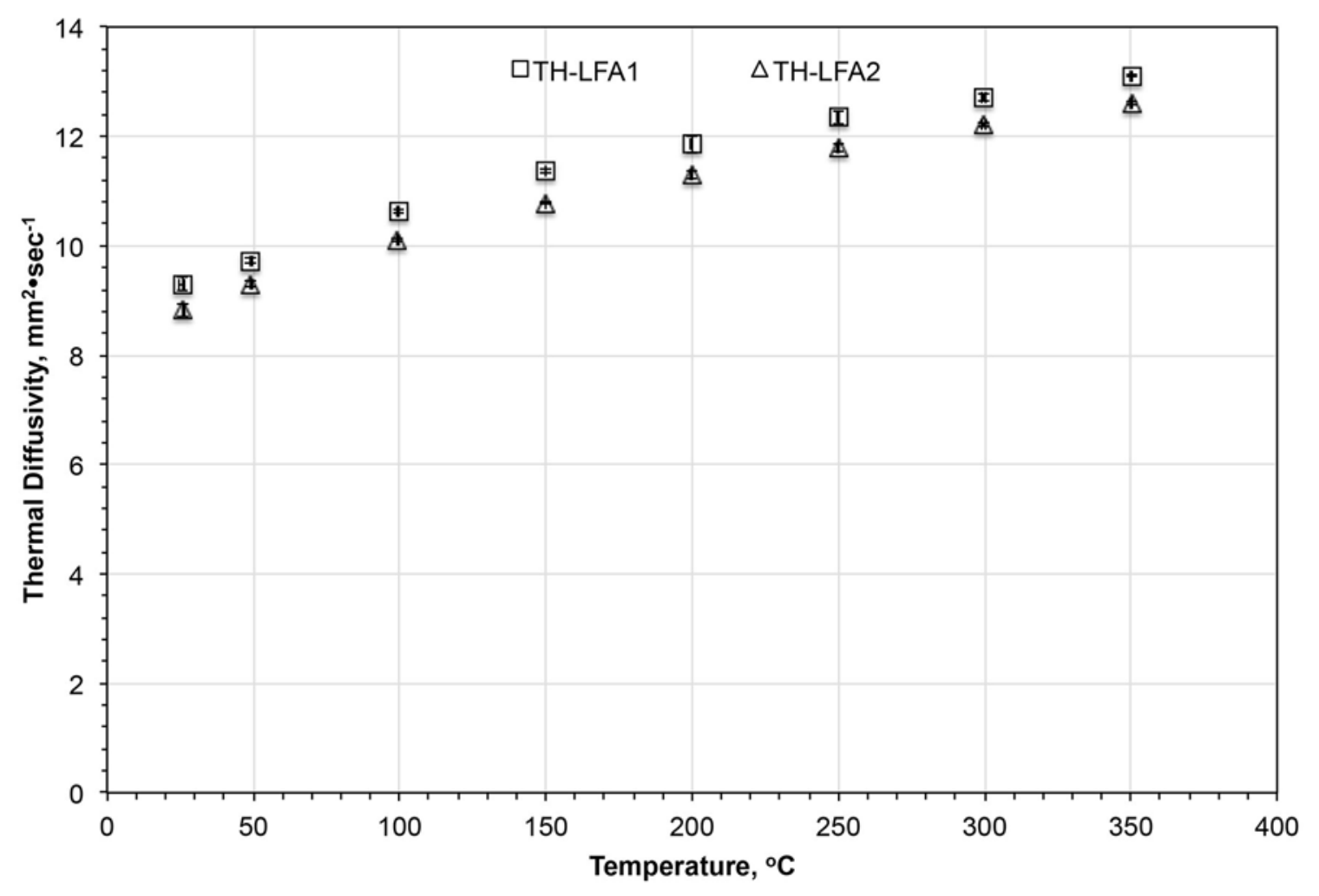

Figure 3.30. Composite Thermal Diffusivity as a Function of Temperature for Segment H

\subsubsection{Segment I}

Thermal diffusivity as a function of temperature for Segment I is provided in Figure 3.31. As observed with all other samples, thermal diffusivity increases nearly linearly as a function of temperature. Measurements made at each temperature are highly reproducible for the TI-LFA1 sample and for the low temperature cycle of the TI-LFA2 sample (although the LFA2 sample is lower than the LFA1 sample, similar to observations on Segments E, F, and H). However, the measurements made during the high temperature cycle for TI-LFA2 are not as reproducible and indicate a loss of integrity of the sample during measurement. The loss of integrity was verified visually post-measurement where cracks along the edge of the sample were clearly observed as shown in Figure 3.32. Similar behavior was observed on some of the samples analyzed in FY13 (see Burkes et al. 2013). There is a slight difference in thermal diffusivity behavior observed between samples TI-LFA1 and TI-LFA2. This is not entirely unexpected after observing some of the microstructural features from the OM analysis (see Figure 3.20), and similar behavior was observed for Segment TB in FY13. Thermal diffusivity values are significantly lower than those observed for Segment TH. This finding is surprising given the modest increase in average burnup for this particular segment. Thermal diffusivity is still higher than that observed for Segment TF LFA samples. 


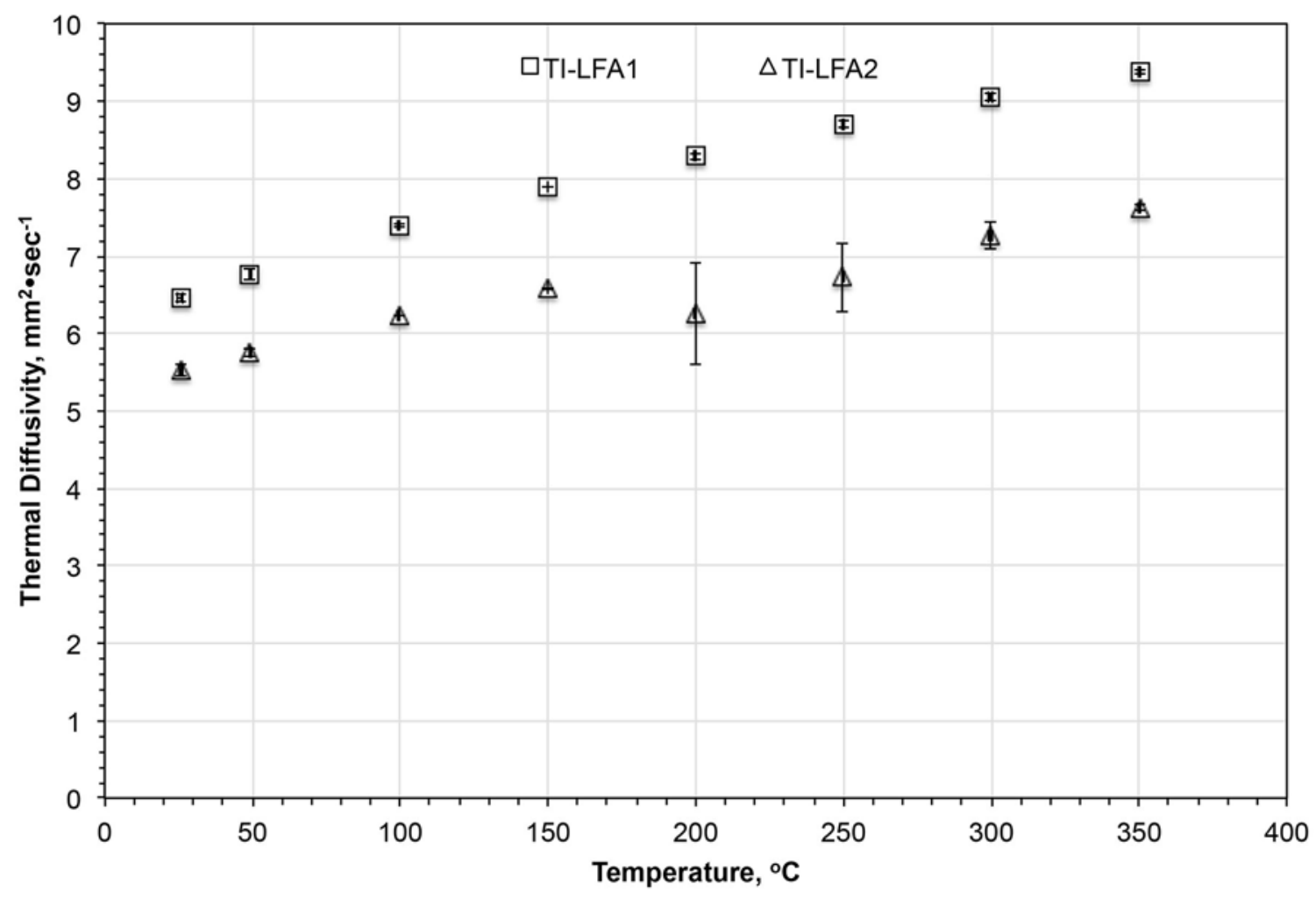

Figure 3.31. Composite Thermal Diffusivity as a Function of Temperature for Segment I

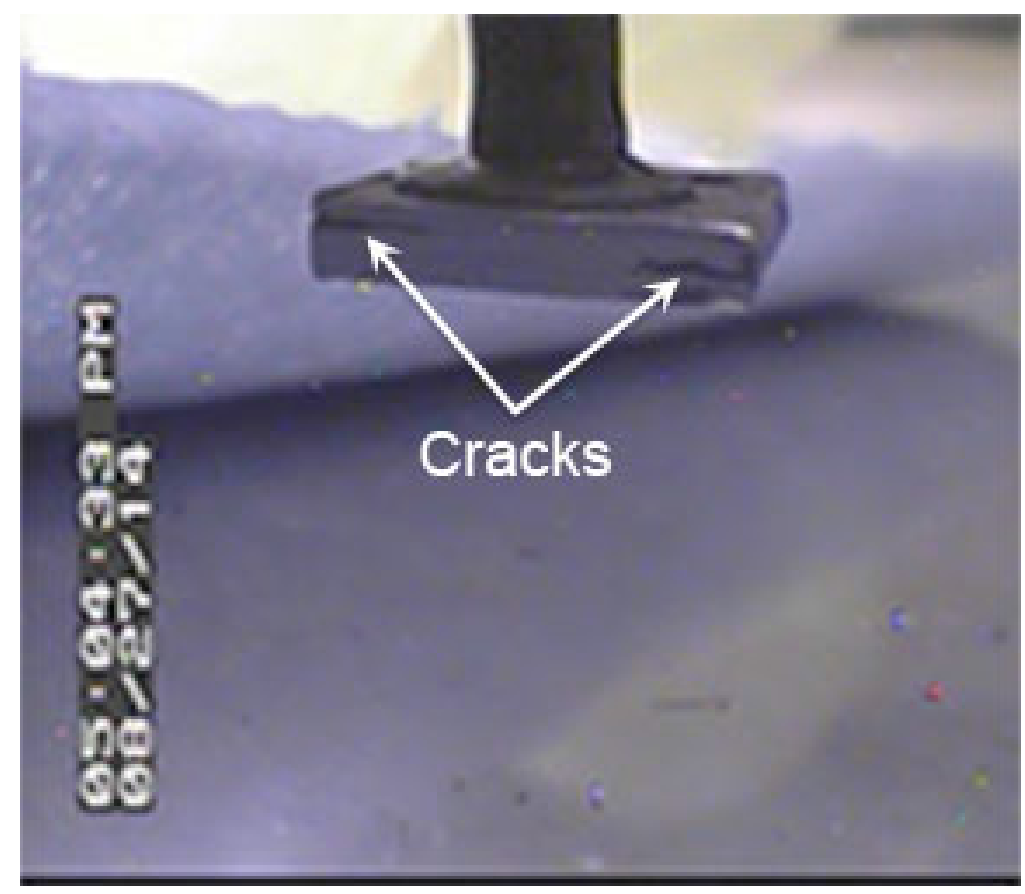

Figure 3.32. Post-LFA Measurement Photograph of the TI-LFA2 Sample. Cracks originating at the edges of the sample and propagating through the interior are labeled. 



\subsection{Analysis}

The average fission density of each fuel segment was determined using the as-fabricated $U$ density value following the method outlined in Burkes et al. 2010b, the initial Mo concentrations reported in Table 2.1, the initial starting ${ }^{235} \mathrm{U}$ enrichments reported in Table 2.1, and following the method outlined in Rest et al. 2009. The calculation results are summarized in Table 4.1 (along with burnup determined according to Equation 5) and include average fission densities for the segments analyzed as part of the FY13 work. In general, the calculated average fission densities for each segment are in good agreement with reported values employing MCNP.

Table 4.1. Summary of Calculated Average Fission Density for Each Fuel Segment Analyzed in FY13 and FY14

\begin{tabular}{ccc}
\hline Segment & Burnup, \% & $\begin{array}{c}\text { Calculated Fission Density, } \\
\times 10^{21}\end{array}$ \\
\hline fissions ${ }^{\bullet} \mathrm{cm}^{-3}$
\end{tabular}

A summary of measured composite, calculated $\mathrm{Zr}+\mathrm{U}-\mathrm{Mo}$, and calculated U-Mo densities as a function of average fission density are provided in Figure 4.1, including results obtained from FY13. The data show a slight decrease in composite, $\mathrm{Zr}+\mathrm{U}-\mathrm{Mo}$, and U-Mo density with increased fission density. However, the $\mathrm{Zr}+\mathrm{U}-\mathrm{Mo}$ and U-Mo densities are slightly higher for Segments TF and TH compared to the other irradiated fuel segments measured. When compared to the other high surface heat flux segment (Segment TI), Segment TH contained lower volume fractions of AA6061 cladding and higher volume fractions of $\mathrm{Zr}$ (based on thickness measurements). Similarly, Segment TF contained higher volume fractions of Zr compared to Segment TI. This is likely the main reason that calculated density values are higher than that calculated for Segment TI. Another contributor could be the form of the porosity in the high specific heat flux samples compared to the moderate surface heat flux samples, i.e., open v. closed, given the pycnometry method used to measure porosity. Another method, such as immersion density, would provide some additional insight into the fraction of closed porosity v. open porosity, but this method was not selected for the current work because density samples are the same as those used for LFA. 


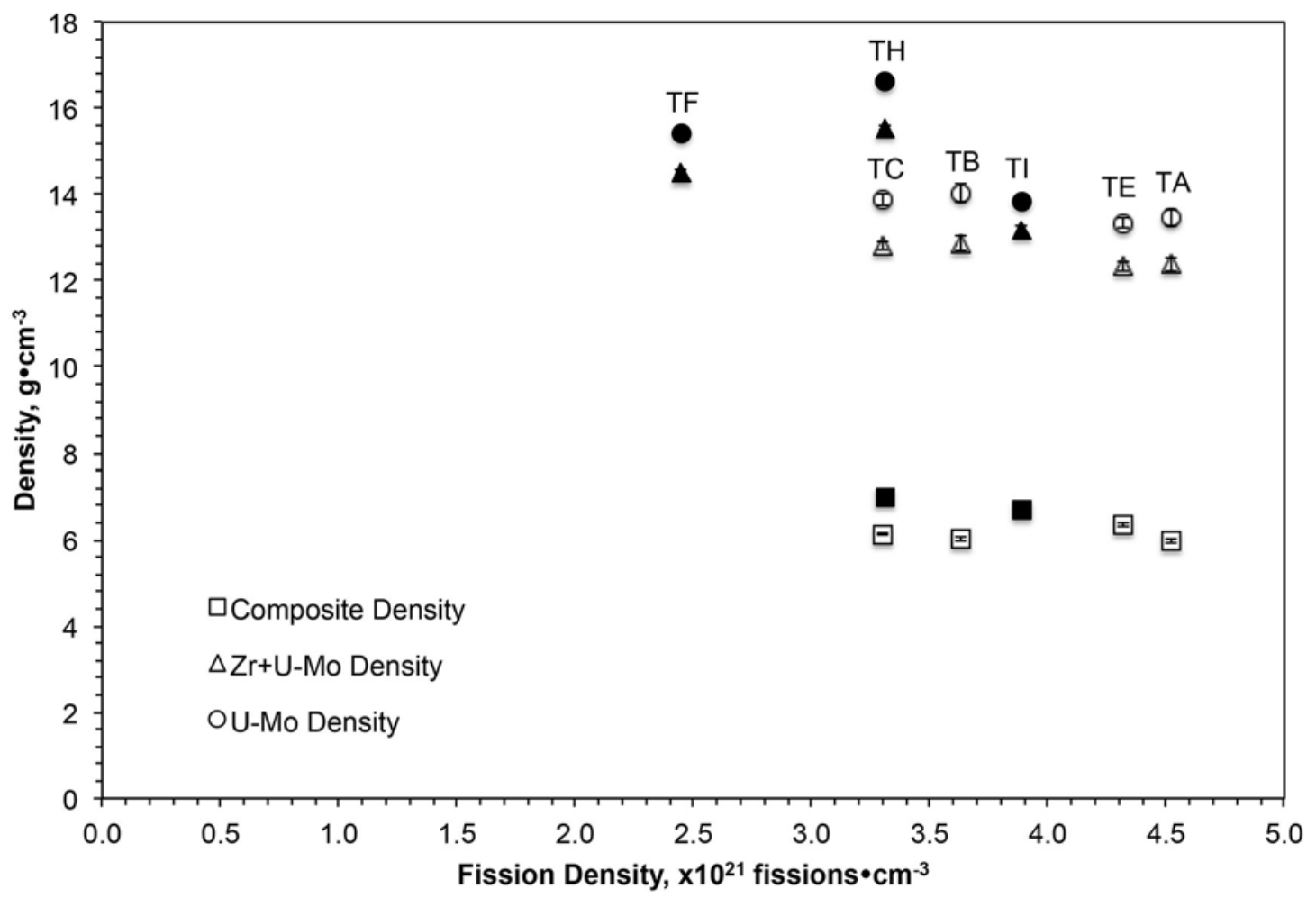

Figure 4.1. Measured Composite, Calculated $\mathrm{Zr}+\mathrm{U}-\mathrm{Mo}$, and Calculated U-Mo Densities as a Function of Average Fission Density for Each Irradiated Fuel Segment Analyzed (Including FY13 Samples). Solid markers represent high surface heat flux samples while open markers represent moderate surface heat flux samples.

The decrease in density was calculated from results presented in Figure 4.1 and compared to asfabricated density values. The as-fabricated alloy density was determined following the method outlined in Burkes et al. 2010b, using the average starting enrichment and Mo concentration reported in Table 2.1. Results of these calculations are summarized in Figure 4.2 as a function of average fission density. The decrease in U-Mo density from as-fabricated values is the result of the burnup of ${ }^{235+236} \mathrm{U}$, as well as the formation of porosity and to a lesser extent solid fission product swelling. Included in Figure 4.2 is the change in volume (attributed to solid and fission gas product swelling) as a function of fission density according to the empirical correlation reported by Kim and Hofman (2011). In general, the experimental calculations agree well with Kim and Hofman's empirical calculation. The one exception is Segment TH, which showed only a $2.9 \%$ decrease in density from the as-fabricated value. As discussed above, this could be the result of a higher percentage of closed porosity present in this particular sample because of microstructural differences but cannot be confirmed conclusively based on the measurements funded as part of this study. 


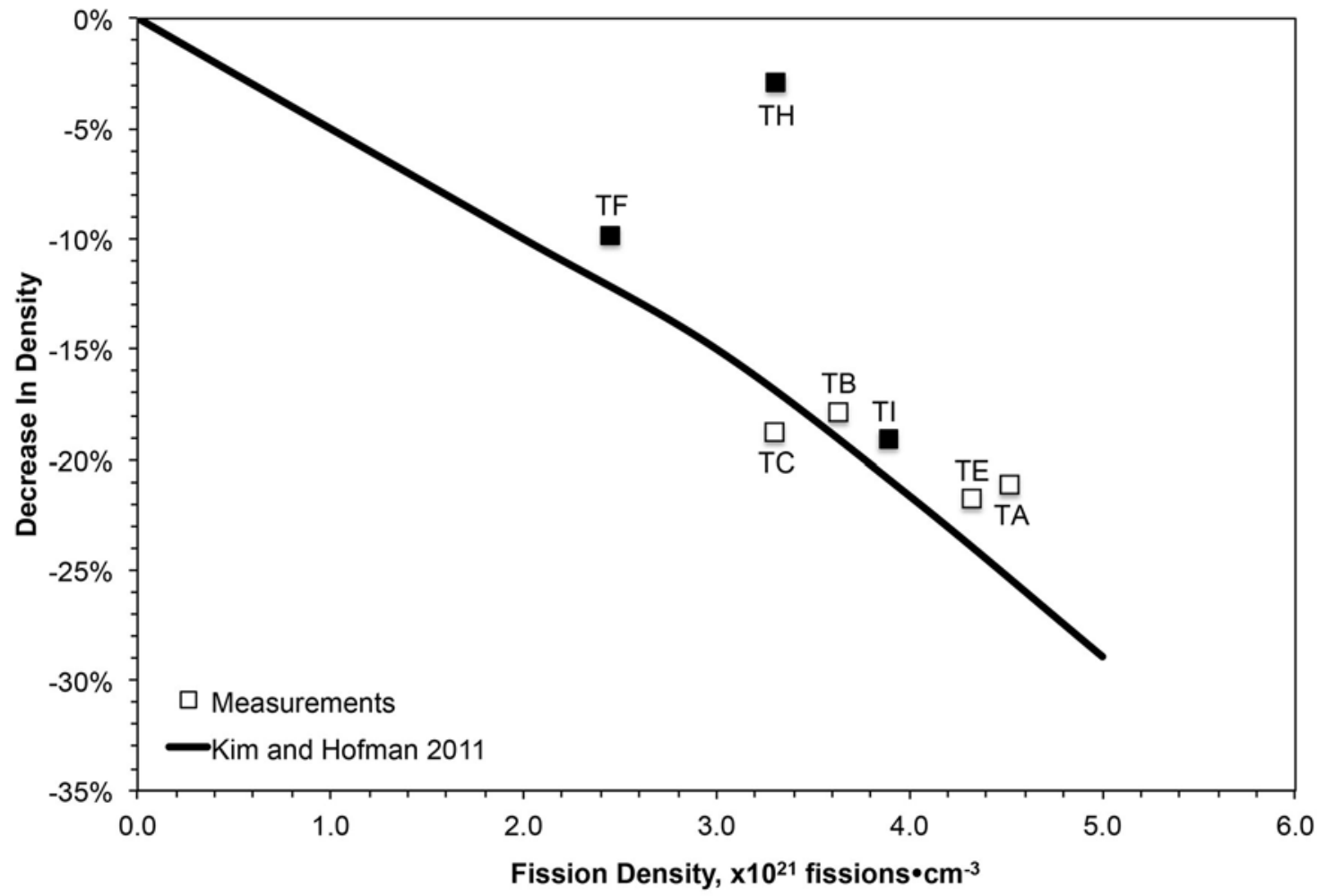

Figure 4.2. Decrease in Density from as-Fabricated Values as a Function of Average Fission Density for Each Fuel Segment (Including FY13 Samples). Solid markers represent high surface heat flux samples while open markers represent moderate surface heat flux samples.

Calculated specific heat capacity of the U-Mo fuel at 100C, 200C, and 300C as a function of average fission density is summarized in Figure 4.3. The data show no strong dependence of specific heat capacity based on the surface heat flux at which each fuel segment was irradiated. In general, specific heat capacity increases slightly with increasing temperature. Specific heat capacity increases with increasing fission density. The slight increase in specific heat capacity is mostly driven by the consumption of uranium and the concomitant increase in Mo concentration within the fuel alloy as fission density increases, because Mo has a higher specific heat capacity than $\gamma$-U. It is likely that the buildup of solid fission products within the fuel alloy as fission density increases also contributes to the increase in specific heat capacity, particularly because the buildup of plutonium isotopes in the alloy is small given the short residence times in the reactor and high fission rates. 


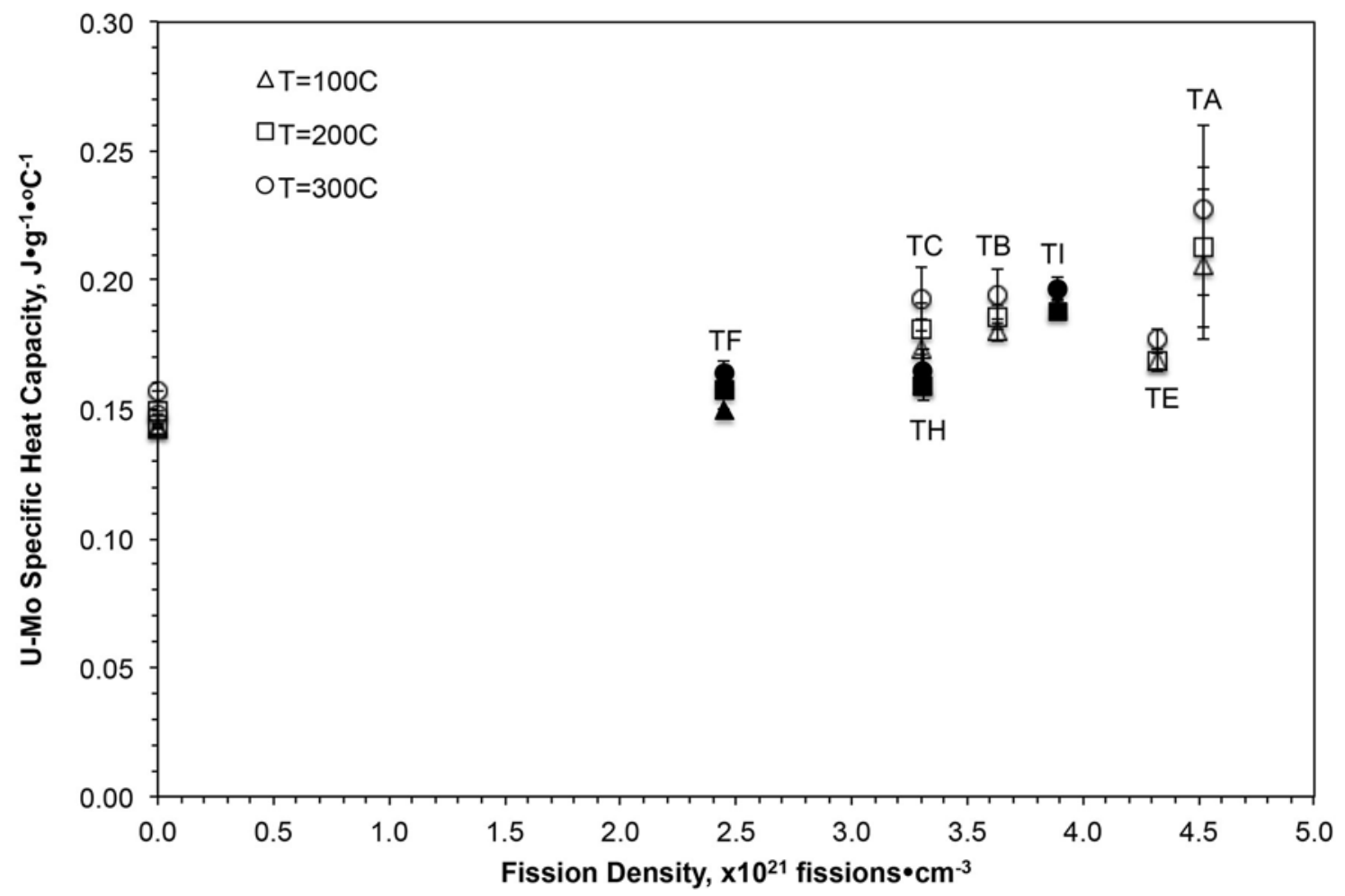

Figure 4.3. Calculated Specific Heat Capacity of the U-Mo Fuel at 100C, 200C, and 300C as a Function of Average Fission Density for Each Fuel Segment (Including FY13 Samples). Solid markers represent high surface heat flux samples while open markers represent moderate surface heat flux samples.

Thermal conductivity values as a function of temperature for each sample can be calculated from the measurements of thermal diffusivity $(\alpha)$, specific heat capacity $\left(C_{P}\right)$ and density $(\rho)$ via the relationship provided in Equation 7.

$$
\lambda=\alpha \cdot C_{P} \cdot \rho
$$

Calculated composite thermal conductivity at 50C, 200C, and 300C as a function of average fission density is summarized in Figure 4.4. Note that because Segment TF samples did not include AA6061 cladding, composite calculations are not included in the figure. In general, composite thermal conductivity increased with increasing temperature and decreased with increasing fission density. The magnitude of composite thermal conductivity degradation appears to be less for samples irradiated at moderate surface heat flux compared to those segments irradiated at high surface heat flux (i.e., Segments $\mathrm{TH}$ and TI). The composite thermal conductivity ranges between 15 and $40 \mathrm{~W} \bullet \mathrm{m}^{-1} \bullet{ }^{\circ} \mathrm{C}^{-1}$ depending upon the temperature and average fission density of the particular sample. The thermal conductivity of the UMo fuel alloy is expected to decrease during irradiation as porosity develops because of precipitation and coalescence of gaseous fission products, the buildup of solid fission products in the fuel, and the alloying effect of Mo because the relative ratio of $U$ to Mo will decline with fuel depletion. The precipitation, nucleation, and growth of fission gas bubbles (porosity) with increased burnup or temperature can significantly hamper heat flow, particularly if they have a tendency to form at material interfaces, such as those created by intermetallics at the $\mathrm{Zr}$ - fuel interface. A prime example of this was pointed out for 
Segment TI in Figure 3.19. Note that the errors reported for the thermal conductivities are associated with the measurement process and should be interpreted as system precision uncertainties, not accuracy uncertainties. Only the propagation of relative error using the mean and standard deviations determined from multiple measurements on each sample for each measurement technique are used to describe the thermal conductivity error.

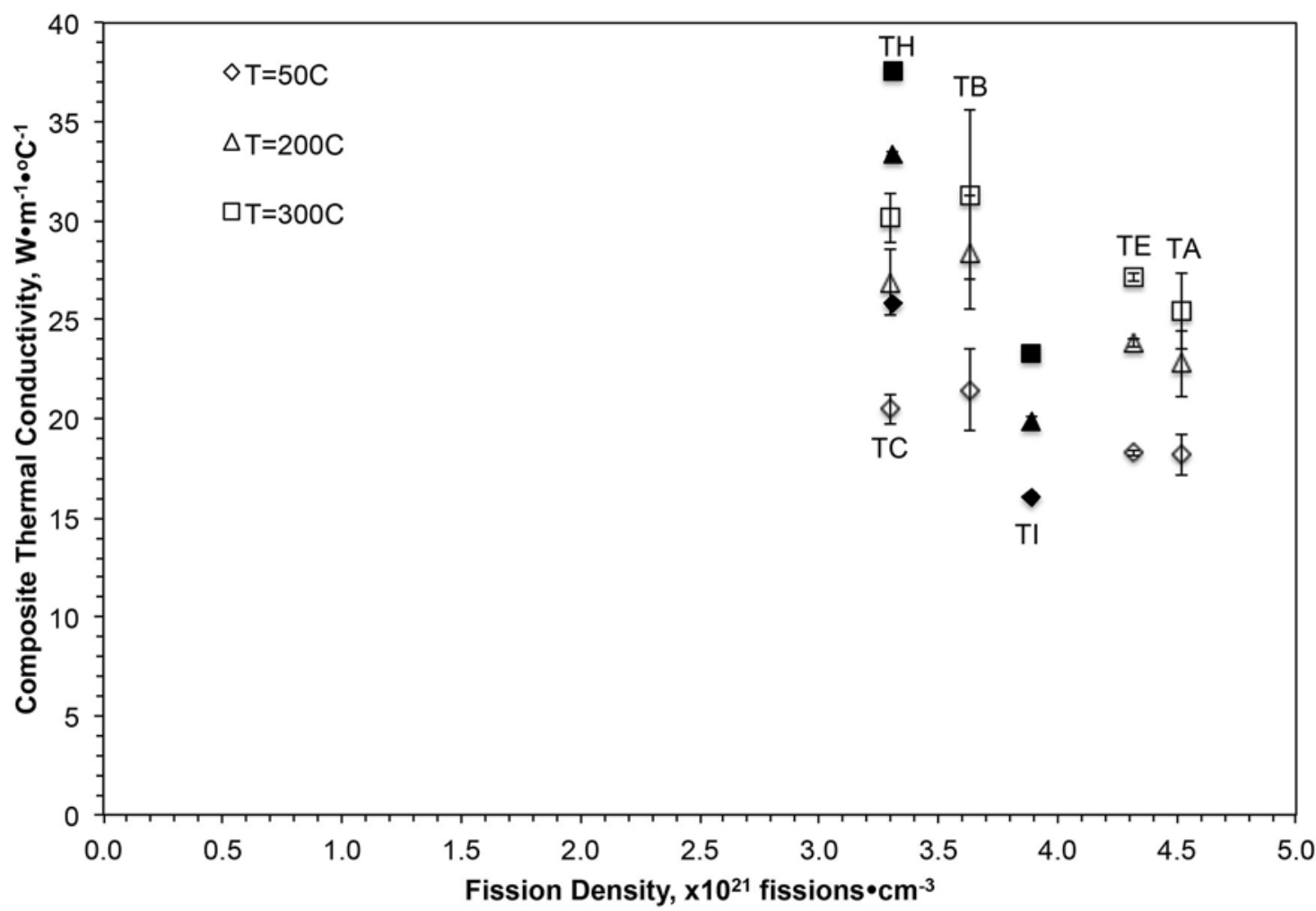

Figure 4.4. Calculated Composite Thermal Conductivity At 100C, 200C, and 300C as a Function of Average Fission Density for Each Fuel Segment (Including FY13 Samples). Solid markers represent high surface heat flux samples while open markers represent moderate surface heat flux samples.

A simple model developed from the mathematical analysis of the flash method for measuring the thermal diffusivity of layered composites was adapted to extract the thermal conductivity of the fuel meat as a function of temperature (Lee 1975). Similar models to the one reproduced for this work can be found in Araki et al. (1992) and Ang et al. (1973). The model reproduced for this work is based on a three-layer system, while the composite itself can, in principle, be considered a five-layer system, neglecting the influence of the relatively thin intermetallic zones that form at the $\mathrm{Zr}$ - fuel interface and AA6061 - Zr interface. To extract the thermal conductivity of the U-Mo fuel meat itself, the data were analyzed twice through the three-layer model. The first analysis assumed a three-layer system comprising AA6061 - Zr + U-Mo - AA6061. The combined Zr + U-Mo values determined for density and specific heat capacity along with the measured composite thermal diffusivity were used as inputs into the model, along with the temperature-dependent properties of AA6061 obtained from Mills (2002) (density and specific heat capacity) and DOD (1998) (thermal conductivity, from which thermal diffusivity was calculated). The second analysis assumed a three-layer system composed of $\mathrm{Zr}$ - U-Mo - Zr. The U-Mo values determined for density and specific heat capacity along with the calculated thermal diffusivity of the $\mathrm{Zr}+$ 
U-Mo layer determined in the first analysis were used as inputs into the model, along with temperaturedependent properties of Zr obtained from Fink and Leibowitz (1995). The average constituent layer thicknesses were taken from the OM measurements provided in Table 3.1 through Table 3.4. For the first analysis, the combined thickness of $\mathrm{Zr}$ and U-Mo was used to represent the middle layer. This approach was recently verified through comparison to a different, independent model developed by the Technische Universität München for Segment TC analyzed in FY13, reported in Burkes et al. (2015). It is noted that for Segment F analysis, the model was only run once, because the AA6061 cladding was dissolved from the sample and the thermal property measurements were performed only on the $\mathrm{Zr}+\mathrm{U}-\mathrm{Mo}$ layers. Throughout the analysis, the model assumes 1) one-dimensional heat flow, 2) no heat loss from the sample surfaces, 3) no interfacial thermal contact resistance, 4) each layer is homogeneous, 5) heat pulse is uniformly absorbed on the front surface, and 6) only one thermophysical property is unknown in one of the layers (in this case, thermal diffusivity). The model was reproduced in Wolfram Mathematica v. 8.0.0.0 for execution.

Results of the U-Mo thermal conductivity extractions are provided in Figure 4.5 for temperatures at $50{ }^{\circ} \mathrm{C}, 200{ }^{\circ} \mathrm{C}$, and $300{ }^{\circ} \mathrm{C}$ as a function of average segment fission density. Also included on the figure are thermal conductivity values on an unirradiated U-10Mo alloy obtained from Burkes et al. (2010a). As with the composite thermal conductivity values, the system precision uncertainty was determined by propagation of relative error using the mean and standard deviation from multiple measurements on each sample for each measurement technique (i.e., composite, $\mathrm{Zr}+\mathrm{U}-\mathrm{Mo}$, and U-Mo). The three-layer model is an iterative algorithm with convergence criteria. Thus, the error associated with a calculation using this model assumes that the measured input thermal diffusivity (whether composite or $\mathrm{Zr}+\mathrm{U}-\mathrm{Mo}$ ) is accurate and the thickness and thermal property inputs of the known material layers are accurate. Based on this assumption, the final calculated thermal diffusivity for the unknown layer (either $\mathrm{Zr}+\mathrm{U}-\mathrm{Mo}$ or U-Mo) has an associated uncertainty equal to the convergence criteria, which is then propagated in the ensuing thermal conductivity calculations. As expected, the thermal conductivity of the U-Mo alloy increased with increasing temperature and decreased with increasing fission density. For moderate surface heat flux samples (i.e., TA, TB, TC, and TE), the U-Mo thermal conductivity decreased nearly linearly at each temperature shown. Included on the figure are measurements made by INL using a scanning thermal diffusivity microscope (Huber et al. 2012) that are in excellent agreement with the extracted U-Mo alloy values at $50{ }^{\circ} \mathrm{C}$ calculated as part of this work. The linear behavior of thermal conductivity is indicative of electron transport while the parabolic behavior is indicative of phonon transport. The fact that the thermal conductivity of the irradiated U-Mo follows a nearly linear trend indicates that electron transport dominates. The slight deviation from linear behavior is likely due to lattice damage, but the phonon transport contribution is still relatively minimal because lattice damage is quite substantial at these burnups and fission rates. The high surface heat flux samples show a slightly different behavior. Segment TH thermal conductivity fits on the nearly linear line at each temperature range for the moderate surface heat flux samples. However, the extracted U-Mo thermal conductivity values for Segments TF and TI are lower than that determined for the other fuel segments at each temperature shown. There is not a strong decrease in thermal conductivity behavior with increased fission density between the TF and TI segments. It is not clear why Segment TH did not also exhibit this behavior, but the fact that both TH and TI were obtained from the same fuel plate with similar fission densities suggests that there may be a strong influence of microstructure on thermal degradation within a given fuel plate. Thermal conductivity at $200{ }^{\circ} \mathrm{C}$ decreased approximately $37 \%$ for a fission density of $3.30 \times 10^{21}$ fissions ${ }^{\bullet} \mathrm{cm}^{-3}$ (TC) and approximately $49 \%$ for a fission density of $4.52 \times 10^{21}$ fissions ${ }^{\bullet} \mathrm{cm}^{-3}$ (TA) for moderate surface heat flux samples. Thermal conductivity at $200{ }^{\circ} \mathrm{C}$ decreased approximately $50 \%$ for a fission density of $2.45 \times$ 
$10^{21}$ fissions $\bullet^{\bullet} \mathrm{cm}^{-3}$ (TF) and approximately $53 \%$ for a fission density of $3.89 \times 10^{21}$ fissions ${ }^{\bullet} \mathrm{cm}^{-3}$ (TI) for high surface heat flux samples.

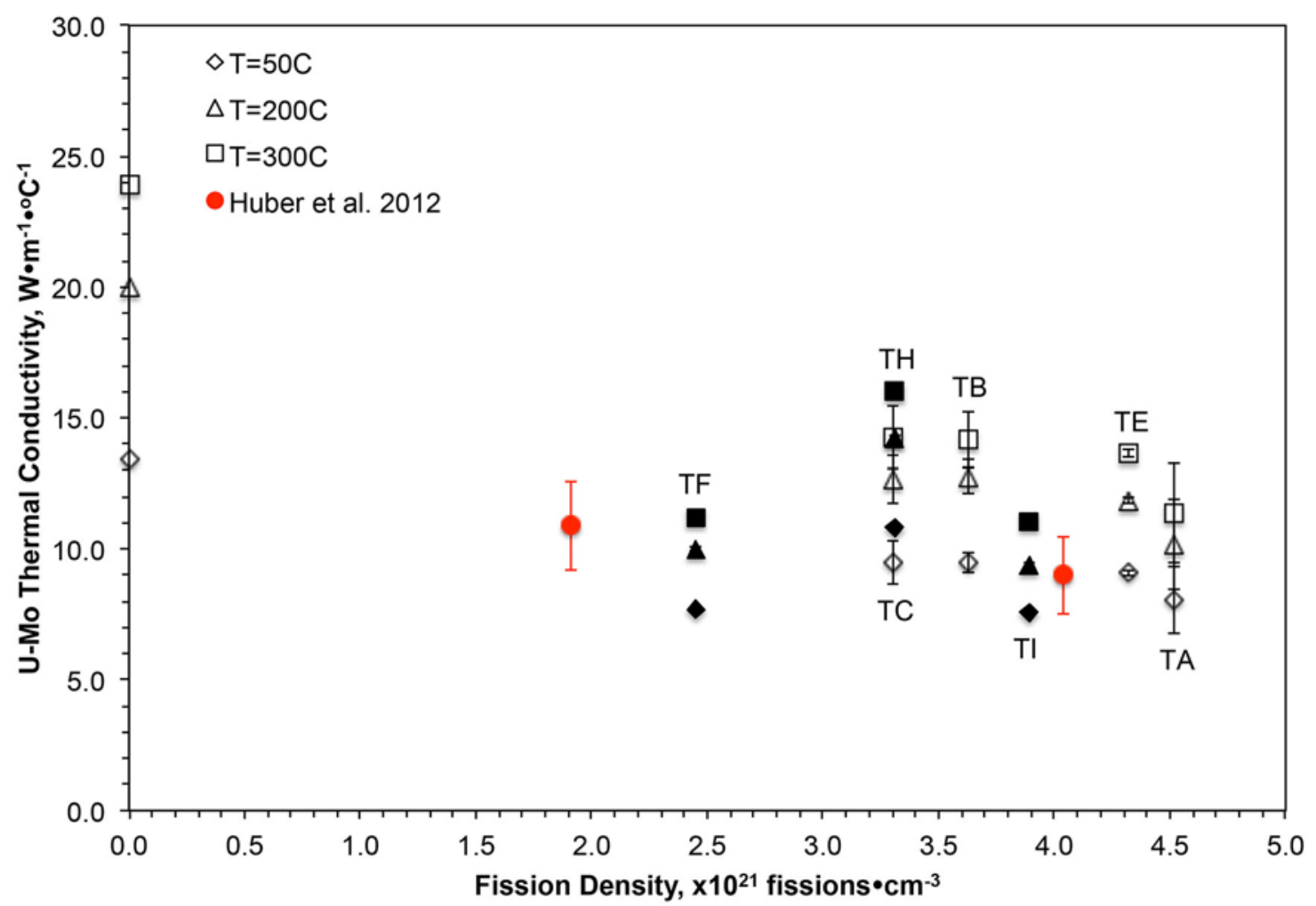

Figure 4.5. Extracted U-Mo Thermal Conductivity at $100{ }^{\circ} \mathrm{C}, 200{ }^{\circ} \mathrm{C}$, and $300{ }^{\circ} \mathrm{C}$ as a Function of Average Fission Density for Each Fuel Segment (Including FY13 Samples). Solid markers represent high surface heat flux samples while open markers represent moderate surface heat flux samples. 



\subsection{Conclusions}

The GTRI Fuel Thermo-Physical Characterization Project at PNNL was tasked with using PNNL facilities and processes to receive irradiated LEU-Mo fuel plate samples and perform analysis in support of the GTRI Convert Program. To this end, a variety of thermal property measurement equipment was installed into hot cells at PNNL in FY12. The equipment was capably demonstrated to acquire OM, analytical chemistry, density, specific heat capacity, and thermal diffusivity information on irradiated fuel samples in FY13 and FY14. Models to extract thermal properties of the U-Mo alloy from the measurements conducted on an integral fuel plate sample (i.e., U-Mo alloy with a thin Zr coating and clad in AA6061) have been developed and were used to analyze experimental data obtained on eight irradiated fuel segments in FY13 and FY14 as a function of temperature and burnup. Specific observations and conclusions from this body of work follow.

- A high level of variability exists in the constituent layer thicknesses from sample to sample. The variability in constituent layer thickness was expected given the different processing methods used to fabricate the different fuel plates from which the different fuel segments were harvested. In general, uniformity appeared to improve with fuel plates fabricated later in the Program, i.e., AFIP-6 MkI and AFIP-6 MkII v. AFIP-2BZ and AFIP-3BZ.

- A change in the behavior of fission gas bubbles along the grain boundaries of the U-Mo fuel is clearly observed with increased burnup and at higher surface heat fluxes. The density of fission gas bubbles appeared to increase along grain boundaries with increasing burnup at moderate surface heat fluxes. In general, the size of the bubbles did not appear to increase significantly, at least based on the OM images obtained. However, the size of the fission gas bubbles did appear to increase rather significantly for fuel segments obtained from fuel plates operated at high surface heat fluxes (TF, TH, and TI). There were clear differences in the irradiated microstructure of the fuel plates, even within segments harvested from the same fuel plate (i.e., TH and TI).

- The Mo concentration within the alloy was enriched with increased burnup. This behavior was expected because the relative ratio of $U$ to Mo will decline with ${ }^{235} U$ depletion during irradiation and is further enhanced by the fact that Mo isotopes represent a relatively significant percentage of the fission products produced during irradiation.

- In general, nuclide activity increases as the fission density of the sample increases. There is minimal apparent influence of surface heat flux on ${ }^{154} \mathrm{Eu},{ }^{134} \mathrm{Cs}$, and ${ }^{106} \mathrm{RuRh}$ nuclide activity. However, the higher surface heat flux of Segments TF, TH, and TI results in slightly higher nuclide inventories for ${ }^{125} \mathrm{Sb},{ }^{137} \mathrm{Cs}$, and ${ }^{144} \mathrm{Ce}$.

- More ${ }^{239} \mathrm{Pu}$ is present in the lower burnup samples (i.e., Segments F, H, and I), while there is more ${ }^{238} \mathrm{Pu},{ }^{240} \mathrm{Pu},{ }^{241} \mathrm{Pu}$, and ${ }^{242} \mathrm{Pu}$ in the higher burnup sample analyzed (i.e., Segment $\mathrm{E}$ ).

- In general, the calculated average fission densities for each segment is in good agreement with reported values employing MCNP.

- The density of the composite fuel samples and U-Mo alloy decreased with increasing burnup. There was no noticeable influence of surface heat flux on the decrease in density. The calculated U-Mo densities agree well with an empirical correlation for change in volume during irradiation as a result of solid and gaseous fission products. 
- Specific heat capacity of the irradiated U-Mo alloys is not significantly influenced by increased temperature. However, the specific heat capacity of the alloy does appear to slightly increase with increasing fission density. The increasing dependence on fission density is most likely caused by a change in the Mo concentration within the alloy as burnup is increased. Operational and system changes over FY14 have shown a dramatic improvement in the repeatability and quality of the DSC data compared to FY15, evidenced by the much smaller errors reported with the measurements.

- Composite thermal conductivity increased as a function of temperature and decreased with increasing burnup. There is no obvious dependence of composite thermal conductivity on fabrication method (i.e., HIP v. friction bonding). Note that all measurements discussed in the current report were fabricated using HIP, while those reported previously in FY13 were fabricated using FB. While the different cladding bonding methods did not appear to influence thermal conductivity, the variability in rolling operations does appear to have some influence likely as a result of the microstructural differences observed in the U-Mo fuel meat.

- The calculated thermal conductivity of the U-Mo alloy increased with increasing temperature and decreased with increasing burnup. Two of the three samples irradiated at high surface heat fluxes showed a much more rapid degradation in thermal conductivity than those irradiated at moderate surface heat fluxes. The accelerated degradation of thermal conductivity for the samples irradiated at high surface heat flux is likely the result of increased fission gas bubble size and location. OM images revealed the presence of fission gas bubble-like features at the $\mathrm{Zr}$-fuel interfaces, which likely contributed to the different behavior. 


\subsection{Recommendations for Future Work}

Recommendations for future work are summarized in this section based on observations from the initial thermal property measurements conducted in FY13 and FY14.

1. Analysis of Additional Irradiated Fuel Samples and Material

Obtain additional samples that represent a different set of irradiation conditions (i.e., higher fission density at moderate surface heat flux and/or higher burnup samples at high surface heat flux), as well as samples from early irradiation campaigns that did not contain the $\mathrm{Zr}$ diffusion barrier. Analysis of additional samples operated at high surface heat flux would confirm whether thermal conductivity degradation is enhanced under these operational conditions. Analysis of samples without the $\mathrm{Zr}$ diffusion barrier would lend insight into whether the presence of fission gas bubbles at material interfaces (and thereby composite thermal conductivity) is influenced by the presence of this barrier.

2. Obtain LFA Sample from Segment D (carryover recommendation from FY13)

The thermal diffusivity behavior of segment B was inconsistent reported in FY13. Although hypotheses for this behavior have been offered, without further analysis or comparable analysis a conclusion cannot be drawn. Segment D was prepared adjacent to segment B, and an adequate amount of material remains from this segment (slated for fission product release studies) to prepare one LFA sample. Performing this measurement will allow a determination of the reasonableness of TB-LFA1 results (i.e., is thermal diffusivity of the D sample comparable to TB-LFA1 or TB-LFA2 [expected]?).

3. Optical Microscopy of Samples after Testing

The microstructure of the unirradiated and irradiated specimens has been interpreted adequately in the OM; specifically, identification of the major features—in this case, fission gas bubbles—can be made. To better understand what drives behavior at increased temperatures, it would be beneficial to perform OM on samples after they have been subjected to the high temperature cycle, either DSC or LFA samples. It is also possible to conduct thermal studies in situ using a specialized OM-compatible thermal stage. The existing OM could be outfitted with such a stage relatively straightforwardly. If fission gas bubbles increase in size or density as a result of the higher temperature cycle, it could help validate/invalidate some of the hypotheses that are offered in this report. This information could be used to advance predictive performance modeling and serve as indicators for fuel failure. The observation and measurement of the layers depends on the contrast in the images. Development of additional methods to improve the visibility of features would be a productive exercise either through comparative SEM imaging (see Recommendation \#4) and/or chemical etching methods.

4. Scanning Electron Microscopy/Backscattered Electron Diffraction/Energy Dispersive Spectroscopy of Irradiated Fuel Samples

While the $\mathrm{OM}$ is adequate to identify major features present in the fuel, it is impossible to state conclusively what the features are and how they can potentially affect thermal property behavior. Coarse gas bubbles are likely to be resolved using the OM, but fine gas bubbles, particularly size and distribution, are not. Furthermore, sample compositional homogeneity and impurity quantification (e.g., carbide content) would provide valuable insight for thermal transport properties. With backscattered electron diffraction combined with elemental mapping, the different phases, their orientations, and grain 
sizes could more easily be determined, providing qualitative and quantitative information on the distribution of different phases. Furthermore, a DualBeam Focused Ion Beam (Helios 660) is available that would enable the identification and extraction of specimens for additional analyses, including transmission electron microscopy (TEM), secondary imaging mass spectrometry (SIMS), and local electron atom probe (LEAP). TEM of samples subjected to thermal conditions outlined in the existing work could be combined with existing analyses to assist with additional determination of the intermetallic and behavior of fission products after thermal treatment (e.g., stability). SIMS and LEAP could be applied to determine the nature of irradiation induced effects that are invisible using only OM. Obtaining this information will allow development of improved predictive models and likely reduce some of the uncertainty associated with extrapolating fuel meat thermal properties from the bulk sample measurements. 


\subsection{References}

Ang CS, HS Tan and SL Chan. 1973. "Three-layer Thermal-diffusivity Problem Applied to Measurements on Mercury.” J. Appl. Phys., 44:687-691.

Araki N, A Makino, T Ishiguro and J Mihara. 1992. "An Analytical Solution of Temperature Response in Multilayered Materials for Transient Methods.” Int. J. Thermo., 13(3):515-538.

ASM. 1990. ASM Handbook Volume 2: Properties and Selection: Nonferrous Alloys and SpecialPurpose Materials, ASM International, Materials Park, Ohio.

ASTM. 2011. ASTM E1461-11, Standard Test Method for Thermal Diffusivity by the Flash Method, ASTM International, West Conshohocken, Pennsylvania.

Burkes DE, CA Papesch, AP Maddison, T Hartmann, and FJ Rice. 2010a. "Thermo-physical Properties of DU-10 wt.\% Mo Alloys.” Journal of Nuclear Materials, 403(1-3):160-166.

Burkes DE, GS Mickum, and DM Wachs. 2010b. Thermophysical Properties of U-10Mo Alloy. INL/EXT-10-19373, Idaho National Laboratory, Idaho Falls, Idaho.

Burkes DE, AM Casella, EC Buck, AJ Casella, MK Edwards, PJ MacFarlan, KN Pool, BD Slonecker, FN Smith, FH Steen, and RE Thornhill. 2013. Fuel Thermo-physical Characterization Project: Fiscal Year 2013 Final Report. PNNL-22981, Pacific Northwest National Laboratory, Richland, Washington.

Burkes DE, AM Casella, AJ Casella, TK Huber, LD Gardner, and H Breitkreutz. 2015. Fuel Thermophysical Characterization Project: Evaluation of Models to Calculate Thermal Diffusivity of Layered Composites. PNNL-24073, Pacific Northwest National Laboratory, Richland, Washington.

Cape JA and GW Lehman. 1963. "Temperature and Finite Pulse-Time Effects in the Flash Method for Measuring Thermal Diffusivity.” Journal of Applied Physics, 34(7):1909-1913.

Cowan, RD. 1963. "Pulse Method of Measuring Thermal Diffusivity at High Temperatures.” J. Appl. Phys. 34: 926-927.

DOD - U.S. Department of Defense. 1998. Metallic Materials and Elements for Aerospace Vehicle Structures. MIL-HDBK-5H, U.S. Department of Defense, Washington, D.C.

Farkas M and E Eldridge. 1968. "Heat Contents and Specific Heats of Some Uranium-bearing Fuels.” Journal of Nuclear Materials, 27(1):94-96.

Fink JK and L Leibowitz. 1995. “Thermal Conductivity of Zirconium,” Journal of Nuclear Materials, 226(1-2):44-50. 
Golosov OA, MS Lyutikova, VB Semerikov, and A Ye Teplykh. 2008. “The Effect of Fuel Burn-up Followed by Annealing on Changes in Structure and Structural Parameters of U-9\% Mo Dispersion Fuel.” RRFM 2008 Transactions - Poster Session, Hamburg, Germany, 02.3-05.3.2008, pp.39-43. Accessed November 5, 2013 at http://www.euronuclear.org/meetings/rrfm2008/transactions/rrfm2008posters.pdf.

Huber TK, MK Fig, D Garrett, JR Kennedy, AB Robinson, and DM Wachs. 2012. First Results of Scanning Thermal Diffusivity Microscope (STDM) Measurements on Irradiated Monolithic and Dispersion Fuel. INL/EXT-12-26708, Idaho National Laboratory, Idaho Falls, Idaho.

Keiser, D, J Jue, and J Hess. 2011. AFIP-6 Characterization Summary Report. INL/EXT-11-21090, Idaho National Laboratory, Idaho Falls, Idaho.

Kim YS and GL Hofman. 2011. “Fission Product Induced Swelling of U-Mo Alloy Fuel.” Journal of Nuclear Materials, 419(1-3):291-301.

Lee HJ. 1975. Thermal Diffusivity in Layered and Dispersed Composites. Ph.D. Thesis, Purdue University, West Lafayette, Indiana.

Lee B-H, J-S Cheon, Y-H. Koo, J-Y. Oh, J-S. Yim, D-S. Sohn, M. Baryshnikov, and A. Gaiduchenko. 2007. "Measurement of the Specific Heat of Zr-40 wt\% U Metallic Fuel.” Journal of Nuclear Materials, 360(3):315-320.

Lowell S, JE Shields, MA Thomas, and M Thommes. 2004. Characterization of Porous Solids and Powders: Surface Area, Pore Size and Density. Kluwer Academic Publishers, Norwell, Massachusetts.

Mills KC. 2002. Recommended Values of Thermophysical Properties for Selected Commercial Alloys. Woodhead Publishing Limited, Cambridge, England.

Moore GA. 2010. AFIP-2 Fabrication Summary Report. INL/EXT-08-1487, Idaho National Laboratory, Idaho Falls, Idaho.

Moore GA and MC Marshall. 2010. Co-Rolled U10Mo/Zirconium-Barrier-Layer Monolithic Fuel Foil Fabrication Process. INL/EXT-10-17774, Idaho National Laboratory, Idaho Falls, Idaho.

Moore GA and MC Marshall. 2011. AFIP-6 Fabrication Summary Report. INL/EXT-11-21655, Idaho National Laboratory, Idaho Falls, Idaho.

NRC - U.S. Nuclear Regulatory Commission. 1988. Safety Evaluation Report Related to the Evaluation of Low-Enriched Uranium Silicide-Aluminum Dispersion Fuel for Use in Non-Power Reactors. NUREG-1313, U.S. Nuclear Regulatory Commission, Office of Nuclear Reactor Regulation, Washington, D.C.

Park BH, CR Clark, and JF Jue. 2010. INL HIP Plate Fabrication. INL/EXT-10-17792, Idaho National Laboratory, Idaho Falls, Idaho.

Perez DM, MA Lillo, GS Chang, GA Roth, NE Woolstenhulme, and DM Wachs. 2011a. AFIP-2 Irradiation Summary Report. INL/EXT-11-21599, Rev. 1, Idaho National Laboratory, Idaho Falls, Idaho. 
Perez DM, MA Lillo, GS Chang, GA Roth, NE Woolstenhulme, and DM Wachs. 2011b. AFIP-6 Irradiation Summary Report. INL/EXT-11-23296, Idaho National Laboratory, Idaho Falls, Idaho.

Perez DM, MA Lillo, GS Chang, GA Roth, NE Woolstenhulme, and DM Wachs. 2012a. AFIP-3 Irradiation Summary Report. INL/EXT-11-21776, Rev. 2, Idaho National Laboratory, Idaho Falls, Idaho.

Perez DM, JW Nielsen, GS Chang, DM Wachs, GA Roth, and NE Woolstenhulme. 2012b. AFIP-6 Mark II Irradiation Summary Report. INL/EXT-12-26305, Idaho National Laboratory, Idaho Falls, Idaho.

Perez E, B Yao, DD Keiser Jr., and YH Sohn. 2010. "Microstructural Analysis of As-processed U-10 wt\%Mo Monolithic Fuel Plate in AA6061 Matrix with Zr Diffusion Barrier.” Journal of Nuclear Materials, 402(1):8-14.

Rest J, Kim, YS, Hofman, GL, Meyer, MK and Hayes, SL. 2009. U-Mo Fuels Handbook. ANL-09/31, Argonne National Laboratory, Chicago, IL.

Shaw TL and JC Carrol. 1998. “Application of Baseline Correction Techniques to the 'Ratio Method' of DSC Specific Heat Determination.” International Journal of Thermophysics, 19(6):1671-1680.

Sheindlin M, D Halton, M Musella, and C Ronchi. 1998. “Advances in the Use of Laser-flash Techniques for Thermal Diffusivity Measurement.” Review of Scientific Instruments, 69(3):1426-1436. 



\section{Distribution}

No. of

Copies

1 U.S. Department of Energy National Nuclear Security Administration Global Threat Reduction Initiative 1000 Independence Ave. Washington, D.C. 20002 Mr. Christopher Landers Mr. Bryan Reed (PDF)

1 Idaho National Laboratory P.O. Box 1625

Idaho Falls, ID 83415

Mr. Jason Schulthess

Mr. Kenneth Rosenberg (PDF)

Dr. Barry Rabin (PDF)

1 Argonne National Laboratory 9700 S. Cass Ave.

Argonne, IL 60439

Dr. Erik Wilson (PDF)
No. of

Copies

1 Local Distribution

Pacific Northwest National Laboratory

Douglas Burkes

K8-34

Andrew Casella

Edgar Buck

(PDF)

(PDF)

Amanda Casella

(PDF)

Matthew Edwards

(PDF)

Paul MacFarlan

(PDF)

Karl Pool

(PDF)

David Senor

(PDF)

Frances Smith

(PDF)

Bruce Slonecker

(PDF)

Franciska Steen 




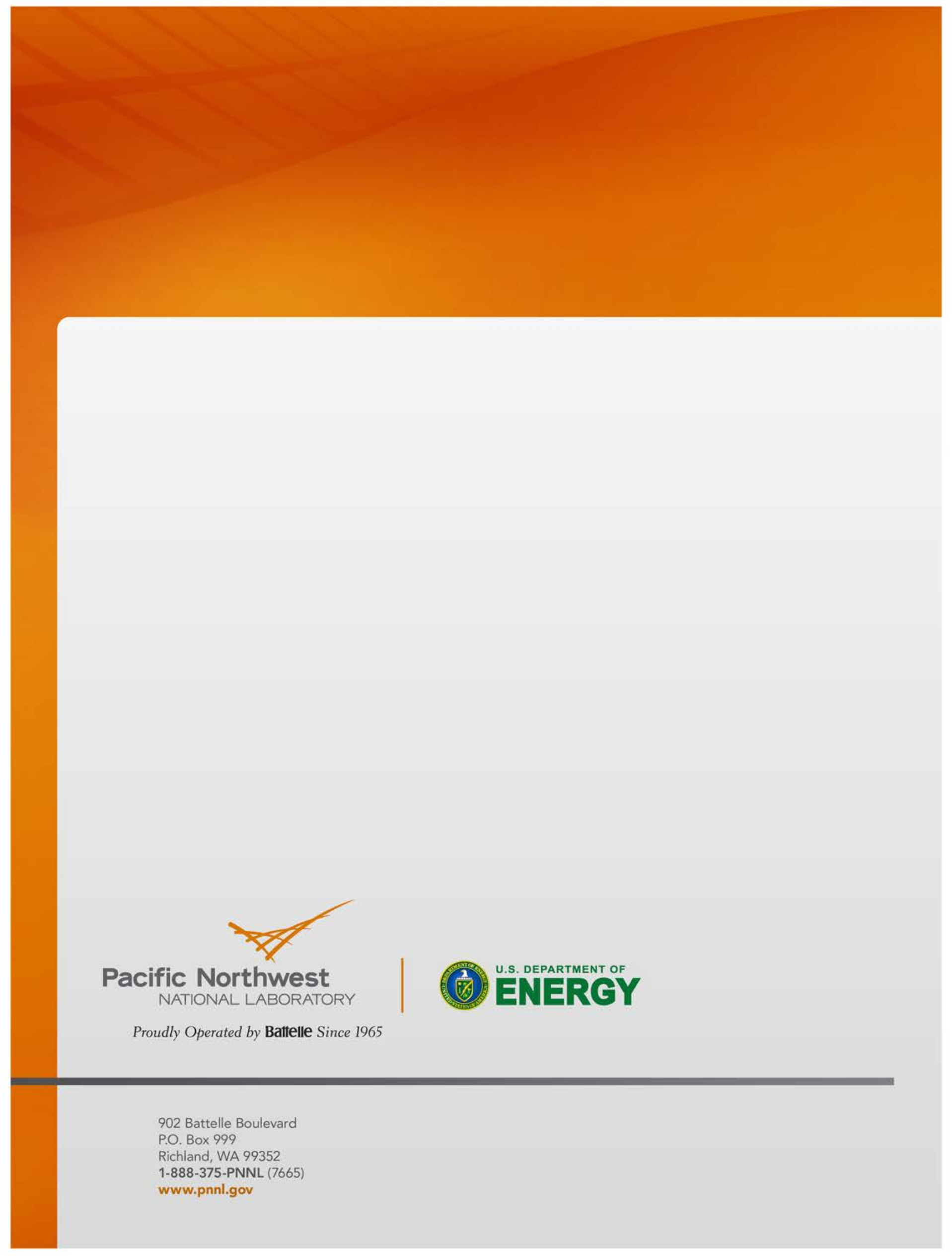

